University of Louisville

ThinkIR: The University of Louisville's Institutional Repository

$12-2020$

\title{
Predicting dental student's performance on national board dental examination (NBDE) part I: exploring demographic factors, dental admission test (DAT) factors, pre-program academic factors, and dental program academic performance.
}

Wei-Shao Lin

University of Louisville

Follow this and additional works at: https://ir.library.louisville.edu/etd

Part of the Dental Public Health and Education Commons, and the Educational Assessment, Evaluation, and Research Commons

\section{Recommended Citation}

Lin, Wei-Shao, "Predicting dental student's performance on national board dental examination (NBDE) part I: exploring demographic factors, dental admission test (DAT) factors, pre-program academic factors, and dental program academic performance." (2020). Electronic Theses and Dissertations. Paper 3571.

https://doi.org/10.18297/etd/3571

This Doctoral Dissertation is brought to you for free and open access by ThinkIR: The University of Louisville's Institutional Repository. It has been accepted for inclusion in Electronic Theses and Dissertations by an authorized administrator of ThinkIR: The University of Louisville's Institutional Repository. This title appears here courtesy of the author, who has retained all other copyrights. For more information, please contact thinkir@louisville.edu. 
PREDICTING DENTAL STUDENT'S PERFORMANCE ON NATIONAL BOARD DENTAL EXAMINATION (NBDE) PART I: EXPLORING DEMOGRAPHIC FACTORS, DENTAL ADMISSION TEST (DAT) FACTORS, PRE-PROGRAM ACADEMIC FACTORS, AND DENTAL PROGRAM ACADEMIC PERFORMANCE

By

Wei-Shao Lin

DDS, Chung-Shan Medical University, 2003

Postgraduate Specialty Certificate in Prosthodontics, University of Rochester, 2010

Postgraduate Specialty Certificate in Implantology, University of Rochester, 2010

\author{
A Dissertation \\ Submitted to the Faculty of the \\ College of Education and Human Development of the University of Louisville \\ in Partial Fulfillment of the Requirements \\ for the Degree of \\ Doctor of Philosophy \\ in Educational Leadership and Organizational Development
}

Department of Education, Leadership, and Human Resource Development

University of Louisville

Louisville, Kentucky

December, 2020 

PREDICTING DENTAL STUDENT'S PERFORMANCE ON NATIONAL BOARD DENTAL EXAMINATION (NBDE) PART I: EXPLORING DEMOGRAPHIC FACTORS, DENTAL ADMISSION TEST (DAT) FACTORS, PRE-PROGRAM ACADEMIC FACTORS, AND DENTAL PROGRAM ACADEMIC PERFORMANCE

By

Wei-Shao Lin

D.D.S., Chung-Shan Medical University, 2003

A Dissertation Approved on

September 9, 2020

by the following Dissertation Committee:

Namok Choi, Dissertation Chair

Jason Immekus, Committee Member

Kristi King, Committee Member

William Scarfe, Committee Member 


\section{DEDICATION}

This dissertation is dedicated to my entire family, especially for my wife, I-Wen Kao, and daughter, Sophia Lin, who have given me invaluable supports in pursuing my passion. 


\section{ACKNOWLEDGMENTS}

I would like to thank my advisor and dissertation committee chair, Dr. Namok

Choi, for her time, guidance and patience. I would also like to thank the other committee members, Dr. Jason Immekus, Dr. Kristi King, and Dr. William Scarfe for their comments and assistance throughout the process.

I would also like to express my thanks to my entire family for their supports and encouragement during these times for me to be able to pursue me passion in education, and chosen the academia as my professional career. 


\begin{abstract}
PREDICTING DENTAL STUDENT'S PERFORMANCE ON NATIONAL BOARD DENTAL EXAMINATION (NBDE) PART I: EXPLORING DEMOGRAPHIC FACTORS, DENTAL ADMISSION TEST (DAT) FACTORS, PRE-PROGRAM ACADEMIC FACTORS, AND DENTAL PROGRAM ACADEMIC PERFORMANCE Wei-Shao Lin
\end{abstract}

September 9, 2020

Dental students need to successfully challenge a national licensure examination to be able to practice dentistry. Dental educators currently have difficulty in identifying candidates who are at risk of failing this examination. This non-experimental quantitative study examined existing dental student data from the 2017, 2018, and 2019 graduating classes, using a retrospective and correlational approach to identify possible markers for at risk students.

Demographic factors, dental admission test (DAT) factors, pre-program academic factors, dental program academic performance, and National Board Dental Examination (NBDE) Part I performance. A series of independent $t$-tests and One-Way analysis of variances (ANOVAs) were used to examine the students' performances regarding their gender and race. Logistic regression models were used to predict NBDE Part I performance at the first attempt from each categorical (demographic factor) and continuous predictor (preprogram academic performance, DAT performance, and dental program academic Performance. 
Gender and race were significantly associated with the student's academic achievement at the undergraduate level and the DAT; however, the influence of these factors diminished in the dental program academic performance and the NBDE Part I. Student's dental program performance were significantly associated with the NBDE Part I outcomes.

Within the limitations of this study, dental students with different gender and race backgrounds all have the potential to successfully complete NBDE. Additional enrichment and bridge programs for the underrepresented minorities students may be used to maximize the future success of the enrolled diverse student body. The dental program can have performance benchmarks starting at program admission and continuing through the end of the second year to help identify at-risk students early and provide them with additional academic support. 
TABLE OF CONTENTS

PAGE

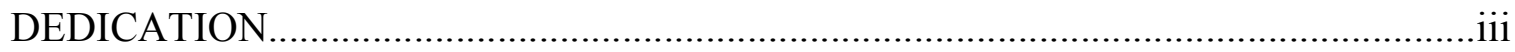

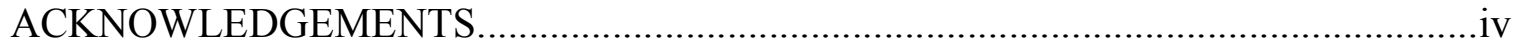

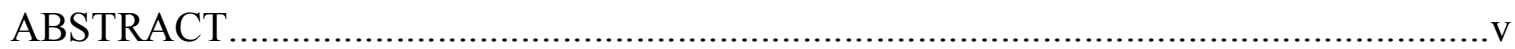

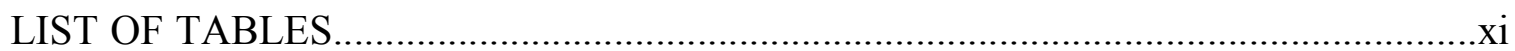

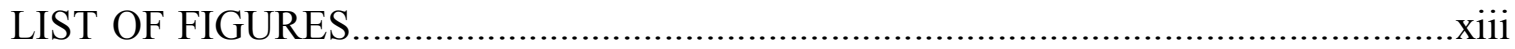

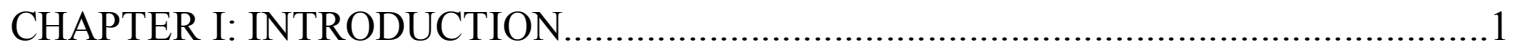

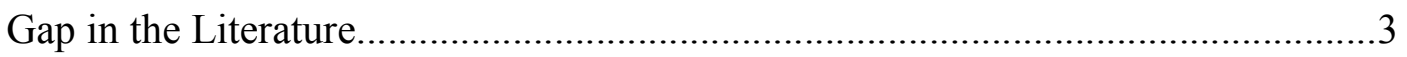

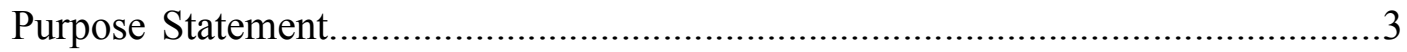

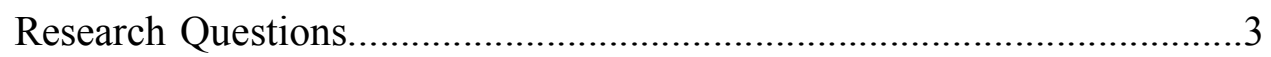

Dental Education in the United States....................................................................

Admission to the Dental Program......................................................................

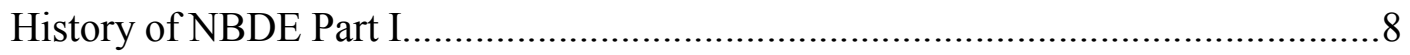

Current Format and Scoring of NBDE Part I...............................................

Reliability and Validity ........................................................................11

Rationale for the Proposed Study......................................................................14

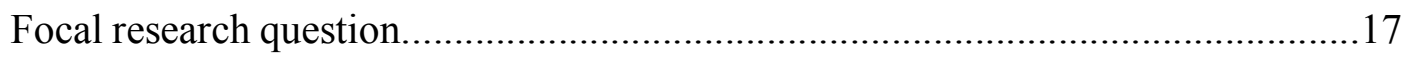

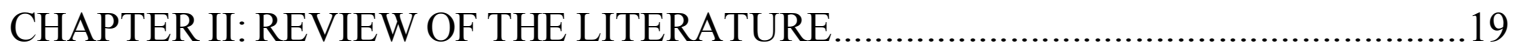

Conceptual Framework................................................................................

Conceptual Model for the Current Study..................................................21

Predictors of Dental Students' Academic and NBDE Part I Performance...............24

Demographic Factors (Gender and Race/Ethnicity)..................................26 
Dental Admission Test (DAT) Factors.................................................32

Pre-program Academic Factors.......................................................40

Dental Program Academic Factors.....................................................44

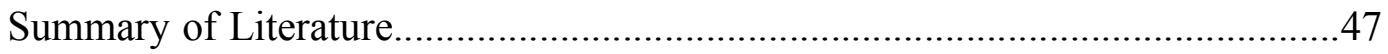

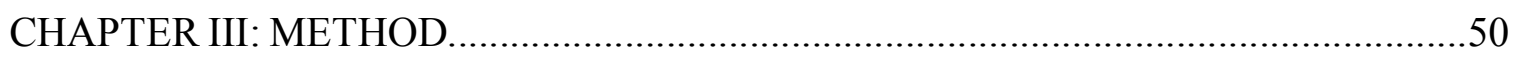

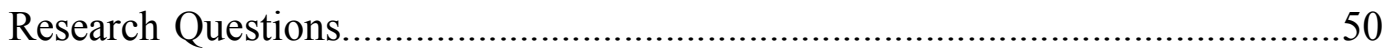

Research Design / Methodology ..................................................................51

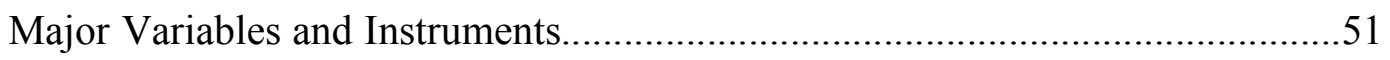

NBDE Part I Measurement..................................................................56

Individual Course Grades and GPAs.................................................59

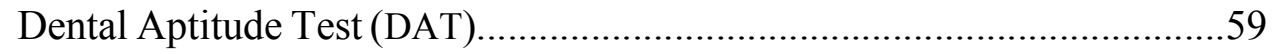

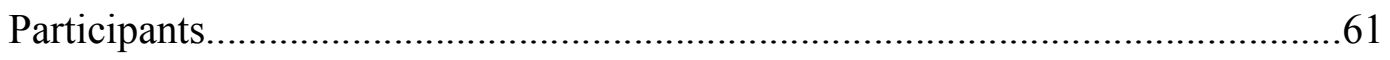

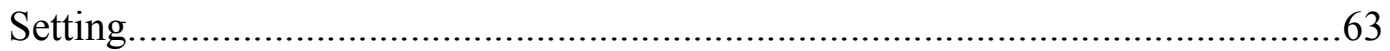

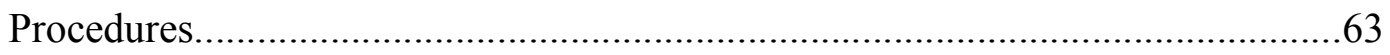

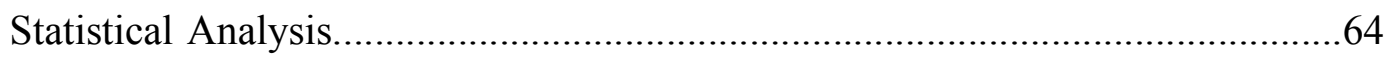

Comparison of Gender and Race Groups............................................65

Bivariate Logistic Regression......................................................66

Summary and Statement of Significance ....................................................6

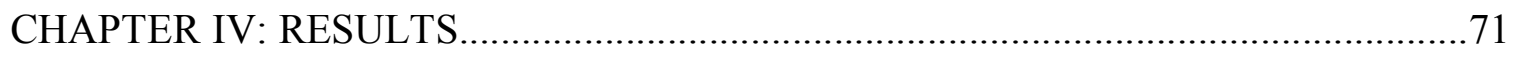

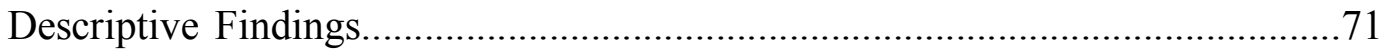

Student Demographics................................................................ 72

Pre-program Academic Performance............................................... 72

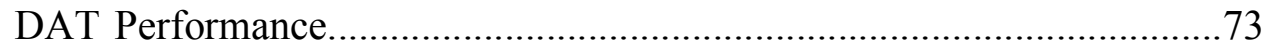


Dental Program Academic Performance...............................................74

NBDE Part I Performance.................................................................. 75

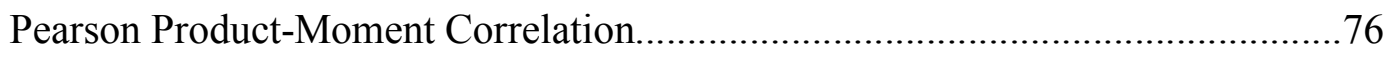

Pre-program Academic Performance....................................................76

DAT Performance........................................................................ 77

Dental Program Academic Performance................................................78

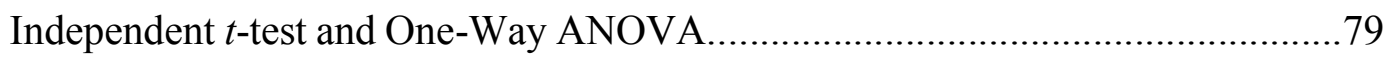

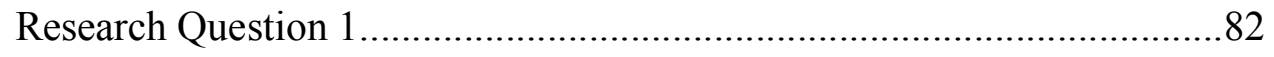

Bivariate Logistic Regression to Test Association with NBDE Performance.........99

Research Question 2...............................................................93

Research Question 3..................................................................... 94

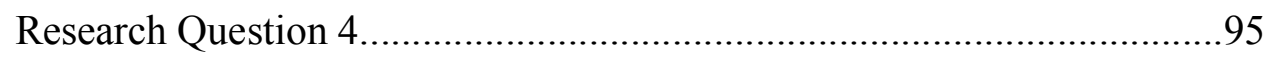

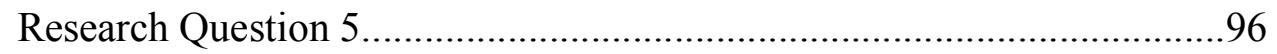

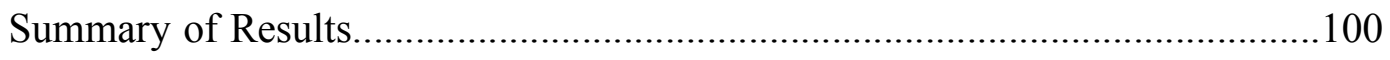

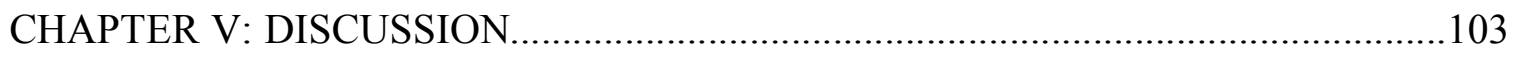

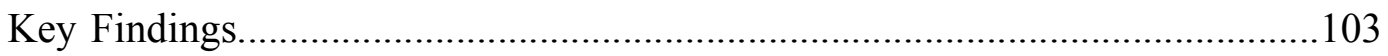

Demographic Characteristics and Academic Performance.....................103

Significant Predictors of NBDE Part I Performance............................108

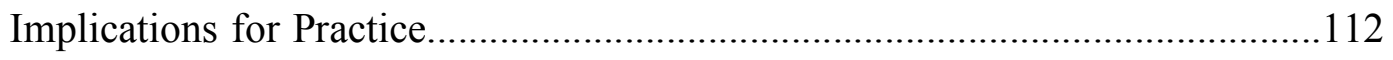

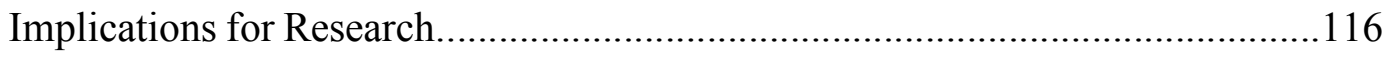

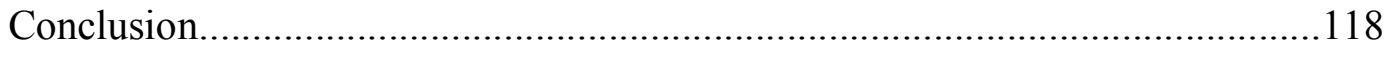

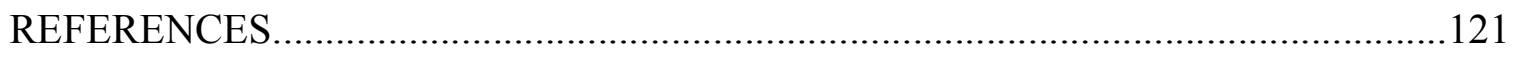

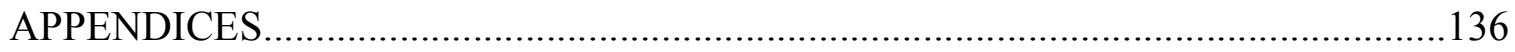




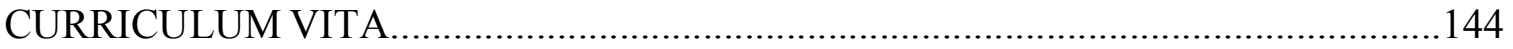




\section{LIST OF TABLES}

TABLE PAGE

Table 1: Numbers and Failure Rates for First-time and Repeating Candidates for NBDE Part I From 2008 To 2017.................................................................11

Table 2: NBDE Part I Descriptive Statistics in 2017.................................................12

Table 3: Variables Included in The Empirical Model.................................................52

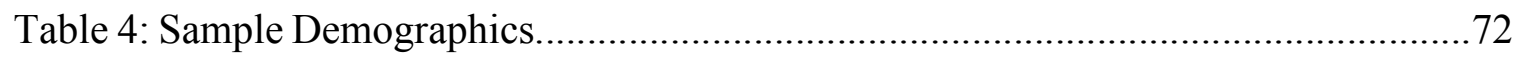

Table 5: Pre-program Academic Performance............................................................ 73

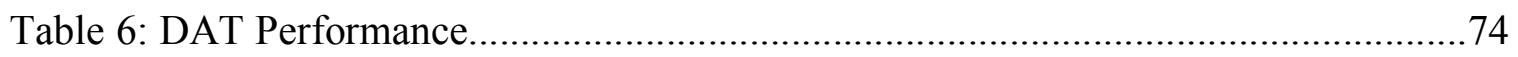

Table 7: Dental Program Academic Performance........................................................ 74

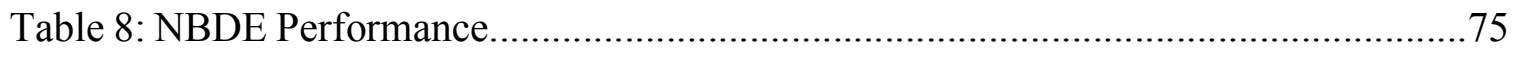

Table 9: Pre-program Academic Performance - Pearson Product-moment

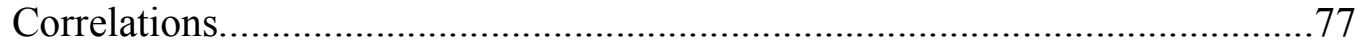

Table 10: DAT Performance - Pearson Product-moment Correlations...............................78

Table 11: Dental Program Academic Performance - Pearson Product-moment

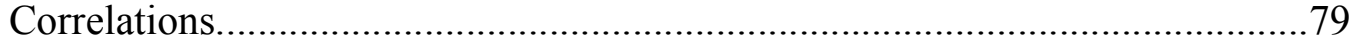

Table 12: Associations of Gender with Pre-program Academic Performance....................83

Table 13: Associations of Gender with DAT performance.......................................... 84

Table 14: Associations of Gender with Dental Program Academic Performance...............85

Table 15: Associations of Race with Pre-program Academic Performance.......................87

Table 16: Associations of Race with DAT performance ............................................. 88

Table 17: Associations of Race with Dental Program Academic Performance..................92 
Table 18: Bivariate Logistic Regression Models using Race and Gender as Predictors for NBDE Failures....................................................................94

Table 19: Bivariate Logistic Regression Models using Pre-Program Academic Performance as Predictors for NBDE Failures..

Table 20: Bivariate Logistic Regression Models using DAT as Predictors for NBDE Failures

Table 21: Bivariate Logistic Regression Models using Dental Program Performance as Predictors for NBDE Failures...................................................................96

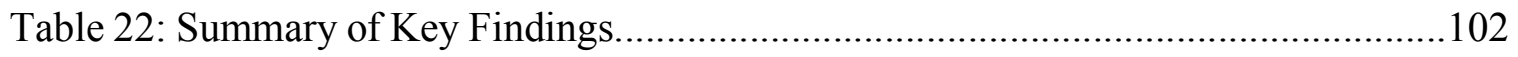




\section{LIST OF FIGURES}

FIGURE PAGE

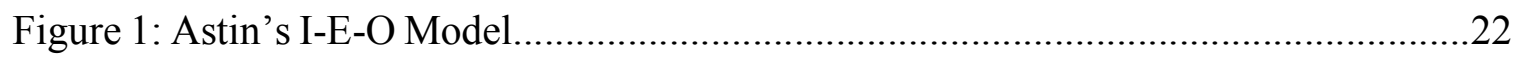

Figure 2. Empirical Model for Predicting NBDE Part I Performance...............................24 


\section{CHAPTER I}

\section{INTRODUCTION}

The dental profession is consistently ranked among the top occupations in the United States by various media outlets (U.S. News \& World Report L.P., 2019). In 2018, the Health Resources and Services Administration (HRSA) estimated a shortage of around 10,800 dentists in the United States. In response to this manpower assessment, several new dental schools have been established (Munson \& Vujicic, 2018). As of 2019, there are 65 Commission on Dental Accreditation (CODA) accredited dental schools in the United States. Typically, dental programs (such as Doctor of Dental Surgery - DDS or Doctor of Dental Medicine - DMD) require four years to complete, including the preclinical and didactic curriculum for the first two years focusing on the basic science and preclinical dental courses (American Dental Association, 2019c). Admission to a dental school is a highly competitive process. Even though a science degree from a college undergraduate institution is not required, college level science courses, including biology, physics, and chemistry, are usually prerequisites for dental school admissions. In addition, scores on the Dental Admissions Test (DAT) are required for seeking admission to dental school (American Dental Association, 2019b). The DAT is a computerized test designed to measure general academic ability, comprehension of scientific information, and perceptual ability. 
The National Board Dental Examination (NBDE) is an examination program used to assist state boards of dentistry in determining the qualifications of dentists who seek licensure to safely practice entry-level dentistry in any state, district, or dependency of the United States (Joint Commission on National Dental Examination, 2016). Although specific dental licensure requirements vary between states, two basic requirements are shared among all jurisdictions: an educational qualification and a written examination component. The educational qualification can be fulfilled by obtaining a DDS or DMD degree from a university-based dental education program accredited by the CODA and Commission on Dental Accreditation of Canada (CDAC) (American Dental Association, 2017b). The CODA has a reciprocal agreement with the CDAC and accredits the dental education programs in the United States and Canada.

The written examination requirement is fulfilled by evidence that a candidate has successfully passed the Parts I and II of NBDE. The NBDEs are the examinations composed of multiple-choice test items. Part I of NBDE covers the basic science disciplines in medicine and dentistry (Joint Commission on National Dental Examinations, 2017a). The students enrolled in the dental education program generally take the NBDE Part I after the first or second year of the program, after completion of the basic science curriculum (American Student Dental Association, 2017). NBDE Part II covers the disciplines in clinical dentistry (Joint Commission on National Dental Examinations, 2017b). The students enrolled in the dental education program generally take the NBDE Part II during the third or fourth year of the program while obtaining practice experiences in the clinical curriculum (American Student Dental Association, 2017). 


\section{Gap in the Literature}

Using Astin's Input-Environment-Output (I-E-O) model as a conceptual framework for understanding dental students' NBDE Part I performance, this study will examine the predictors of dental students' performance as first-time examinees for NBDE Part I. This study fills a gap in the current literature by providing dental educators a foundation for understanding the factors associated with the dental students' NBDE Part I performance and for identifying students who may be at-risk of failure on the NBDE Part I.

\section{Purpose Statement}

This study seeks to identify the predictors for success or failure on the NBDE Part I for the students enrolled in dental education programs. This study is designed to explore whether demographic factors, dental admission test factors, pre-program academic factors, and dental program academic performance during the first and second year of the dental program (basic science curriculum) are associated with students' first attempt performance on the NBDE Part I.

\section{Research Questions}

The focal research question for this study was, "Do dental students' demographic factors, dental admission test factors, pre-program academic factors, and academic performances in basic science curriculum predict passing the NBDE Part I?" To answer this primary question, the researcher developed five sub-questions:

Question 1: Are there significant relationships between dental students' genders or races, and their dental admission test performances, grade point averages at the undergraduate 
level in the college or university, and individual course grades and cumulative grade point averages in the dental program?

Question 2: Are there race and gender differences on the NBDE Part I outcome?

Question 3: Do the grade point averages at the undergraduate level in the college or university predict the NBDE Part I outcome?

Question 4: Does the dental admission test performance predict the NBDE Part I outcome?

Question 5: Do the first-year and second-year dental program individual course grades and cumulative grade point averages predict the NBDE Part I outcome?

To provide a more comprehensive understanding of the context of dental education in the United States and the NBDE, the following sections provide an overview and history of dental education and the NBDE.

\section{Dental Education in the United States}

Formal dental education in the United States started in the $19^{\text {th }}$ century. In 1840 , the University of Maryland refused to include dental education in its medical education's curriculum, and the state of Maryland funded an independent institution, the Baltimore College of Dental Surgery, as the first dental college in the United States and the world (Geis, 1926). The initial slow growth of dental schools in the 1800 s reflected the resistance from both prospective and established dentists. The prospective dentists preferred to serve an apprenticeship under an established dentist rather than enrolling in an expensive dental program, and the established dentists obtained financial gains by serving as preceptors. In 1870 , only $15 \%$ of dentists in the United States were trained in the official dental programs (Flexner, 1910). The American Dental Association (ADA) 
was founded in 1860 and charged a committee to prepare an annual report of the state of dental education (McCluggage, 1959). The efforts from ADA led to a forum for collective discussion about the standardized dental education and criteria for granting dental degrees.

Modern dental curriculum has been strongly influenced by a series of reports on professional education in the United States, which were published in the early $20^{\text {th }}$ century by the Carnegie Foundation for the Advancement of Teaching (Field, 1995; Kassebaum \& Tedesco, 2017). Abraham Flexner's 1910 study of medical education was the fourth report of the series and was a landmark commentary on medical preparation (Flexner, 1910). Several important themes were reinforced in the Flexner report, including the requirement of higher standards for admission and the movement toward medical education's grounding in scientific research (Flexner, 1910). The tenth report of the series was published in 1926 and was authored by Dr. William Gies. Dr. Gies was a Columbia University biochemistry professor who is now recognized as the founder of modern dental education (Donoff, 2006). Both Flexner and Gies emphasized the importance of basic science education in the early part of the medical and dental school curricula, and this emphasis has shaped modern dental education.

The current prominent dental education model is a four-year dental program and is generally preceded by a baccalaureate college degree with appropriate preprofessional sciences coursework. The first two years of the dental curriculum contribute to an understanding of basic and preclinical science (Field, 1995). Although an accurate estimate is difficult to assess, it is estimated that the basic and clinical sciences occupy $16.6 \%$ (813.7 hours) and $76.2 \%(3,743$ hours $)$ of the total dental curriculum, respectively. 
The mean percentage of total curriculum time occupied by the behavioral, social, information, and research sciences is estimated to be only 7.2\% (353 hours) (Kassebaum $\&$ Tedesco, 2017).

\section{Admission to the Dental Program}

Each dental program has specific mission statements and goals to select optimal applicants to fulfill said mission. Admission committees at each institution are charged with the responsibility of identifying suitable candidates who are most likely to become successful students in the dental program, as well as successful clinicians in the dental profession. The enrollment of unsuitable candidates with low academic performance would require additional school and faculty resources and hinder the normal operations of a dental program (Sandow, Jones, Peek, Courts, \& Watson, 2002). In addition, dental students who fail to make proper academic progress and fail to obtain practice licenses may experience negative financial consequences. Based on the information from the American Dental Education Association (ADEA), the average educational debt for indebted dental school graduates in the Class of 2018 was $\$ 251,869$ and $\$ 326,133$, for public and private dental schools, respectively (American Dental Education Association, 2019b). Failing students could also cause financial loss for dental programs due to the loss of tuition revenue. For the dental programs in the state-supported or state-assisted public intuitions, failing dental students also cause financial burden for the taxpayers and the solvency of the institution, since these dental programs receive some financial assistance from state governments (Pew Charitable Trusts, 2015).

Several factors have been considered in the dental program admission process to select suitable applicants with the potential for higher future academic performance. 
Dental program admission committees often consider undergraduate GPA scores along with scores on the DAT when selecting students, as some studies have shown that these two scores together have validity in predicting an applicant's potential for academic performance in the dental programs (Kim \& Lee, 2007; Kramer \& DeMarais, 1986). Undergraduate GPAs and scores on the DAT have also been proposed to predict a student's performance on the dental licensing examination, where the correlations are higher in the NBDE Part I scores, focusing on the assessment of students' knowledge of basic science (De Ball, Sullivan, Horine, Duncan, \& Replogle, 2002). However, the predictive value of undergraduate GPAs and scores on the DAT may be limited in determining the dental student's performance during the preclinical years. In addition, the ability of both GPAs and scores on the DAT to predict a student's clinical performance is still unclear (Smithers, Catano, \& Cunningham, 2004).

Demographic factors, such as students' gender, race, and ethnicity, have also been considered to affect dental or medical students' academic and licensure examination performance. Demographic factors are important because if they negatively affect admission decisions or graduation rates, then the dental profession may have limited diversity. Diversity can provide a better educational experience for all students and lead to better access to healthcare for patients (American Dental Education Association, 2019a). In 2010, the CODA approved new Accreditation Standards for Predoctoral Dental Education Programs, which included statements to mandate that dental programs have policies to "engage in ongoing systematic and focused efforts to attract and retain students, faculty and staff from diverse backgrounds" (American Dental Association, 2019a, p. 21). 
Underrepresented minorities (URM), including African Americans, Hispanics, and American Indians, comprise about $30 \%$ of the US population. However, only $6 \%$ of the dentists are URM (Lacy, McCann, Miller, Solomon, \& Reuben, 2012). While the ADEA and CODA have made major efforts working with dental programs in recent years to increase the diversity of admitted dental students, the percentage of dental students who are URM is still significantly below that of the general population (Lacy et al., 2012). Limited authors have shown that having the status of a URM has a significantly negative impact on medical students' licensure examination performance (Davis et al., 2013; Sesate, Milem, McIntosh, \& Bryan, 2017). The relationship between students' statuses as URM and dental students' academic performance is still unclear.

In addition to race and ethnicity, gender also has been shown to have a relationship with scores on the dental or medical licensure and admission examinations and could affect the pre-admission qualifications of applicants. For example, on the DAT, female students have higher scores in verbal reasoning and biological science, and male students have higher scores in the Perceptual Ability portion of the test (Kim \& Lee, 2007; Ranney, Wilson, \& Bennett, 2005). Although female students tend to perform as well as male students in the classroom and in course-related examinations, male students tend to outperform female students on both parts I and II of the NBDE (Behar-Horenstein et al., 2011; Fields, Fields, \& Beck, 2003; Stewart, Bates, Smith, \& Young, 2006).

\section{History of NBDE Part I}

The ADA established the National Board of Dental Examiners in 1928 to conduct written licensure examinations for state boards of dentistry. These examinations were formulated to provide a national standard for testing the basic science and clinical 
dentistry necessary to practice entry-level dentistry (Joint Commission on National Dental Examination, 2016). With advances in testing methods in the 1950s, the examination format was changed from essay questions to multiple-choice questions and norm-referenced scoring procedures. In the 1960s, the Council of National Board Examinations succeeded the National Board of Dental Examiners and started the computer-based scoring and statistical analysis of the test results. In the 1980s, the Joint Commission on National Dental Examinations (JCNDE) succeeded the Council of National Board Examinations. The JCNDE implemented procedures to equate examinations by using anchor items and ended use of norm-referenced scoring. In the early 1990s, a criterion-referenced scoring method of setting performance standard, based on the Rasch psychometric theory, was instituted for the NBDE Part I (Joint Commission on National Dental Examinations, 2018; Wright \& Stone, 1979). The passing score was set with the Rasch measurement model, and an examination candidate's ability and test item difficulty were described by a single measurement scale (Joint Commission on National Dental Examination, 2016). In 2007, one single comprehensive NBDE Part I examination was used to replace the traditional format of four individual examinations. In 2012, the JCNDE changed the reporting of results for candidates to the pass or fail format.

\section{Current Format and Scoring of NBDE Part I}

Since administration of the first National Board examination in 1934, the NBDE Part I has gone through many changes. The current computer-based examination consists of 400 test items and covers four disciplines in the basic science curriculum, including:

(a) anatomic sciences; (c) biochemistry and physiology; (c) microbiology and pathology; 
and (d) dental anatomy and occlusion. Approximately $80 \%$ of the test items focus on a single discipline, and $20 \%$ of the test items (100 test items) are interdisciplinary testletbased. A testlet, as described by Wainer and Kiely (1987), is an aggregation of items that are based on a single stimulus and can be arranged either hierarchically or linearly (Wainer \& Kiely, 1987). In NBDE Part I, the testlet includes a clinical, patient-based scenario and a set of test items covering interdisciplinary knowledge pertinent to the scenario. Each candidate has 8 hours and 30 minutes to complete the examination.

JCNDE constructed examination item banks, and items for each candidate are selected from the banks according to the content requirement in each individual examination form with a unique combination of test items. Based on the Rasch measurement model (Wright \& Stone, 1979), score conversion is estimated for each examination candidate. This model is a mathematical equivalent to the one-parameter logistic model. The Rasch model allows each candidate to complete a set of exam items, which are different than those completed by any other candidate but are still scored under the same scale of measurement. In addition, the Rasch model allows for extensive crosschecking of item parameters to ensure the item difficulties do not drift too far away from the intended scale of measurement.

The converted scale score of NBDE Part I ranges from 49 to 99, and a score of 75 represents a passing score. A raw score is computed by the total number of correct answers achieved by each candidate and converted into a scale score, which is adjusted by the differences in difficulty across NBDE Part I forms. Table 1 shows the numbers and failure rates for first-time and repeating candidates from accredited dental programs who took NBDE Part I (Joint Commission on National Dental Examinations, 2018). 
Although no further statistical analysis was provided, the failure rates for repeating candidates appear to be higher. This could be interpreted that students who fail the NBDE Part I for the first time may possess a higher risk of failing the examination in their subsequent attempts.

Table 1

Numbers and failure rates for first-time and repeating candidates for NBDE Part I from 2008 to 2017.

\begin{tabular}{ccccccc}
\hline \multirow{2}{*}{ Year } & \multicolumn{2}{c}{ First-time } & \multicolumn{2}{c}{ Repeating } & \multicolumn{2}{c}{ First-time and Repeating } \\
\cline { 2 - 7 } & Number & \% Failing & Number & \% Failing & Number & \% Failing \\
\hline 2008 & 4,607 & 7.4 & 418 & 31.8 & 7,994 & 20.8 \\
2009 & 4,881 & 5.3 & 615 & 22.3 & 8,815 & 18.4 \\
2010 & 4,923 & 5.3 & 462 & 29.4 & 7,701 & 17.5 \\
2011 & 5,068 & 4.5 & 396 & 33.6 & 8,098 & 18.3 \\
2012 & 5,497 & 6.1 & 344 & 39.2 & 8,404 & 20.3 \\
2013 & 5,574 & 6.3 & 504 & 30.6 & 8934 & 20.0 \\
2014 & 6,041 & 3.7 & 337 & 26.3 & 9,617 & 16.5 \\
2015 & 6,092 & 3.4 & 308 & 28.6 & 9,668 & 16.7 \\
2016 & 6,260 & 5.2 & 340 & 33.5 & 9,973 & 18.2 \\
2017 & 5,995 & 10.6 & 669 & 33.5 & 9,997 & 24.1 \\
\hline
\end{tabular}

(Joint Commission on National Dental Examinations, 2018)

\section{Reliability and Validity}

The NBDE follows the recommendation from the Standards for Educational and Psychological Testing to develop, administer, and score the examinations (American Educational Research Association, American Psychological Association, \& National Council on Measurement in Education, 2014). The reliability and validity evidence are documented and published in the technical documentation from JCNDE (Joint Commission on National Dental Examination, 2016; Joint Commission on National Dental Examinations, 2018). Internal consistency concerns the extent to which the individual items on the test are correlated with each other, and the advantage of internal consistency reliability is that it can be estimated with one single text administration 
(Bolarinwa, 2015). Cronbach's alpha (Cronbach, 1951), the Kuder-Richardson Formula 20 (KR-20), and the Kuder-Richardson Formula 21 (KR-21) are among the best-known measures of internal consistency reliability. KR-20 was first published in 1937 as a measure of internal consistency reliability for measures with dichotomous choices (Kuder \& Richardson, 1937). The values of KR-20 range from 0 to 1.00 and may be affected by difficulty of the test, the spread in scores, and the length of the examination. The JCNDE reported the score reliability of NBDE Part I using KR-20, and it ranged from 0.94 to 0.97 (Joint Commission on National Dental Examination, 2016; Joint Commission on National Dental Examinations, 2018). Table 2 provides the aggregated results for all NBDE Part I testlets in 2017.

\section{Table 2}

NBDE Part I descriptive statistics in 2017

\begin{tabular}{ll}
\hline Descriptive statistics & Value \\
\hline Total number of candidates in the reference Group & 5,962 \\
Standard score mean & 80.60 \\
Standard score standard deviation & 4.97 \\
Mean score & 66.08 \\
Kuder-Richardson Formula 20 & $.94-.97$ \\
\hline
\end{tabular}
(Joint Commission on National Dental Examination, 2016; Joint Commission on National Dental Examinations, 2018)

Validity can be referred to as the extent of evidence and theory-supporting interpretations of test scores for proposed uses of a test (Urbina, 2014, p. 167). In the test development phase, a criterion-referenced scoring method was implanted for the NBDE Part I, and the passing score was set with the Rasch measurement model. Kramer and DeMarais (1992) examined the construct validity of the NBDE and confirmed the examinations were unidimensional. The finding of unidimensionality was essential to 
meet the assumption for the Rasch measurement model to be used for constructing and scoring NBDE (Kramer \& DeMarais, 1992).

Validation is not an activity that only occurs during the test development stage but, rather, is an ongoing process to gather evidence in supporting or questioning the interpretation's propositions (American Educational Research Association et al., 2014; Messick, 1995). The intended interpretation of NBDE Part I results is concerned with whether or not the test candidate possesses an adequate level of biomedical and dental science knowledge to practice entry-level dentistry. The test content of NBDE Part I is under continuous evaluation, and the validity studies involving practice analyses are conducted every five years. The Committee on Examination Development in the JCNDE oversees the content specifications for the NBDE. In 2001, ADEA defined the competencies necessary for a general dentist to practice entry-level dentistry, and the practice analysis for NBDE Part I was conducted to gather empirical evidence of validity (American Dental Education Association, 2002). The findings suggested that the content of NBDE Part I examination should be revisited with more clinically-relevant test items. Thus, the JCNDE adapted the NBDE Part I with the current comprehensive format of combining single discipline test items and interdisciplinary testlet-based items (Joint Commission on National Dental Examination, 2016). A follow-up study on the current NBDE Part I format demonstrated the improvement of its validity in assessing candidates' knowledge in a more clinically relevant and interdisciplinary assessment context (American Dental Association, 2017a).

Since 2009, the JCNDE has been developing a new examination that integrates the NBDE Parts I and II, named the Integrated National Board Dental Examination 
(INBDE). The INBDE aims to mirror the NBDE Program to determine the minimum qualifications of the individuals seeking licensure to practice entry-level dentistry. The INBDE will be available for administration on August 1, 2020. However, evidence of the validity of INBDE may not be available for an extended period of time, but dental education programs still need to strive to provide quality education for all dental students and additional support for at-risk students during the early stages of a dental program.

\section{Rationale for the Proposed Study}

This proposed study aims to study the relationships among the demographic factors, DAT factors, pre-program academic factors, dental program academic factors, and the students' NBDE Part I performance. Dental students are required to successfully challenge the different licensure examinations to practice dentistry, and the NBDE Part I is the first step toward that goal. Numerous failed attempts by candidates on the NBDE Part I may threaten the viability of a dental program and consume additional resources for students, faculty, and dental school administrators preparing them to re-challenge the examination. This study will use the Astin's I-E-O model as the theoretical framework. Astin (1993) developed the Input-Environment-Output (I-E-O) model as a guiding theoretical framework for assessment in higher education. This theoretical model focuses on the student inputs (I), the educational environment (E), and student outcomes $(\mathrm{O})$, allowing the researcher to assess how do the input variables and environmental variables affect outcome variables (Astin \& Sax, 1998). Using Astin's model, this study will investigate the predictability of environment factors (dental program academic factors), and input factors (demographic factors, pre-program factors, and DAT factors) on the students’ NBDE Part I performance (outcome). 
During the first-year and second-year dental curricula, it is imperative for course faculty and school administrators to recognize the importance of academic factors on students' NBDE Part I performance. The findings from this study can provide evidence for dental programs on the overall effectiveness of the curriculum and if specific courses provided by the dental program can indeed assist students to successfully challenge the NBDE Part I. Although a new examination format (INBDE) with integration of NBDE Parts I and II will be implemented in the near future, it is necessary to analyze the available data, since the INBDE still aims to mirror the NBDE Program with the same test domains to determine the minimum qualifications of the individuals seeking licensure to practice the entry-level dentistry.

The results from this study can be used by educators and administrators to evaluate a student's academic performance in the dental program and identify individuals at risk of poor performance in either the NBDE exam or the new format of INBDE. The findings from this proposed study could guide educators and administrators to develop benchmarks throughout the first year and second year of the dental program to identify at-risk students who may benefit from additional academic support. After the identification of at-risk students, educators and administrators could design tailored intervention programs for students to receive academic support opportunities or remediation for their deficiencies. Early identification of at-risk students can minimize possible student attrition in the dental program.

Diversity in the student population in dental programs improves students' learning processes and increases the healthcare access for patients from different racial-cultural backgrounds. Many dental programs strive to admit students from various racial and 
cultural backgrounds. However, to address the equity issues further, providing additional educational supports for minority students while they are enrolled in the dental programs is equally important. Based on the findings of this research, additional enrichment and bridge programs for URM students may be established to maximize the future success of the enrolled diverse student body. In addition to race and ethnicity, gender also has been shown to have a relationship with scores on the dental or medical licensure and admission examinations and could affect the pre-admission qualifications of applicants. As such, the findings of this research can also be utilized to evaluate admission criteria for the dental programs.

Furthermore, this proposed study will also provide an assessment on the validity of educational content in the dental program in terms of preparing students for licensure examinations. It is important for faculty to properly design and develop a curriculum that aligns with current dental knowledge and satisfies the expectation of authorities who administer licensure examinations.

During the admissions process, most dental programs set minimum scores on the DAT and GPA as part of the selection criteria. This assumes that the scores on the DAT and pre-program GPAs can serve as reliable indicators to predict the future success of dental students. The results from this proposed study can potentially provide more information on the predictive validity of this practice. This practice may negate an applicant's potential to develop professional knowledge and skills if they were afforded the opportunities to receive dental education. The findings of this study on scores on the DAT and pre-program academic factors may support or refute this common admission practice. 
Even though this proposed study could address the gaps in current literature on predicting dental students' NBDE Part I performance, additional research can be considered in the future. First, guided by the findings from this research, educators and administrators can improve curriculum design and associated learning support systems as means of structuring a successful educational environment. New studies can then be designed and tested to gain detailed knowledge of student success trends at particular institutions.

This proposed study is the first to utilize the Astin's I-E-O model as the theoretical framework on the research empirical model to understand dental students' performance in licensure exams. The findings from this proposed study will serve as a foundation to either support or refute the use of selected predictor variables to predict licensure exam performance using the proposed research empirical model. Testing of other predictor variables, such as age, socioeconomic status, personality traits, and study habits, that may confound pre-program academic outcomes can provide a more complete understanding of predicting dental students' academic success. After the new format of the INBDE has been administered and collected sufficient data, educators can use the findings of this research to exam the application of prediction models on the INBDE. Educators can also use these findings to develop holistic admission selection criteria to ensure admitted candidates are those most likely to be successful in dental programs and subsequent licensure examinations.

\section{Focal research question}

The focal research question for this study is, 'Do dental students' demographic factors, dental admission test factors, pre-program academic factors, and academic 
performances in basic science curriculum predict passing the NBDE Part I?" To answer this primary question, the researcher developed five sub-questions to explore the relationship of: (1) demographic factors, (2) dental admission test (DAT) factors, (3) preprogram academic factors, and (4) dental program academic performance with the NBDE Part I performance. 


\section{CHAPTER II}

\section{REVIEW OF THE LITERATURE}

This chapter summarizes the existing research on predictors of dental students' NBDE Part I performance. The organization of this section is as follows: (a) description of the conceptual framework for this current study, (b) identification of dental students' academic and NBDE performance prediction model for the current study, and (c) a review of prior research on predictors of dental students' academic and NBDE performance prediction.

\section{Conceptual Framework}

Different levels of higher education from colleges, universities, graduate schools, and professional schools may have very different definitions of student success. Multidimensional factors may also interact and influence student and institutional performance, and there is no single view comprehensive enough to explain all the effects (Kuh, Kinzie, Buckley, Bridges, \& Hayek, 2006). Student success in higher education may be defined by using traditional measures of academic achievement, including the scores on standardized examinations, academic achievement, or credited hours earned in consecutive terms. In addition, post-graduation achievements are also considered, as well as other traditional measures of student success in higher education, such as disciplinespecific admission test scores, admission, and enrollment in graduate school or

professional school (Kuh et al., 2006). For undergraduate students, persistence and 
educational attainment, or achieving the desired educational credential, are often cited as the measures for student success (Braxton, Shaw Sullivan, \& Johnson, 1997).

Another perspective of student success is described in the landmark interactionalist theory, proposed by Tinto (1975). He theorized that academic and social integration are complementary but independent processes in the student's adjustment process to college life (Tinto, 1975). A higher level of academic and social integration can promote students' commitment to the institution and increase the likelihood of college students' persistence and educational attainment.

In healthcare professional schools, student success can also be defined by the first time pass rate on a licensing or certification exam or post-graduation employment (Jeffreys, 2015). Although the authors of many studies have attempted to understand student success and the predictors associated with student success in the healthcare field, there is no current commonly accepted theoretical foundation for these studies. Different authors have proposed various factors that may affect student success in healthcare professional schools. For example, in medicine, the Committee of Deans and Heads of Medical Schools in the United Kingdom commissioned a systematic review to examine the significant predictors that may be associated with medical students' success (Ferguson, James, \& Madeley, 2002). They examined numerous factors to investigate their relationship to medical students' success, including cognitive factors (previous academic ability), non-cognitive factors (personality, learning styles, interviews, references, personal statements), and demographic factors (sex, ethnicity). Among those factors examined, the previous academic performance or tests measuring prior learning (grade point average and medical college admission test) were shown to be a good 
predictor of student success in medical school. It accounted for $23 \%$ of the variance in the students' performance in pre-doctoral medical training.

For the field of nursing, Jeffreys' Nursing Universal Retention and Success (NURS) model proposed a theoretical framework to globally examine multidimensional factors, including student profile characteristics, professional integration factors, and academic outcomes, that affect undergraduate and graduate nursing students' retention and success (Jeffreys, 2015).

In dentistry, many authors have reported on the factors that may predict a students' performance on the NBDE examination, including the dental admission test (DAT) factors (eight standard scores reported by DAT), pre-program academic factors (undergraduate science GPA and undergraduate non-science GPA), and dental program academic factors (individual course GPAs and cumulative GPA). However, most researchers in dentistry did not explicate the theoretical foundation of their studies (American Dental Association, 2009; Bergman, Susarla, Howell, \& Karimbux, 2006; De Ball et al., 2002; Hermesch, McEntire, Thomas, \& Berrong, 2005; Holmes, Doering, \& Spector, 2008; Kingsley, Sewell, Ditmyer, O’Malley, \& Galbraith, 2007; Sandow et al., 2002).

\section{Conceptual Model for the Current Study}

Assessment in higher education is important to enhance student learning outcomes and can provide feedback to both faculty and students. Assessment in higher education can be defined as gathering information about how students, faculty, and institutions function. Assessment can provide information on the extent of causal relationships between education practices and outcomes. Astin (1993) developed the 
Input-Environment-Output (I-E-O) model as a guiding theoretical framework for assessment in higher education. This theoretical model focuses on the student inputs (I), the educational environment (E), and student outcomes (O) (Astin, 1968, 1993; Astin \& Antonio, 2012). The primary purpose of this model is to allow the researcher to control for input variables and thus produce a less biased and more accurate estimate of how environmental variables affect outcome variables (Astin \& Sax, 1998). Figure 1 depicts Astin's I-E-O model (Astin, 1993).

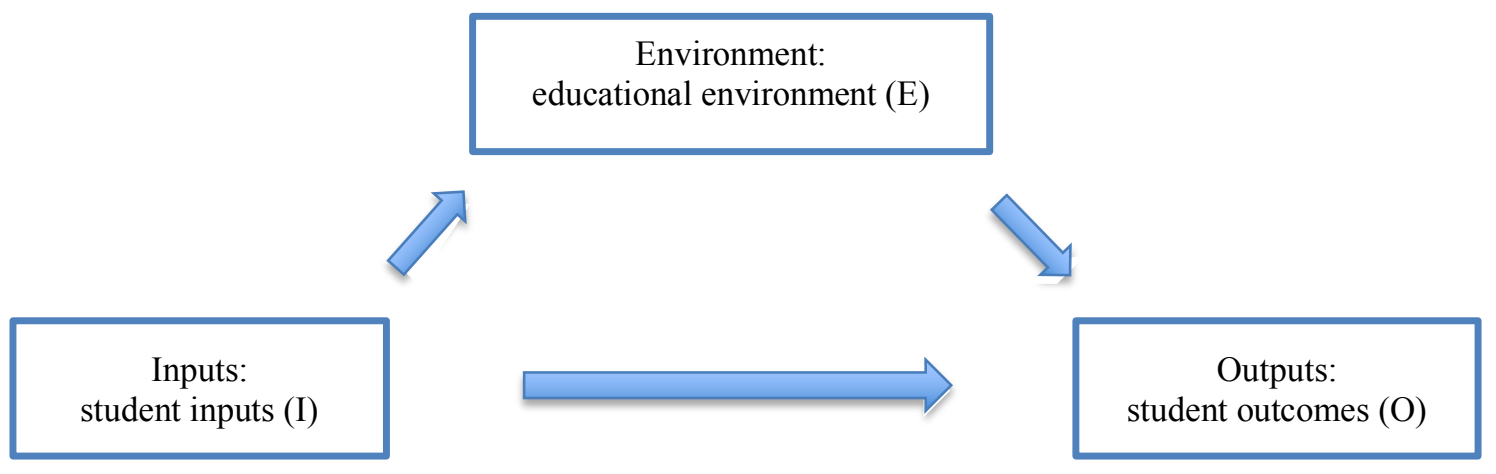

Figure 1. Astin's I-E-O model.

Note. Electronic image created by author based on information found "How College Students' Engagement Affects Personal and Social Learning Outcomes" by T. Strayhorn, 2008, Journal of College and Character, p.3. Copyright 2014 by Taylor \& Francis.

Three constructs included in the Astin's I-E-O model are inputs, environment, and outcomes. Inputs refer to the student's personal qualities that they bring to the education program initially, including their initial level of developed talent at the time of entry and antecedent conditions. The inputs can function as control variables in the research design. The input data in the I-E-O model will have direct influence on both environment and output constructs and indirect influence on outputs through environmental constructs. Some examples of student inputs include demographic variables, educational 
background, pre-program abilities, behavior patterns, and degree aspiration. According to Astin (Astin, 1993), environment refers to the student's actual experiences during the educational program. It may include anything that occurs to the students during the educational program, such as educational experiences, practices, programs, interventions, extra-curricular activities, and organizational affiliation. Outputs are the outcome variables, which may include grade point average (GPA), scores from the examinations, academic performance, degree completion, and overall satisfaction with the education program (Astin, 1968, 1993; Astin \& Antonio, 2012; Thurmond \& Popkess-Vawter, 2003). Astin's I-E-O has been utilized in different empirical research to investigate the institutional excellence (Astin, 1968), service programs on undergraduate student development (Astin \& Sax, 1998), student satisfaction, and degree completion (House, 1999).

In medicine, Astin's I-E-O model was used to assess the relative impact of admissions factors (i.e., Medical College Admission Test score, college GPA, college major, interview score) and medical program academic factors (first-year and secondyear mean GPA in groups of related subjects) on the United States Medical Licensing Exam (USMLE) Step 1 scores (Sesate et al., 2017), while controlling for preadmission demographic characteristics (sex, race, parental education, residency status). Different quadratic regression models were built in this study to explore the relative impact of admissions factors and medical program academic factors on USMLE Step 1 scores (Sesate et al., 2017). The Association of American Medical Colleges also recommended using the I-E-O model to evaluate the role that the medical school environment plays to achieve desired education outcomes (Witzburg \& Sondheimer, 2013). 
Using the I-E-O model as the conceptual framework, this study will examine the influence of: (1) demographic factors, (2) DAT factors, (3) pre-program academic factors, and (4) dental program academic performance on the NBDE Part I performance. Figure 2 depicts the empirical model that will be tested in this study.

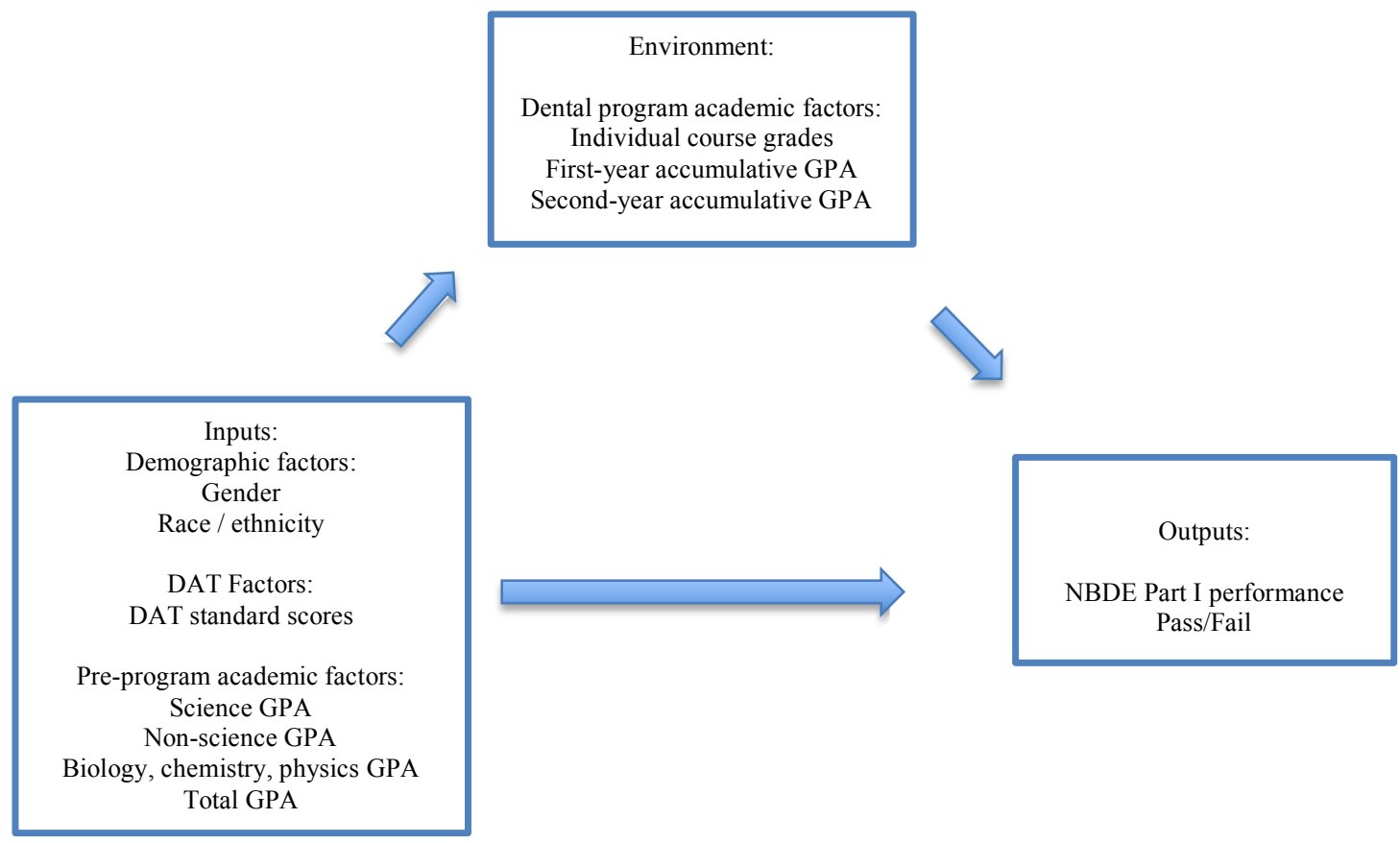

Figure 2. Empirical model for predicting NBDE Part I performance

\section{Predictors of Dental Students' Academic and NBDE Part I Performance}

Although it is important to utilize different practices in recruitment, admission, and retention to achieve diversity in American dental education, current dental schools have primarily sought to admit and enroll the most highly qualified applicants among the application pools (Sinkford \& Valachovic, 2003). Different studies have been conducted to relate various qualifying factors to the dental students' success or performance in the dental curriculum. Applicant's past academic performance (such as college GPA), scores on the DAT, manual dexterity or perceptual ability test developed by individual dental schools, personality assessments, interviews, and demographic characteristics have all 
been studied as the predictors for dental students' success or performance in the dental curricula (Ranney et al., 2005).

To define the success or performance in the evaluation process, different outcome variables have been used in the existing literature, including dental school overall and individual year GPA, performance in dental treatment techniques, performance on NBDE Parts I and II, performance in the regional licensure examination, and delays in graduation (Ranney et al., 2005). Most of the authors of the reported studies did not ground their studies in student success theory (which is lacking in the context of dental education), resulting in statistical modeling of a wide array of dental students' success or performance predictors and inconsistent support for a uniform set of predictors.

There are two limitations identified in the current dental literature investigating relationships between predictors and outcomes of dental students' success or performance. Considerable variations have been observed among admission years and across different dental schools, and these have created problems in interpreting the findings from existing literature. For instance, the generally unknown reliability of dental school grades may cause difficulty to generalize the meaning of relationships between the DAT and students' dental school overall and individual year GPA. Furthermore, the range restriction in those who are admitted as dental students as compared to those who are the applicants in the total application pool may have contributed to reduced correlations in the current literature. When the variance is smaller in the admitted dental student population than that in the entire application pool, the studies may demonstrate decreased correlation coefficients between predictors and outcome variables (Ranney et al., 2005). 
The following section will present the findings from existing literature in the context of relevant predictors of dental students' academic and NBDE Part I performance, and the results will be utilized in conjunction with the existing theoretical frameworks from other fields in higher education to develop an empirical model for the current study.

\section{Demographic Factors (Gender and Race/Ethnicity)}

Diversity in Higher Education. President John F. Kennedy used the term "affirmative action" in the executive order No. 10925 on March 6, 1961, and this order directed government contractors to take affirmative action to ensure that "applicants are employed, and employees are treated during employment, without regard to their race, creed, color, or national origin” (Birnbaum, 1962, p. 17). In 1967, this executive order was extended to include sex. Since then, admission policies for higher education have adopted the concept of affirmative action. Although affirmative action can be applied to a broader definition and maximize educational opportunity for all underrepresented racial, gender, and socioeconomic groups, it has generally focused on racial minorities.

However, the legality of this policy has been challenged constantly for over 40 years (Raphel, 2015). It has been considered that affirmative action may be unconstitutional under the Equal Protection Clause of the $14^{\text {th }}$ Amendment of the United States Constitution. That said, in the most recent Supreme Court decision, Fisher v. University of Texas at Austin, the court held that race-conscious undergraduate admissions programs did not violate the Equal Protection Clause. However, there are a few important opinions from Justice Anthony Kennedy, including that: 
[A] college must continually reassess its need for race-conscious review. [...] The Court's affirmance of the University's admissions policy today does not necessarily mean the University may rely on that same policy without refinement. It is the University's ongoing obligation to engage in constant deliberation and continued reflection regarding its admissions policies. (Supreme Court of the United States, 2016)

Regardless of the legal controversy about affirmative action, creating a higher education institution with diversity can provide an inviting environment within which all faculty and students can flourish. A diverse student body can increase students' academic performance, retention, and engagement (Glazer, Bankston, Clark, \& Ying, 2014). Particularly in the healthcare professions, students from underrepresented minorities (URM, including African Americans, Hispanics, and American Indians) and underserved communities could bring their lived experiences and cultural background into the daily interaction with their peers, coworkers, and patients. When these students participate in the academic environment, they can influence others in their sphere and further prepare an entire student cohort as a culturally prepared healthcare workforce. With such cultural competency, these healthcare providers would be more able to provide accessible and quality care to an increasingly diverse population and help achieve optimal healthcare outcomes. A diverse healthcare workforce can contribute to a pathway to reduce the disparities in healthcare access, thereby improving the health of the overall population, especially that of underserved populations (Cooper, Beach, Johnson, \& Inui, 2006; Cooper \& Roter, 2003; Thomas \& Dockter, 2019). 
The gender gap has also been noted in healthcare professions. In present times, fewer African American and Hispanic women are entering the healthcare professions (Hernandez \& Kumar, 2018). Further, the gender gap in medicine has been shown to be field-specific and still prominent in some healthcare specialty fields. For instance, $91 \%$ of registered nurses and $75 \%$ of medical technicians are female. Further, optometrists, chiropractors, and dentists have the highest concentration of men, while pediatricians, veterinarians, and pharmacists have the lowest. In $2012,72 \%$ of the dentists were men, and female dentists earned 24\% less than their male counterparts (Carnevale, Smith, Gulish, \& Beach, 2012). That said, the gender gap for physicians is closing. Female students in US medical schools have been increasing from $32 \%$ in 1985 to $47 \%$ in 2011 , and roughly half of graduating physicians will be female in 2020 .

It has been reported that female physicians consistently engage in patient-centered communication more than their male colleagues, and they spend more time with their patients to develop a sense of partnership. The patient-centered communication may have contributed to the lower productivity of female physicians, but this type of interaction is most valued by patients. Patients generally experience higher levels of satisfaction with their care from female physicians (Barr, 2017). The addition of more women in the healthcare workforce in dentistry can extend a substantial value to dental care quality with their patient-centered interaction skills.

\section{Gender as a predictor of dental program academic and NBDE performance}

The gender gap in academic performance (such as course grades in the academic program) and in standardized achievement tests have been discussed extensively in the literature (Voyer \& Voyer, 2014). In a meta-analysis of 502 effect sizes drawn from 369 
samples, the results showed that there is a significant female advantage in school grades extending to most course subjects (language, math, and science). In contrast, the analysis on the standardized tests performance showed that the male students outperform female students in mathematics and science. However, female students still showed an advantage in standardized tests related to reading comprehension (Voyer \& Voyer, 2014). In many healthcare science professions, different high-stakes testing events can impact the program admission and licensure obtainment of a student, such as the Medical College Admissions Test (MCAT) and the DAT, and national certifying examinations, like the United States Medical Licensing Examination (USMLE Step 1, 2, and 3), the NBDE Parts I and II, and the National Board of Osteopathic Medical Examiners (NBOME Level 1, 2, and 3) (Fields et al., 2003).

In dentistry specifically, the DAT is the first high-stakes standardized test that potential dental student candidates encounter during the admissions process. Male students significantly outperform female students in all areas, except reading comprehension, biology and organic chemistry (Behar-Horenstein et al., 2011; Fields et al., 2003). This gender gap may have detrimental effects in the dental programs' admission process if an admission committee attempts to develop specific algorithms, including DAT components, that systematically disadvantage female students (Fields et al., 2003).

In terms of the NBDE Parts I and II, a potential gender gap may also exist. One study has found gender to be predictive of passing the NBDE Parts I and II, and male students tend to outperform female students (Behar-Horenstein et al., 2011). Another study also showed that male students significantly outperformed female students in the 
NBDE Part II (Fields et al., 2003). However, an interesting finding from the dental literature confirms that female students have higher cumulative GPAs compared to their male counterparts in dental programs (Sawair, Baqain, Al-Omari, Wahab, \& Rajab, 2009).

These studies suggest that, with increasing female dental student enrollment, it is important to periodically assess student performance to determine whether instructional modifications are needed to accommodate gender differences (Stewart et al., 2006). It is also important to further investigate the effect of the gender gap in academic programs, within dentistry and beyond. The findings of these studies could be used to guide policy decisions, such as additional educational support in dental programs or additional funding for students to prepare for high-stakes standardized tests, such as licensure examinations.

\section{Race and ethnicity as a predictor of academic performance and NBDE}

performance in the dental programs. There is scarce literature on the association of race and ethnicity with dental students' academic and licensure examination performance. Historically, dental program admission committees have placed great emphasis on applicants' past academic performance (such as college GPA) and scores on the DAT, even though strong correlations between these criteria and students' potential performance remain elusive (Chaviano-Moran, Chuck, \& Perez, 2019). One study has shown that, among all interviewed and admitted candidates, URM reported a higher total number of employment hours during their undergraduate years and lower undergraduate GPAs, although a specific relationship between these two factors was unclear. Metricbased selection criteria favor the applicants with higher GPAs and scores on the DAT (Chaviano-Moran et al., 2019). Many authors have proposed dental program admission 
committees consider factors beyond academic performance in selecting a more diverse and culturally sensitive dental professional workforce to improve overall profession and oral care access (Ranney et al., 2005).

Although diversification of the dental profession remains an important focus, dental programs need to provide adequate educational support to ensure academic and future success of all admitted students. Few studies have shown that a minority status may negatively affect students' performance in dental programs. One study assessed the relationship of students' past academic history, their demographic backgrounds, and their academic performance in the first year of a dental program (Perez, Sabato, Jiang, \& Feldman, 2018). Perez at al. (2018) analyzed data from 2011 to 2018 for 174 students, and broad measures of student success were used to determine academic performance, including student continuation in curriculum, student withdraw/dismissal, or student remediation of at least one course. When comparing the top 10 performing and lowest 10 performing students across the classes, the following variables were significant: Barron's score of undergraduate institution, undergraduate science GPA, number of failures or withdrawals from science courses during undergraduate education, scores on the DAT, and URM status (Perez et al., 2018). URM status had a significant relationship with low academic performance in the first year of dental program, since 35 out of 38 URM students were in the low performing population. Although the education-occupation indicator was often used as a proxy for the parents' socioeconomic status, this indicator was found to be non-significant in this study. This finding implied that the academic challenge of these URM students may not be largely related to economic or educational disadvantages. 
Similar findings have been noted in medicine (Andriole \& Jeffe, 2010; Davis et al., 2013; Sesate et al., 2017). Medical programs utilize the MCAT as a selection criterion for admission. Because the MCAT is designed as the standardized examination to assess the knowledge and skills that are a prerequisite to the study of medicine, it is also expected to be predictive of medical students' academic success, including the performance in the United States Medical Licensing Exams (USMLEs). One study has shown that URM status was associated with about an 11-point decrease in the USMLE Step 1 scores (Sesate et al., 2017). This finding is consistent with a few other studies in medicine (Andriole \& Jeffe, 2010; Davis et al., 2013; Sesate et al., 2017). However, small sample sizes reduce the strength of these results to allow for generalization. Therefore, the significance of URM status and low academic or licensure exam performance should be evaluated with caution, and further research to evaluate this phenomenon is necessary. Future research should also place emphasis on the educational support and resources that can help students with URM status to overcome barriers before or during dental programs to improve their success.

\section{Dental Admission Test (DAT) Factors}

History and current format and scoring of DAT. The Dental Admission Testing Program started its development in 1945 when there were only 39 accredited dental schools with 12,000 enrolled dental students. As of 2014, there were 65 accredited dental schools with 24,000 enrolled students. There were three reasons for the development of the Dental Admission Testing Program at its inception. First, 20-25\% of first-year dental students withdrew from the dental program before graduation. Therefore, there was a need to develop a specific aptitude test to provide data for dental school 
admission committees to select the best-suited applicants, improve performance, and reduce the early attrition rate. Second, the veterans of World War II were beginning to apply to dental programs, and dental schools were unable to compare the educational records of veterans to the more recent records of non-veteran applicants. Dental schools were seeking a more standardized way to evaluate these applicants. Last, grades from various high schools and colleges were highly variable, and a national standardized test was thought to provide a common basis to compare the applicants' readiness for the dental programs (American Dental Association, 2009).

The DAT consists of multiple-choice test items in a battery of four domains, including Survey of the Natural Sciences (100 items divided into three sections: 40 items of biology, 30 items of general chemistry, and 30 items of organic chemistry), Perceptual Ability (90 items of two-dimensional and three-dimensional problems), Reading Comprehension (50 items), and Quantitative Reasoning (40 items, consists of 30 items of mathematical problems and 10 items of applied mathematics). The total test time for a DAT examination is 5 hours and 15 minutes. Eight standard scores are reported on the DAT, including Quantitative Reasoning, Reading Comprehension, Biology, General Chemistry, Organic Chemistry, Total Science (combining Biology, General Chemistry, and Organic Chemistry), Perceptual Ability, and Academic Average (the rounded arithmetic mean of the standard scores on the Quantitative Reasoning, Reading Comprehension, Biology, and General and Organic Chemistry tests) (American Dental Association, 2020; Holmes et al., 2008).

DAT results are reported as scale scores, which are the conversion of raw scores completed using equating procedures developed by ADA. The standard score scale from 
1 to 30 is based on the log ability scale defined by the Rasch Model range for dichotomous item responses and allows for meaningful comparison among applicants (Wright \& Stone, 1979). A scale score of 18 usually represents the average performance from the national perspective. Each test also includes experimental questions, which are not scored in the examination and are used for later test construction procedures. These unscored test items are used to ensure the appropriateness of the questions before they become scored items in future examinations (American Dental Association, 2017a). The reliability of scores on the DAT are measured with KR-20, and the ADA has reported the reliability coefficients of scores on the DAT as follows: 0.79 for the Quantitative Reasoning Test; 0.81 for the Reading Comprehension Test; 0.93 for the Survey of the Natural Sciences Test; and 0.90 for the Perceptual Ability Test (American Dental Association, 2009).

The recommended timeframe for applicants to take the DAT is at the end of the spring semester in the junior year of undergraduate school or immediately after the completion of organic chemistry courses (American Dental Education Association, 2020). The evidence indicating the validity of scores on the DAT is usually investigated from two sets of criteria: dental students' academic performance in the first year and second year of dental curricula and their performance on the NBDE Part I. The following sections will discuss the current available evidence on the association among scores on the DAT, dental program academic factors, and NBDE Part I scores.

Scores on the DAT as a predictor of the dental program academic factors. In addition to the pre-program academic factors, scores on the DAT were found in the early literature to be one of the most consistent predictors of dental program academic factors, 
such as the dental students' academic performance in the first year and second year of dental curricula. The estimates of correlation between Academic Average score on DAT and dental students' academic performance (in the first year and second year of dental curricula) are in the range of 0.19 to 0.55 , accounting for $4-30 \%$ of the variances in students' academic performance (Dworkin, 1970; Ginley, 1966; Ranney et al., 2005). The scores on the DAT have generally been shown to be a significant predictor for dental students' academic performance in the early dental curricula (usually the didactic and technique training portions are in the first and second year of the curricula); however, it is not as effective in predicting the students' performance in the later years of curricula (usually the clinical training portion is in the third and fourth year of the curricula) (Kramer, 1986). Another study showed that scores on the DAT had no predictive value for clinical achievement, and the Academic Average scores on the DAT only accounted for $0.46 \%$ of the variance of the final clinical grades, while the DAT Perceptual Ability Test scores only accounted for $0.26 \%$ of the variance (Gray, Deem, \& Straja, 2002).

The ADA conducts annual validity studies examining students' course grades in dental programs to determine the predictive validity of DAT relative to the students' academic performance. The most recent study was released by the ADA in 2020 (American Dental Association, 2020). For the first-year class, 52 out of 65 accredited dental schools provided the ADA requested data, while 50 out of 65 accredited dental schools provided the data of the second-year class. Pre-program factors (i.e., pre-dental college total GPA, pre-dental science GPA, and scores on the DAT), course grades in the first-year class (i.e., biomedical science grades, preclinical dental technique grades, and first-year cumulative GPA), and course grades in the second-year class (i.e., biomedical 
science grades, preclinical dental technique grades, and second-year cumulative GPA) were provided by each participating dental school. Multiple regression was used to examine the relationship between the pre-program factors and the dental program factors, using the pre-program factors as predictors and the dental program factors as the criterion variables.

The scores on the DAT alone had a stronger relationship with the dental program factors than the pre-dental college total GPA or pre-dental science GPA. The greatest variance in each dental program factor was accounted for by using all predictors (predental college total GPA, pre-dental science GPA, and scores on the DAT). Findings from the ADA suggested that $26 \%$ of the variance in first-year biomedical grades, $24 \%$ of the variance in second-year grade, $19 \%$ of the variance in first-year pre-clinical dental technique grades, $23 \%$ of the variance in second-year pre-clinical dental technique grades, $27 \%$ of the variance in first-year cumulative GPA, and $28 \%$ of the variance in first-year cumulative GPA can be accounted for by the combination of all predictors.

Although this validity study was conducted with the intention to include participation of all accredited dental programs in the United States, some programs did not participate. The predictors (i.e., pre-program factors, such as pre-dental college total GPA, pre-dental science GPA, and scores on the DAT) and criteria (i.e, dental program factors, such as biomedical grades, preclinical dental technique grades, and cumulative GPA) in this study were also subject to the effect of range restriction because enrolled dental students tend to be higher scoring individuals. The range restriction may reduce the magnitude of obtained correlation coefficients and underestimate the true magnitude 
of the relationship between the predictors and criteria (American Dental Association, 2020).

\section{Scores on the DAT as a predictor for the NBDE Part I performance. In}

addition to the predictive validity of the scores on the DAT in relation to dental students' academic performance in the first two years of their dental education, scores on the DAT have a positive correlation with dental students' NBDE Part I performance. Using the 2008 student cohort in the ADA report as an example, the DAT Academic Score averages can explain about $20 \%$ of variance in students' NBDE Part I performance, while the Survey of the Natural Sciences score can explain about $19 \%$ of the variance (American Dental Association, 2009). Additional research has investigated scores on the DAT as a predictor of dental students' NBDE Part I performance. In a study using student samples from the College of Dentistry of the University of Iowa (Holmes et al., 2008), data were collected for five pre-program academic factors (i.e., college GPA, college science GPA, DAT Academic Average score, DAT Perceptual Ability Test score, and DAT Total Science score) and five dental program academic factors (i.e., overall dental school GPA, scores on NBDE Part I and Part II, final grade in the Clinical Competencies in Comprehensive Care, and pass/fail status on the student's first attempt at the Central Regional Dental Testing Service (CRDTS) regional licensure examination). Pearson product moment correlations $(r)$ were computed for the sets of the pre-program academic factors and dental program academic factors. The results showed that the students' scores on the NBDE Part I were moderately correlated with the DAT Academic Average score $(r=.61, p<.05)$ and DAT Total Science score $(r=.58, p<.05)$ and weakly correlated with the DAT Perceptual Ability score $(r=.36, p<.05)($ Evans, 1996; 
Holmes et al., 2008). In summary, among all pre-program academic factors, the DAT Academic Average score was the best predictor of NBDE scores, although it is suggested that the underlying constructs identified by these pre-program measures may overlap.

In another study, De Ball, Sullivan, Horine, Duncan, and Replogle (2002) collected the DAT and NBDE Part I scores of 114 students enrolled at the University of Mississippi School of Dentistry in 1992, 1993, 1994, and 1995 and tested the association bewteen these sets of scores. The predictors in this study included six standard scores reported on the DAT: biology (DAT-BIO), general chemistry (DAT-GC), organic chemistry (DAT-OC), reading comprehension (DAT-RC), quantitative reasoning (DATQR), and perceptual ability (PAT). The criterion variables were the different subsets of scores from the NBDE Part I: anatomical sciences (AS), biochemistry and physiology (BCP), microbiology and pathology (MP), and dental anatomy and occlusion (DA). Multiple regression analysis was used to examine relationships between the predictors and criterion variables. In different regression models, scores on the DAT accounted approximately $27 \%(R=.52)$ of the variance in the NBDE anatomic sciences subtest, $28 \%(R=.53)$ of the variance in the biochemistry-physiology subtest, $21 \%(R=.46)$ of the variance in the microbiology-pathology subtest, and $30 \%(R=.55)$ of the variance in the dental anatomy and occlusion subtest. The noteworthy findings from this study were that the perceptual ability (PAT) and general chemistry (DAT-GC) in the scores on the DAT were not significant predictors of the students' performance on any of the subtests of NBDE Part I, while the reading comprehension (DAT-RC) was the most consistent predictor on all of the subtests of NBDE Part I. The finding that the reading comprehension was the most consistent predictor seemed to highlight the importance of 
this basic academic skill and indicate that it may be necessary for dental students to have this ability to enhance their performance on the NBDE Part I, in which the test content was highly concentrated on basic science field.

Further, Bergman, Susarla, Howell, and Karimbux (2006) conducted a study at the Harvard School of Dental Medicine (HSDM) investigating the relationship between the students' performances on the DAT and the NBDE Part I. Student data were collected from the 244 students enrolled in the HSDM dental program from September 1995 to September 2002. The predictors included in this study were six standard scores reported on the DAT: biology (DAT-BIO), general chemistry (DAT-GC), organic chemistry (DAT-OC), reading comprehension (DAT-RC), quantitative reasoning (DAT-QR), and perceptual ability (PAT). The outcome measures in this study were the different subsets of scores from the NBDE Part I: anatomical sciences (AS), biochemistry and physiology (BCP), microbiology and pathology (MP), and dental anatomy and occlusion (DA). Different multiple linear regression analyses were used to examine the relationship among the predictors and outcome variables. The results showed that the DAT reading comprehension score was the most consistent predictors of the students' NBDE Part I Performance $(p<.01$ for all subsets of scores from the NBDE Part I). However, the results from this study suggested that the scores on the DAT only accounted for a small percentage of variance in different subsets of scores from the NBDE Part I, including $6 \%$ for anatomical sciences $(R=.25), 8 \%$ for biochemistry and physiology $(R=.28), 11 \%$ for microbiology and pathology $(R=.33)$, and $10 \%$ for dental anatomy and occlusion $(R$ $=.32)$. 
Although these results indicated that there were associations between the students' performances on the DAT and NBDE Part I, the percentage of variance in NBDE scores accounted by the scores on the DAT in this study was much smaller than other studies (American Dental Association, 2009; Holmes et al., 2008). The selected study population in the HSDM had consistently scored at the top of the national rankings, and the negatively skewed distribution of scores on the DAT and NBDE with a narrow score range may have contributed to a restriction of range and reduced the correlation in this study.

Except for the studies conducted by the ADA, most independent studies limited their study population to only one dental school. Although scores on the DAT have been found to be one of the most consistent predictors of the first-year and second year dental program academic factors and the students' performance on the NBDE Part I, the geographic limitations, the class size differences, and admission criteria variations in each dental school may have influenced associations among the scores on the DAT and students' academic and NBDE Part I performances (Bergman et al., 2006; De Ball et al., 2002; Dworkin, 1970; Ginley, 1966; Holmes et al., 2008; Kramer, 1986; Ranney et al., 2005; Sinkford \& Valachovic, 2003). The scores on the DAT could provide dental school administrations a better basis for adjusting admission formulas, selecting suitable dental students, and monitoring their academic progress if predictive validity studies can be conducted in different schools, since the findings may vary from school to school.

\section{Pre-program Academic Factors}

\section{Pre-program Academic Factors in medicine and the healthcare professions.}

In healthcare professions, significant literature is present focusing on the associations 
between pre-program academic factors and students' academic performance in the professional programs and their performance in licensure examinations. Most research has been done in the field of medical education. In a review article, Sinkford and Valachovic (2003) reviewed 87 articles across healthcare disciplines on the reliability and validity of admissions criteria used to select students. Pre-admission science GPA and overall GPA provided what the authors considered valid measure of cognitive abilities. The authors concluded that the evidence was clear that pre-program academic factors are predictive of healthcare professional students' academic performance in the programs and their performance on the licensure examinations. A consensus statement and recommendations from the Ottawa 2010 Conference on the applicant assessment methods in medicine and the healthcare professions reported similar findings and concluded that there was evidence for the predictive validity of pre-admission GPA, particularly in combination with the MCAT for medical school and licensing examination performance (Prideaux et al., 2011). However, literature in the field of dentistry on this association is scarce. This following section will present the findings from existing literature in the context of pre-program academic factors as predictors of dental students' NBDE Part I performance.

Pre-program academic factors in dentistry. To examine the relationship between the admission criteria (including pre-program academic factors of undergraduate science GPA, undergraduate non-science GPA, DAT Academic Average score, DAT Perceptual Ability score, and admission interview score) and dental school performance (including NBDE Part I and Part II scores and yearly and final cumulative dental school GPA), Sandow, Jones, Peek, Courts, and Watson (2002) studied 459 students at the 
University of Florida College of Dentistry (UFCD) from classes attending from 1994 to 1999. Pearson correlation coefficients were utilized first to examine the individual relationships between admission criteria and dental school performance. A moderate positive correlation was found between the DAT Academic Average score and NBDE Part I score $(r=.51, p<.05)$, while a weak positive correlation was found between the undergraduate science GPA and NBDE Part I score $(r=.31, p<.05)$. The positive correlation between undergraduate science GPA and dental school GPA $(r=.43, p<.05)$ was stronger than that between undergraduate non-science GPA and dental school GPA $(r=.29, p<.05)$. To consider the overall effect of all admission criteria on the dental school performance, seven ordinary least squares regression (OLS) models were built. When the NBDE Part I score was used as the criterion variable, the result of the OLS indicated that $32.8 \%$ of the variance in the dental school performance was accounted for by five admission criteria predictors, and undergraduate science GPA and DAT academic score were the only two significant predictors within the model. Among the models using yearly and final cumulative dental school GPA as the dependent variables, admission criteria explained most variance for the first-year dental school GPA at $40 \%$, and undergraduate science GPA remained the most significant predictor within the models. In summary, the authors concluded that, among all five admission criteria in the study, the undergraduate science GPA was consistently the most important predictor for both NBDE scores and dental school GPAs (Sandow et al., 2002).

Kingsley, Sewell, Ditmyer, O’Malley, and Galbraith (2007) found different results in a study in which they analyzed admissions and performance data from the first three classes of students at the University of Nevada, Las Vegas, School of Dental 
Medicine (UNLV-SDM). Students' NBDE Part I scores were used to perform a linear regression with the individual admission variables (including undergraduate science GPA, undergraduate cumulative GPA, and scores on the DAT) from the combined data from three classes of students. This study found that only the DAT Reading Comprehension and Biology score were significant linear model predictors of NBDE Part I scores $(p<.05)$. The other scores on the DAT and undergraduate GPAs were not predictive of NBDE Part I scores (Kingsley et al., 2007).

Hermesch, McEntire, Thomas, and Berrong (2005) also reported that undergraduate cumulative GPA may not have strong correlations with the dental school performance (including NBDE Part I and Part II scores and yearly and final cumulative dental school GPA). This study set out to compare the academic performance (NBDE Part I and Part II scores and cumulative dental school GPA) of the students accepted by the Dental Early Acceptance Program (DEAP) to those who were accepted by the standard admissions process. Three hundred and sixty-one dental students who matriculated into the University of Texas Health Science Center at San Antonio (UTHSCSA) Dental School first-year classes from 1993 through 1996 were included in the study. Their cumulative college GPA and scores on the DAT were recorded to evaluate their relationships with students' academic performance with Pearson's correlation coefficients. Although not the primary research question, this study showed the cumulative college GPA was only weakly correlated with the NBDE Part I score $(r$ $=.39$ for early acceptance students; $r=.28$ for standard admissions students) and moderately correlated with the cumulative dental school GPA ( $r=.50$ for early 
acceptance students; $r=.42$ for standard admissions students) (Hermesch, McEntire, Thomas, \& Berrong, 2005).

Limitations of using pre-program academic factors in research. It is possible that the strength of the relationship between pre-program academic factors and students' performance in dental school (academic grades or licensing examination results) is greater than that suggested in the literature. Restriction of the range in the variables could pose a significant problem in research. Most applicants applying for dental programs have strong academic records, and only the top candidates are selected for admission. The variability of pre-program academic factors is then limited by the nature of applicants and admitted dental students. Furthermore, students in health professional programs are usually highly competitive and can achieve high performance in dental school, and this results in a limited range of academic grades or licensing examination scores. Using predictor and criterion variables with a limited range can result in lower correlation coefficients. Other threats to the reliability and validity of results in the available correlational studies may include: the passage of time itself, the different nature of performance being examined (academic or clinical), and the variability of pre-program academic factors across different colleges and undergraduate majors.

\section{Dental Program Academic Factors}

Program academic factors in medicine and health professions. Unlike the DAT and pre-program academic factors, far fewer studies in dentistry have examined the ability of dental program academic factors to predict student success on the NBDE Part I or subsequent licensure examinations. However, in medicine and other healthcare professions, similar findings of the positive correlation between the program GPA and 
student performance in the respective licensure examinations are observed. Using medicine as the primary example, predoctoral medical education has a four-year curriculum, and predoctoral medical students typically challenge the United States Medical Licensing Exam (USMLE) Step 1 at the conclusion of the preclinical basic science curriculum and USMLE Step 2 toward the end of the clinical curriculum (Sesate et al., 2017; United States Medical Licensing Examination, 2017). This is a similar sequence to dental students' academic progress toward challenging the NBDE Part I and Part II examinations (American Student Dental Association, 2017; Joint Commission on National Dental Examinations, 2017a, 2017b). Hence, the results from medicine may be more applicable to dentistry than those from other healthcare fields.

A recent study by Sesate, Milem, McIntosh, and Bryan (2017) used admissions factors (i.e., MCAT scores, college GPA, college major, and interview score) and curricular measures (i.e., first-year and second-year mean GPA in groups of related subjects) of 96 medical students from an undisclosed medical school in the southwest United States to examine the amount of variation in USMLE Step 1 scores. This study also controlled for pre-admission demographic characteristics (i.e., sex, race, parental education, and residency status). Four quadratic regression models were used to explore the relative impact of admissions factors and curricular measures on Step 1 scores. The first model only investigated the impact of pre-admission demographic characteristics on Step 1 scores. The second model explored the impact of pre-admission demographic characteristics and admissions factors on Step 1 scores. The third model explored the impact of pre-admission demographic characteristics, admissions factors, and first-year curriculum on Step 1 scores. The last model investigated the combined impact of pre- 
admission demographic characteristics, admissions factors, and first-year curricular measures on Step 1 scores.

The first-year curricular measures had a positive and significant association with the Step 1 scores $(p<.05)$, with every 1-point increase in the first-year average scores showing 2.1 points increase in the Step 1 scores. In the subsequent model with the addition of second-year curricular measures, the second-year curricular measures also had a positive and significant association with the Step 1 scores $(p<.05)$. That is, every 1-point increase in the second-year average scores showed 2.3 points increase in the Step 1 scores (Sesate et al., 2017). The inclusion of first-year and second-year curricular measures in the model 4 accounted for approximately $77 \%$ of the variance in Step 1 scores, while the demographic characteristics and admissions factors alone in model 2 accounted for only $46 \%$ of the variance in Step 1 scores (Sesate et al., 2017). Different studies in medicine (Gohara et al., 2011), dental hygiene (DeWald, Gutmann, \& Solomon, 2004), and nursing (Truman, 2012) show similar findings supporting program academic factors (as an environmental exposure) could be strong predictors for the licensure examination focusing on the basic science curricula.

Program academic factors in dentistry. Few investigators have examined the role of dental program academic factors in predicting student success on the NBDE Part I or subsequent licensure examinations. Holmes et al. (2008) studied the relationships among dental program academic factors, including overall dental school GPA, scores on NBDE Part I and Part II, final grade in the Clinical Competencies in Comprehensive Care, and pass/fail status on the student's first attempt at the CRDTS regional licensure examination (Holmes et al., 2008). The Pearson correlation among various measures of 
dental program academic factors showed that the dental school cumulative GPA was strongly and significantly correlated with the NBDE Part I $(r=.76, p<.05)$ and Part II scores $(r=.70, p<.05)$. Similar findings were shown by Hermesch et al. (2005), who investigated the outcome assessment of the early acceptance program at the University of Texas Health Science Center at San Antonio (UTHSCSA) Dental School. They showed that the dental school cumulative GPA was strongly correlated with the NBDE Part I score $(r=.74$ for early acceptance students; $r=.60$ for standard admissions students $)$ and NBDE Part II score $(r=.72$ for early acceptance students; $r=.64$ for standard admissions students) (Hermesch et al., 2005).

\section{Summary of Literature}

Predicting student performance in education programs and licensure examinations remains an important mission for educators. The evolving nature of student composition and licensure examination passing standards require the continuous efforts of researchers to establish current and timely information for accurate prediction. The identification of at-risk students in an academic program can allow educators to provide these students assistance and help prepare them for the licensure examination. Most literature focuses on the prediction of NBDE Part I scores, with no studies available after 2012 when the JCNDE changed the reporting of NBDE results for candidates to the pass/fail format. The current binary nature of NBDE outcome may warrant further research to explore its predictors. Furthermore, while the current literature in medicine and other healthcare professions suggests positive correlations between program GPA and student performance in the respective licensure examinations (DeWald et al., 2004; Gohara et al., 2011; Sesate et al., 2017; Truman, 2012), there is a dearth of evidence in dentistry 
(Hermesch et al., 2005; Holmes et al., 2008). The possibility of linking or confirming the predictive nature of dental program academic factors (such as first-year individual course scores and first-year cumulative GPA) toward students' performance in the NBDE Part I can allow dental educators to monitor student progress and assist the ones who are at-risk to better prepare for the licensure examination.

Based on the review of available literature, scores on the DAT are the most tested predictors of dental students' performance on the NBDE Part I (American Dental Association, 2009; Bergman et al., 2006; De Ball et al., 2002; Holmes et al., 2008). Furthermore, scores on the DAT have also been identified to be strong predictors of dental program academic factors, such as the dental students' academic performance in the first year and second year of dental curricula (American Dental Association, 2020; Dworkin, 1970; Ginley, 1966; Ranney et al., 2005). The pre-program academic factors (undergraduate science GPA in particular) are predictive of healthcare professional students' academic performance in the programs and their performance in the licensure examinations (Sinkford \& Valachovic, 2003), and dental research found preliminary evidence to support similar findings (Sandow et al., 2002).

However, the evidence in dentistry is not overwhelming; conflicting findings call for reconsidering the correlations between pre-program academic factors and dental students' performance on the NBDE Part I and during initial years of dental curricula (Hermesch et al., 2005; Kingsley et al., 2007). Evidence on the influence of demographic factors, such as gender and URM, is even more scarce in dentistry. Demographic factors, pre-program academic factors, scores on the DAT, and dental program academic factors are all potential predictors of performance on licensure examinations, and no literature 
has considered examining the predictive nature of all these factors to students' performance on the NBDE in a single study. 


\section{CHAPTER III}

\section{METHOD}

This chapter provides an overview of the research design, research methods, participant selection and characteristics, study site characteristics, research procedures, and statistical analysis used for this study. The chapter also provides an overview of research questions and describes the methodology used to answer the research questions.

\section{Research Questions}

The focal research question for this study is: "Do dental students' demographic factors, dental admission test factors, pre-program academic factors, and academic performances in basic science curriculum predict passing the NBDE Part I?’ To answer this primary question, the researcher developed the following five sub-questions: Question 1: Are there significant relationships between dental students' genders or races, and their dental admission test performances, grade point averages at the undergraduate level in the college or university, and individual course grades and cumulative grade point averages in the dental program?

Question 2: Are there race and gender differences on the NBDE Part I outcome? Question 3: Do the grade point averages at the undergraduate level in the college or university predict the NBDE Part I outcome?

Question 4: Does the dental admission test performance predict the NBDE Part I outcome? 
Question 5: Do the first-year and second-year dental program individual course grades and cumulative grade point averages predict the NBDE Part I outcome?

\section{Research Design / Methodology}

This proposed study is a non-experimental quantitative research design without the manipulation of the study variables (Creswell, 2012). A retrospective, correlational approach was used based on existing dental student data of enrollment students from the 2017, 2018, and 2019 graduating classes (i.e., the 2013 Fall, 2014 Fall, and 2015 Fall enrolling cohorts, respectively).

\section{Major Variables and Instruments}

As shown in Figure 1, Astin's I-E-O model was used as the study's conceptual framework. Specifically, NBDE Part I performance served as the dependent variable, measured dichotomously as pass/fail. The DAT factors will include all eight DAT standard scores reported by the ADA. The pre-program academic factors will include pre-program (undergraduate) science and non-science GPAs. The primary predictors of interest are dental program academic factors, including the first-year and second-year individual course grades (i.e., grades from the courses relevant to the contents of NBDE Part I, which includes ten individual course grades) and cumulative GPAs (i.e., first-year spring semester cumulative GPA and second-year spring semester cumulative GPA) in the dental program. As presented previously, Figure 2 visually depicts the empirical model for the study, which will examine the relationship of: (1) demographic factors, (2) dental admission test (DAT) factors, (3) pre-program academic factors, and (4) dental program academic performance with the NBDE Part I performance. 


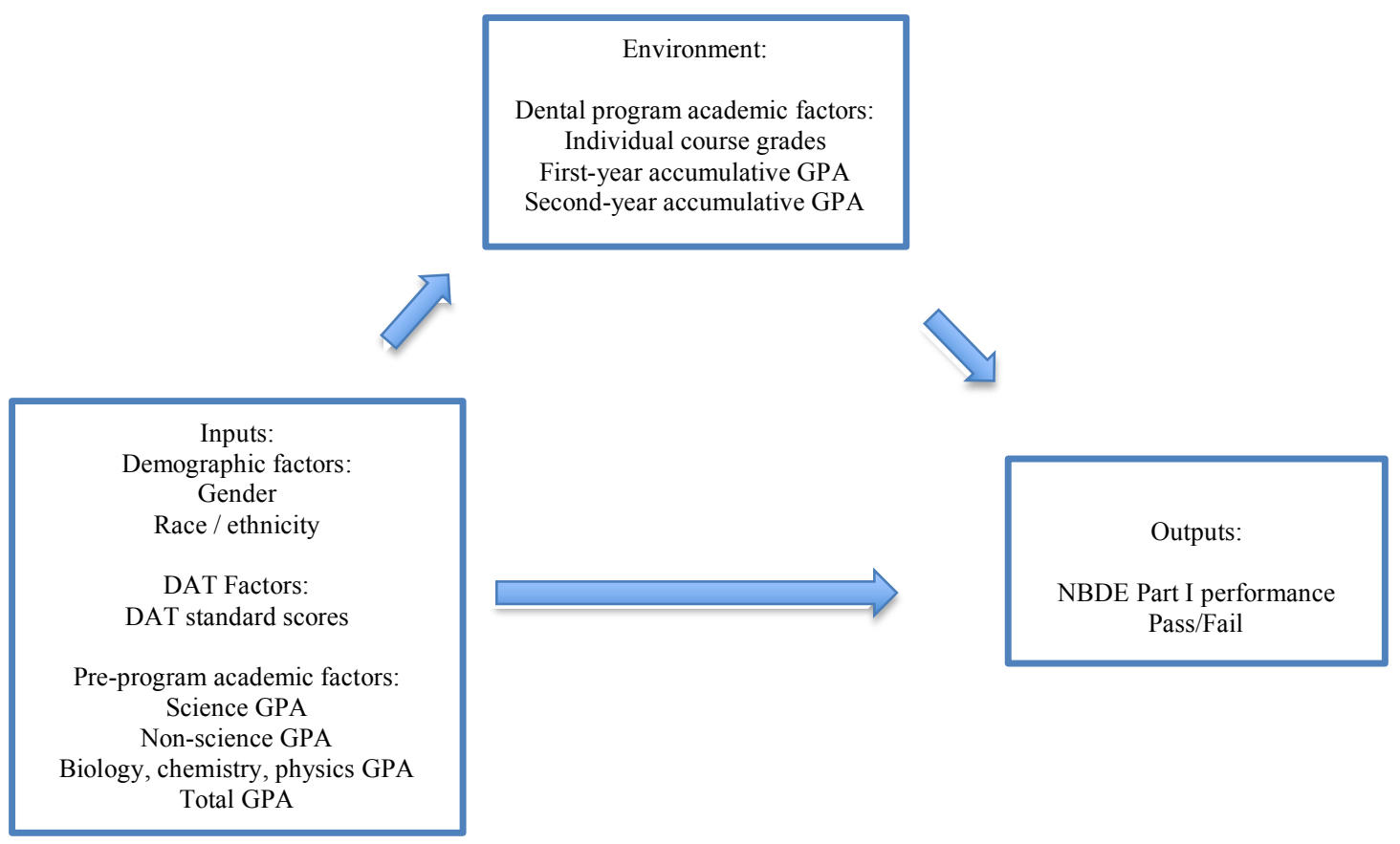

Figure 2. Empirical model.

Table 3 presents descriptions of the variables in the empirical model.

Table 3

Variables included in the empirical model

Variables

Operation Definitions

Outcome Variable

NBDE Part I performance

Results of an individual's NBDE Part I on first attempt. Calculated by the ADA and reported as either pass or fail. (Pass $=0$, Fail $=1$ )

\section{Predictor Variables}

Demographic Factors

Gender

Race / ethnicity

A student's reported gender, as documented in the university records through self-report on admissions application. $($ Male $=0$, Female $=1$ )

A student's self-identified race, as documented in the university records. Due to the disproportionate number of students who identify as White and Asian in comparison to other individual racial groups, race was coded as White $(=0)$, Asian $(=1)$, and Underrepresented Minority $(=2)$. Underrepresented Minority students included individuals classified as 
Black, Hispanic/Latino, Native American, Pacific Islander, or Others through self-report on admissions application.

DAT factors

Perceptual Ability

Quantitative Reasoning

Reading Comprehension

Biology

General Chemistry

Organic Chemistry

Total Science
It includes 90 multiple-choice test items. The standard score is scaled and standardized on the log ability scale defined by the Rasch Model range for dichotomous item responses. This value is calculated and scored as a continuous value ranging from 1.00 to 30.00 .

It includes 40 multiple-choice test items. The standard score is scaled and standardized following the aforementioned log ability scale. This value is calculated and scored as a continuous value ranging from 1.00 to 30.00 .

It includes 50 multiple-choice test items. The standard score is scaled and standardized following the aforementioned log ability scale. This value is calculated and scored as a continuous value ranging from 1.00 to 30.00 .

It includes 40 multiple-choice test items. The standard score is scaled and standardized following the aforementioned log ability scale. This value is calculated and scored as a continuous value ranging from 1.00 to 30.00 .

It includes 30 multiple-choice test items. The standard score is scaled and standardized following the aforementioned log ability scale. This value is calculated and scored as a continuous value ranging from 1.00 to 30.00 .

It includes 30 multiple-choice test items. The standard score is scaled and standardized following the aforementioned log ability scale. This value is calculated and scored as a continuous value ranging from 1.00 to 30.00 .

It is calculated based on the 100 multiple-choice test items from the Biology, General Chemistry, and Organic Chemistry tests. The standard score is scaled and standardized following the aforementioned log ability scale. This value is calculated and scored as a continuous value ranging from 1.00 to 30.00 . 
Academic Average

Pre-program academic factors

Science GPA

Non-science GPA

Biology, Chemistry, and Physics GPA

Total pre-program GPA
The rounded arithmetic means of the standard scores on the Quantitative Reasoning, Reading Comprehension, Biology, and General and Organic Chemistry tests. This value is calculated and scored as a continuous value ranging from 1.00 to 30.00 .

Student's academic performance in required prerequisite science courses at the undergraduate level in the college or university, prior to admission into the dental program. This information is reported in the student's admission database from ADA to the individual dental program. Calculated through multiplying quality points by number of credit hours, then dividing by total hours attempted. This value was calculated as a continuous value ranging from 0.00 to 4.00 .

Student's general academic performance in nonscience courses at the undergraduate level in the college or university, prior to admission into the dental program. This information is reported in the student's admission database from ADA to the individual dental program. Calculated through multiplying quality points by number of credit hours, then dividing by total hours attempted. This value was calculated as a continuous value ranging from 0.00 to 4.00 .

Student's general academic performance in biology, chemistry, and physics courses at the undergraduate level in the college or university, prior to admission into the dental program. This information is reported in the student's admission database from ADA to the individual dental program. Calculated through multiplying quality points by number of credit hours, then dividing by total hours attempted. This value was calculated as a continuous value ranging from 0.00 to 4.00 .

Student's general academic performance in all courses at the undergraduate level in the college or university, prior to admission into the dental program. This information is reported in the student's admission database from ADA to the individual dental program. Calculated through multiplying quality points by number of credit hours, then 
dividing by total hours attempted. This value was calculated as a continuous value ranging from 0.00 to 4.00.

Dental program academic factors

Individual course grades

Histology

Physiology

Dental Anatomy and

Occlusion (lecture)

Dental Anatomy and Occlusion (laboratory)

Biochemistry

Survey of Dental Gross and Neuroanatomy

Preclinical Occlusion and TMD
Course number (BMSC 802 - 01). A student's overall performance in Histology. The grade is reported to the university by the course director. Recorded as a continuous value ranging from 0.00 to 4.00 .

Course number (BMSC 805 - 01). A student's overall performance in Physiology. The grade is reported to the university by the course director. Recorded as a continuous value ranging from 0.00 to 4.00.

Course number (GDOM 800 - 01). A student's overall performance in Dental Anatomy and Occlusion (lecture). The grade is reported to the university by the course director. Recorded as a continuous value ranging from 0.00 to 4.00 .

Course number (GDOM 801 - 01). A student's overall performance in Dental Anatomy and Occlusion (laboratory). The grade is reported to the university by the course director. Recorded as a continuous value ranging from 0.00 to 4.00 .

Course number (BMSC 804 - 01). A student's overall performance in Biochemistry. The grade is reported to the university by the course director. Recorded as a continuous value ranging from 0.00 to 4.00.

Course number (BMSC 809 - 01). A student's overall performance in Survey of Dental Gross and Neuroanatomy. The grade is reported to the university by the course director. Recorded as a continuous value ranging from 0.00 to 4.00 .

Course number (OHR 860 - 03). A student's overall performance in Preclinical Occlusion and TMD. The grade is reported to the university by the course director. Recorded as a continuous value ranging from 0.00 to 4.00 . 
General Pathology

Oral Pathology

Microbiology and

Immunology

Cumulative GPAs

First-year accumulative GPA

Second-year accumulative GPA
Course number (SUHD 821 - 03). A student's overall performance in General Pathology. The grade is reported to the university by the course director. Recorded as a continuous value ranging from 0.00 to 4.00 .

Course number (SUHD 803-02). A student's overall performance in Oral Pathology. The grade is reported to the university by the course director. Recorded as a continuous value ranging from 0.00 to 4.00 .

Course number (BMSC 806-02). A student's overall performance in Microbiology and Immunology. The grade is reported to the university by the course director. Recorded as a continuous value ranging from 0.00 to 4.00 .

A student's cumulative grade point average in all required courses during first-year fall and spring semesters. Calculated from grades reported in university records, through multiplying quality points by number of credit hours, then dividing by total hours attempted. This value was calculated as a continuous value ranging from 0.00 to 4.00 .

A student's cumulative grade point average in all required courses during first-year fall and spring semesters and second-year summer, fall, and spring semesters. Calculated from grades reported in university records, through multiplying quality points by number of credit hours, then dividing by total hours attempted. This value was calculated as a continuous value ranging from 0.00 to 4.00 .

\section{NBDE Part I Measurement}

The NBDE examinations are under periodical review by the Joint Commission on National Dental Examinations (JCNDE) (Joint Commission on National Dental Examination, 2016). The purpose of the NBDE is to determine the qualification of individuals who seek to practice dentistry independently. The qualifications include the ability to understand important information from basic and clinical science and apply 
such information in a problem-solving context. The content specifications of NBDE are based on studies investigating its validity every five years. The ADA maintains a high level of security for all exam materials, and the JCNDE offers the exams via the Prometric Professional Level Testing Centers throughout the United States, US territories, and Canada. NBDE exams are criterion-referenced and not norm referenced. Minimum passing scores are determined by a panel of experts, and an equating process was designed and used to control for differences in the difficulty of items from one examination form to another (Joint Commission on National Dental Examinations, 2018).

Validity. The Standards for Educational and Psychological Testing (American Educational Research Association, American Psychological Association, \& National Council on Measurement in Education [AERA, APA, \& NCME], 2014) define validity as "the degree to which evidence and theory support the interpretations of test scores for purposed uses of tests" (p. 11). The primary evidence for the validity of NBDE is from the use of: (1) practice analyses that identify the knowledge and skills necessary to safely and independently practice dentistry in the United States and (2) content experts to determine or modify the examination specifications.

JCNDE assembles 18 test construction teams to develop NBDE examinations. The Part I and Part II discipline-based teams meet once per year for three days, and the Part I Testlet Development Team meets three times per year. During these meetings, the test construction teams review the statistical characteristics of examinations administered since the last meeting, including the reliability, mean, standard deviation of examination score item difficulty, the proportion of candidates choosing each option, and the item discrimination index. The test construction teams also review the exam specifications to 
ensure the exam content of NBDE still reflects current practice standard in dentistry. New exam items are then developed during the meetings as well.

Since different forms of the NBDE are administered for different candidates, statistical adjustments are used to ensure direct and meaningful comparison between test results among candidates. Test equating is used to adjust raw scores and form the standardized examination scores on a common measurement scale. The Rasch model and the unconditional maximum likelihood estimation procedure are used in the NBDE to equate the raw test scores. Various validity studies have been conducted to investigate significant threats to validity and provide new sources of validity evidence (Kramer \& DeMarais, 1992; Kramer \& Neumann, 2003; Tsai, Neumann, \& Littlefield, 2012).

Reliability. The reliability of the pass/fail points on the NBDE measurement scales has been studied to confirm the probabilities of correct and consistent classifications of candidate performance. NBDE followed the procedure proposed in 1990 by Hanson and Brennan to evaluate the reliability of the pass/fail point with two types of statistics: classification accuracy and classification consistency. Classification accuracy refers to the probability of correct classification, false positive rate, and false negative rate. Classification consistency refers to the probabilities of consistent classification and misclassification. The reliability study was conducted by the JCNDE with 1000 candidates enrolled in accredited dental schools who challenged the NBDE for the first time. The results showed a high reliability of the pass/fail points on the examination measurement scales, with classification accuracy of $97 \%$ and classification consistency of 96\% (Joint Commission on National Dental Examinations, 2018). 


\section{Individual Course Grades and GPAs}

Within dental programs, different courses may have different exam formats. The major type of validity concerning individual course exam scores is content validity. Course faculty have either a dental degree and/or doctoral degree in basic science. The course faculty are considered the content experts in their respective professional field. The dental school administration possesses the curriculum map, which are reviewed periodically by the Commission on Dental Accreditation (CODA) during site visits once every seven years to maintain accreditation. Course faculty develop exam items to assess minimum competency in their respective area, and exams are administered in either computerized or pencil-paper format in a proctored classroom setting. The individual course grades and cumulative GPAs from each semester are maintained by the school administration, along with other student records during the dental program.

\section{Dental Aptitude Test (DAT)}

The DAT was originally developed to address the high rate of student attrition during dental programs. It was anticipated that admission committees could utilize the information from the DAT to lower the likelihood of selecting students who may withdraw from the dental program because of poor academic performance. Furthermore, admission committees at the time were generally aware that the previous academic performance from different colleges have different measurement scales and meanings, indicating that scores from previously attended schools may not be predictive of future performance. As such, a national, standardized test was considered to enable admission committees to compare students' academic achievement in a far more objective manner (American Dental Association, 2017a). 
Validity. Content validity of the scores on the DAT is assessed by experts in the respective fields. For instances, the Natural Sciences portion of the DAT contains items covering general biology, and general and organic chemistry as typically presented in the undergraduate curriculum in predental courses. The test construction team, which is composed of subject matter experts, judge the relevance and representativeness of the test items relative to the content domain. External predictive validity studies are also conducted to determine the extent to which important outcomes can be predicted by the DAT test performance. The scores on the DAT are found to have a significant positive relationship with performance in the first year of dental school. The use of overall scores on the DAT (Quantitative Reasoning, Reading Comprehension, Biology, General Chemistry, Organic Chemistry, and Perceptual Ability) as a set shows better prediction of the first-year dental program GPA than the use of individual predictors in isolation (American Dental Association, 2020, 2017a).

Reliability. Internal consistency reliability coefficients based on the KuderRichardson Formula 20 (KR-20) has been reported for scores on the DAT. The KR-20 is a measure of internal consistency for measures that feature dichotomous items. The values of KR-20 range from .00 to 1.00, and a higher value indicates a higher level of internal consistency of test scores. Coefficients above .70 are considered to be acceptable, but those above .80 are typically preferred. Coefficients above .90 indicate excellent consistency. Any coefficient lower than .70 indicates that the scores of a measure has poor internal consistency and should not be used for future analysis (Wombacher, 2017, p. 1419). Within four domains of the DAT, the range of reliability coefficients are as follows: Quantitative Reasoning Test (40 items), 0.80 to 0.89; Reading Comprehension 
Test (50 items), 0.78 to 0.86; Survey of the Natural Sciences (100 items), 0.92 to 0.93;

and Perceptual Ability Test (90 items), 0.90 to 0.92. Similar ranges for the reliability coefficients of DAT have been obtained and maintained since the 1970s (American Dental Association, 2017a, 2020). The reported internal consistency of the scores generated from the DAT in all domains show acceptable to excellent internal consistency.

\section{Participants}

The target population for this proposed study was the students who attended a US-based, ADA accredited dental program and challenged the NBDE Part I examination after 2012 when the NBDE score reporting changed to a pass/fail format. Data from a convenience sample was collected from a single dental program at a large, public university located in an urban setting within the Southeast region of the US. Data from all students enrolled from 2017, 2018, and 2019 graduating classes (i.e., the 2013 Fall, 2014 Fall, and 2015 Fall enrolling cohorts, respectively) was collected to determine the eligibility for inclusion. Those students who met the following inclusion criteria were included in the study: (1) no missing scores on the DAT or pre-program GPA information in the admission database; (2) completion of all required didactic dental program courses in the first-year fall semester, first-year spring semester, second-year fall semester, and second-year spring semester; (3) no missing, deferred, or transferred grades in the aforementioned didactic courses; and (4) completion of the first attempt on the NBDE Part I after 2012, following the NBDE score reporting format changes. The total enrollment of dental students in the 2017, 2018, and 2019 classes was 356 . The inclusion criteria were applied to examine the eligible participants for this proposed study. After inspecting the data following the inclusion criteria, a total of 324 dental students were 
included in the study. Majority of students was male (55.2\%) and White (77.8 \%). The study sample consisted of more male students (55.2\%) than female students (44.8\%). White students (77.8 \%) were overwhelmingly less than the Asian (11.1\%) and URM students $(11.1 \%)$.

Peduzzi, Concato, Kamper, Holdford, and Feinstein (1996) examined the effective sample size needed to reliably estimate logistic regression models and Cox proportional hazards models. For the logistic model, the number of outcome events is the smaller number of binary outcomes, such as pass or fail. The number of events per predictor variable (EPV) was recommended to be at least 10 for the logistic regression models and Cox proportional hazards models to be estimated accurately, with an expected relative bias of less than 10\% (Austin \& Steyerberg, 2015; Peduzzi, Concato, Kemper, Holford, \& Feinstein, 1996). Vittinghoff and McCulloch (2006) found that, larger sample sizes and more outcome events are preferable and the rule of 10 EPV could be relaxed to 5-9 EPV in the context of confounding adjustment. In situations in which confounding cannot be addressed without violating the rule of $10 \mathrm{EPV}$, the results from the logistic and Cox models should be interpreted with caution and compared with those from the models with excluded weaker predictors (Vittinghoff \& McCulloch, 2007). Courvoisier, Combescure, Agoritsas, Gayet-Ageron, and Perneger (2011) suggested that the number of EPV is not a single value for all contexts. Rather, it depends on the number of predictors, the anticipated magnitude of the regression coefficients, and the correlations between the predictor variables (Courvoisier, Combescure, Agoritsas, GayetAgeron, \& Perneger, 2011). These principles will be carefully considered during the data 
analysis and model specification to ensure the logistic regression models can be more accurately estimated in this proposed study.

\section{Setting}

The selected dental program is within a public research university and located in the southeastern region of the United States. It was established in 1887, and, since then, approximately 8,000 dental students have graduated from this institution. In 1970, this school of dentistry was relocated into its current facility and offers dental care to more than 100,000 patient visits each year. Based on the information from the 2015-2016 admission cycle, the selected dental program had an application pool of 3,073 applicants, comprising 164 in-state residents and 2,909 non-residents. For 2019, there were 120 students in the entering class (64 males, 56 females), comprising 44 in-state residents and 76 non-residents. The racial demographics of the 2019 entering class were predominantly white (77\%), with 11\% Black or African American, Hispanic, or mixed race and the remaining 12\% Asian. The average age of the 2019 class was 23 years (range, 20 to 37 years). The college GPA average was 3.54, and the average scores of both the DAT Academic Average and Perceptual Ability was 20. This equates to the 75th percentile of all DAT test takers (American Dental Association, 2017a). In the preceding five years, student retention at this institution has been extremely high (range, $98 \%$ to $100 \%$ ), attributable to the implementation of various student support programs.

\section{Procedures}

The complete research protocol presented in this non-experimental quantitative study was reviewed and exempted by the Institutional Review Board at the investigator's institution (IRB \# 17.0865) (Appendix A). Dental students' demographic information 
(gender, race), DAT standard scores, and pre-program records were gathered from the admissions office. The data of the enrolled students from the 2017, 2018, and 2019 graduating classes were collected to determine the eligibility for inclusion. The dental academic records were obtained from the Office of Institution Research. The NBDE Part I performance (pass/fail results) were obtained from the Academic Affairs office at the institution. All records were de-identified and sorted by student identification number and graduating classes. The data were then compiled into a single spreadsheet with all personal identifiers removed. The investigator only secured the de-identified data in a password-protected file and maintain the file in an encrypted system in electronic format only.

\section{Statistical Analysis}

Various statistical analyses were conducted to answer the five research questions: a set of independent $t$-tests and One-Way analysis of variances (ANOVAs) to examine the association of gender and race with students' academic performance, and logistic regression to examine the association between students' academic performance in dental program and NBDE performance at the first attempt.

There were two types of variables in this study, nominal and continuous. Nominal variables included dental student's gender (male and female), race (White, Asian, and URM), and NBDE outcome at the first attempt (pass and fail). The continuous variables

included, pre-program GPAs (Science, Non-science, Biology-Chemistry-Physics, and Total GPAs), standard scores on the DAT (Perceptual Ability, Quantitative Reasoning, Reading Comprehension, Biology, General Chemistry, Organic Chemistry, Total Science, and Academic Average), and dental program individual course scores 
(Histology, Physiology, Biochemistry, Survey of Dental Gross and Neuroanatomy, Dental Anatomy and Occlusion - lecture, Dental Anatomy and Occlusion - laboratory, Preclinical Occlusion and TMD, General Pathology, Microbiology and Immunology, and Oral Pathology) and cumulative GPAs (First-year and Second-year). Initial descriptive analysis of the data was performed on the variables of interest, including frequency, percentage, measures of central tendency (mean and median), and measures of variability (minimum, maximum, and standard deviation) (Nick, 2007).

\section{Comparison of Gender and Race Groups}

To answer Research Question 1 and compare the students' performances (preprogram GPAs, scores on the DAT, and dental program individual course scores and cumulative GPAs) regarding to their gender and race, independent $t$-tests and One-Way analysis of variances (ANOVAs) were used. Numerical data that are normally distributed can be analyzed with parametric tests. For the skewed data, the natural logarithms of raw data can be used to approximate a normal distribution and then be analyzed with parametric tests. To inspect the assumption of normality on the continuous variables, the data were plotted as Q-Q plots and visually inspected. The assumptions of normality and were met for using independent $t$-tests and One-Way ANOVAs to compare students' performances regarding to their gender and race (Hazra \& Gogtay, 2016; Hoekstra, Kiers, \& Johnson, 2012).

The assumption of homogeneity of variance was used to test equal population variances per group. Levene's test was used to assess the equality of variances for the variables calculated for race and gender groups, at $\alpha=.05$. In the cases that Levene's tests showed unequal variances in the independent $t$-test, degrees of freedom were 
adjusted and $t$ statistics not assuming homogeneity of variance was computed and reported. In the cases that Levene's tests showed unequal variances in the $F$ statistics, degrees of freedom were adjusted and Welch $F$ statistics and post hoc Games-Howell tests were performed and reported as the multiple comparison analyses for these analyses.

The statistical significance for independent $t$-tests were at $\alpha=.05$. Depending on the numbers of multiple comparisons, Bonferroni correction was used to compensate for the likelihood of incorrectly rejecting a null hypothesis (inflation of Type I error). The $\alpha$ level was adjusted by testing each individual hypothesis at a significance level of $\alpha / \mathrm{m}$, where $\alpha$ was the desired overall significance level (.05) and $m$ was the number of hypotheses (Abdi, 2007). Due to the unequal group sample sizes, the statistical significance for $F$-statistics was set at a more stringent levelof .01, as suggested by Keppel(1991). Similarly, Bonferroni correction was also used to adjust the significance level in each subset of $F$-statistics. After the significant $F$ test, post hoc multiple comparison analysis was performed to determine the differences between particular pairs of race groups. Tukey's multiple comparison analysis method was selected for this study after significant One-Way ANOVA. The Tukey method uses a conservative estimate of $\alpha$ and tests all the contrasts as familywise error rate. This reduces the likelihood of making a Type I error and making a false claim of significance. It has less power to find difference between pairs. The Tukey method is also more robust with respect to the unequal group sample sizes (McHugh, 2011). Cohen's $d$ was reported as the effect size for the independent $t$-tests as the quantitative measure of the magnitude of a phenomenon, and the $d=0.2,0.5$ and 0.8 corresponded to small, medium and large effects (Cohen, 1988). The $\eta^{2}$ (Eta squared) was reported as the effect size for the One-Way ANOVA, 
and the $\eta^{2}=0.01,0.059$ and 0.138 corresponded to small, medium and large effects (Cohen, 1988).

\section{Bivariate Logistic Regression}

Logistic regression models were used to predict NBDE performance at the first attempt from each categorical (demographic factor) and continuous predictor (preprogram academic performance, DAT performance, and dental program academic performance). The model probability was $P(\mathrm{NBDE}=1)$. In the models, z-scores were used for the continuous variables. Due to the limited numbers of NBDE failures, no multivariate logistic regression analyses were performed. The significance level was set as $\alpha=.05$.

Twenty-four continuous variables were converted into standard scores as z-scores. Following Osborne's (2015) recommendations, when compared with the usage of nonstandardized values, using z-scores for continuous variables in logistic regression can enhance the interpretability while maintaining the predicted probabilities (Osborne, 2015). The standardized values of z-scores can provide a meaningful intercept for the continuous predictors (mean values) and the predicted probability of failure in the outcome variable (NBDE Part I) can be more easily calculated for or an individual at, below, and above the mean for each continuous variable (Osborne, 2015).

Model specification. The goal of logistic regression is to find the best fitting model to describe the relationship between the dichotomous outcome variable and a set of predictor variables. It generates coefficients to predict the logit transformation of the probability of presence of the event/characteristic of interest. Equation 1 presents the general form of the model. Logit (Ỳ) represents the dependent variable after 
transformation from the probability of the event/characteristic of interest, whereas $\pi$ indicates the probability of an event, $\beta_{0}$ is the intercept, and $\beta_{1}$ to $\beta_{m}$ represent the slope coefficients for the primary predictors, which represent the effect of each predictor on the outcome of interest (NBDE performance) (Sperandei, 2014).

Equation 1. General form of the Logistic Regression Model

$$
\operatorname{Logit}(\grave{Y})=\ln \left(\frac{\pi}{1-\pi}\right)=\beta_{0}+\beta_{1} \chi_{1}+\beta_{2} \chi_{2}+\ldots \ldots \beta_{m} \chi_{m}
$$

Bivariate logistic regression models with only one predictor were used to predict NBDE performance at the first attempt from each categorical (demographic factor) and continuous predictor (pre-program academic performance, DAT performance, and dental program academic performance). For the predictors considered as continuous in this study, a bivariate logistic regression was performed for each predictor. For gender, the comparison was made as Male versus Female where the Female was the reference group. For race, since there were 3 levels, the comparisons were made for three pairs, including Asian versus White (where White was the reference group), URM versus White (where White was the reference group), and URM versus Asian (where Asian was the reference group).

The Wald $\chi^{2}$ statistic was evaluated for each logistic regression model to test the significance of individual coefficient in the model, and $\alpha=.05$ was utilized to evaluate the significant results. Bonferroni correction was used to address the likelihood of inflated Type I error rate.The statistically significant Wald test was used to determine the significant predictors to the NBDE performance. In the logistic regression model, an equivalent statistic to coefficient of determination $\left(R^{2}\right)$ does not exist, and the model estimates are maximum likelihood estimates arrived at through an iterative process. To 
evaluate the usefulness of logistic model, Nagelkerke $R^{2}$ was presented in this study. The Nagelkerke $R^{2}$ is an adjusted version of the Cox \& Snell $R^{2}$ and covers the full range from 0 to 1 . Although it does not measure the goodness of fit of the regression model, it indicates how useful the explanatory variables are in predicting the outcome. It could be referred to as the measure of effect sizes (Bewick, Cheek, \& Ball, 2005).

The regression coefficient $\left(\beta_{1}\right)$ is the estimated increase in the log odds of the outcome per unit increase in the value of the exposure, and the exponential function of the regression coefficient $\left(e^{\beta 1}\right)$ is the odds ratio associated with a one-unit increase in the exposure (Szumilas, 2010). A large odds ratio indicates the occurrence of the outcome of interest of a particular group is much greater than that of the reference group. The odds ratios were used to compare the relative odds of the occurrence of the outcome of interest (NBDE Part I performance), given exposure to the variable of interest. The odds ratio were presented to demonstrate whether a particular exposure was a risk factor for a particular outcome, and to compare the magnitude of various risk factors for that outcome (Szumilas, 2010).

\section{Summary and Statement of Significance}

Some existing studies in dentistry on NBDE performance prediction focus on various predictors: (a) demographic factors (race and gender), (b) dental admission test (DAT) factors (standard scores reported by DAT), (c) pre-program academic factors (undergraduate science GPA and undergraduate non-science GPA), and (d) dental program academic factors (individual course GPAs and cumulative GPA). However, no theoretical foundation or empirical models are employed in these studies. This proposed study will attempt to fill the gap with current existing literatures by proposing an 
empirical model using Astin's Input-Environment-Output (I-E-O) model as a theoretical framework (Astin, 1968). The study will test the predictors of NBDE Part I performance following the 2012 decision of the JCNDE which changed the reporting of results for candidates to the pass or fail format. There is no current study available on NBDE Part I performance prediction following the 2012 reporting format change.

The findings from this proposed study can provide the educators and administrators information to evaluate student's academic performance in the basic science curriculum in the dental program and discern between students who are likely to pass the NBDE Part I and individuals at risk for failure. Based on the findings of this research, educators and administrators in the dental program can establish important benchmarks in the early dental curriculum to identify at-risk students. The identification of at-risk students in the early dental curriculum can ensure these students receive timely academic support in their learning process and remediate on their deficiencies to minimize possible attrition and potential licensure examination failures. 


\section{CHAPTER IV}

\section{RESULTS}

This study focused on the relationship among student demographic characteristics, prior academic performance, dental admission test performance, and dental program performance as predictors of NBDE Part I outcomes. In addition, this study explored relationships between dental students' background characteristics, and their academic performances in the dental admission tests, at the undergraduate level and in the dental program. This chapter presents the findings from statistical analyses used to answer the research questions. Descriptive findings on the research samples are presented, followed by statistical analyses findings related to each research question.

\section{Descriptive Findings}

Those students who met the following inclusion criteria were included in the study: (1) no missing scores on the DAT or pre-program GPA information in the admission database; (2) completion of all required didactic dental program courses in the first-year fall semester, first-year spring semester, second-year fall semester, and secondyear spring semester; (3) no missing, deferred, or transferred grades in the aforementioned didactic courses; and (4) completion of the first attempt on the NBDE Part I after 2012, following the NBDE score reporting format changes. After inspecting the data following the inclusion criteria, a total of 324 dental students were included in the analyses. Initial descriptive analysis of the data were performed on the variables o 
interest, including frequency, measures of central tendency and measures of variability. For the categorical variables, sum, frequency, and percentage were calculated. For the continuous variables, mean, median, standard deviation, minimum, and maximum were calculated. Furthermore, the descriptive findings were also provided grouped by the NBDE pass and fail observations.

\section{Student Demographics}

With respect to the demographic characteristics, the sample consisted of 324 dental students and the majority were male (55.2\%) and White (77.8 \%). The study sample consisted of more male students (55.2\%) than female students (44.8\%). The distribution of sample was similar between male and female students. In the race distribution, Asian (11.1\%) and URM students (11.1\%) were overwhelmingly less than the White students (77.8\%). Table 4 provides detailed demographic characteristics of the sample by gender and race, including frequencies and percentages.

Table 4

\begin{tabular}{lcc} 
Sample demographics & & \\
\hline & & \\
\hline Gender & 179 & $55.2 \%$ \\
Male & 145 & $44.8 \%$ \\
Female & & \\
Race & 252 & $77.8 \%$ \\
White & 36 & $11.1 \%$ \\
Asian & 36 & $11.1 \%$ \\
URM & &
\end{tabular}

Note. Underrepresented Minorities (URM)

\section{Pre-program Academic Performance}

The non-science GPA of the sample $(M=3.70, S D=0.28)$ was the highest among different GPAs at the undergraduate level. The Science GPA of the sample $(M=3.43, S D$ $=0.34)$ was very similar with the Biology, Chemistry, Physics GPA $(M=3.42, S D=0.35)$.

The sample's total GPA at the undergraduate level ranged from 2.23 to 4.04, with a mean 
of $3.54(S D=0.27)$. These findings indicated that the average GPAs of the study sample were slightly lower than the national average GPAs published by the American Dental Association. The 2017-18 Survey of Dental Education were sent to all 66 United States dental schools and ten Canadian dental schools in August 2017, and the data showed the first-year dental students' mean science GPA was 3.50, and the total GPA was 3.59 at the undergraduate level (American Dental Association, 2018). Table 5 presents the descriptive statistics for the sample's pre-program academic performance, including minimum, median, maximum, mean, and standard deviation in the undergraduate GPAs. Table 5

\begin{tabular}{lccccc} 
Pre-program academic performance & \multicolumn{1}{c}{} \\
\hline \multicolumn{1}{c}{ Variable } & Minimum & $M d n$ & Maximum & $M$ & $S D$ \\
\hline Undergraduate GPA & & & & & \\
Science & 1.65 & 3.47 & 4.03 & 3.43 & 0.34 \\
$\quad$ Non-science & 2.55 & 3.78 & 4.16 & 3.70 & 0.28 \\
Biology, Chemistry, Physics & 1.70 & 3.45 & 4.03 & 3.42 & 0.35 \\
$\quad$ Total & 2.23 & 3.58 & 4.04 & 3.54 & 0.27 \\
\hline
\end{tabular}

\section{DAT Performance}

Among eight standard scores reported on the DAT, the average score on the Reading Comprehension $(M=20.61, S D=2.35)$ was the highest, and the average scores on the Quantitative Reasoning was the lowest $(M=17.89, S D=2.17)$. The remaining six standard scores, including the scores on the Perceptual Ability $(M=19.65, S D=2.19)$, Biology $(M=19.2, S D=1.91)$, General Chemistry $(M=19.31, S D=2.31)$, Organic Chemistry $(M=19.47, S D=2.69)$, Total Science $(M=19.1, S D=1.69)$, and Academic Average $(M=19.3, S D=1.5)$ were very similar. The findings from this study sample were slightly lower than the national average GPAs published by the American Dental Association. The 2017-18 Survey of Dental Education showed the national mean 
Perceptual Ability score was 20.1, the mean Total Science score was 19.8 , and the mean Academic Average score was 20.3 (American Dental Association, 2018). Table 6 presents the descriptive statistics for the DAT performance, including minimum, median, maximum, mean, and standard deviation in the different scores on the DAT.

Table 6

\begin{tabular}{|c|c|c|c|c|c|}
\hline Variable & Minimum & $M d n$ & Maximum & $M$ & $S D$ \\
\hline \multicolumn{6}{|l|}{ Scores on the DAT } \\
\hline Perceptual Ability & 14 & 20 & 29 & 19.65 & 2.19 \\
\hline Quantitative Reasoning & 13 & 18 & 24 & 17.89 & 2.17 \\
\hline Reading Comprehension & 15 & 20 & 28 & 20.61 & 2.35 \\
\hline Biology & 14 & 19 & 27 & 19.2 & 1.91 \\
\hline General Chemistry & 13 & 19 & 29 & 19.31 & 2.31 \\
\hline Organic Chemistry & 13 & 19 & 30 & 19.47 & 2.69 \\
\hline Total Science & 15 & 19 & 25 & 19.1 & 1.69 \\
\hline Academic Average & 16 & 19 & 24 & 19.3 & 1.5 \\
\hline
\end{tabular}

\section{Dental Program Academic Performance}

Table 7 presents the descriptive statistics for the sample's academic performance in the dental program, including minimum, median, maximum, mean, and standard deviation in the different individual course grades and cumulative GPAs.

\section{Table 7}

\section{Dental program academic performance}

\begin{tabular}{lccccc}
\hline \multicolumn{1}{c}{ Variable } & Minimum & $M d n$ & Maximum & $M$ & $S D$ \\
\hline Individual course grades & & & & & \\
Histology & 1.7 & 3 & 4 & 3.15 & 0.6 \\
Physiology & 0 & 3 & 4 & 3.42 & 0.62 \\
Biochemistry & 1 & 3.7 & 4 & 3.53 & 0.65 \\
Survey of Dental Gross and Neuroanatomy & 2 & 3 & 4 & 3.16 & 0.63 \\
Dental Anatomy and Occlusion (lecture) & 2 & 4 & 4 & 3.77 & 0.46 \\
Dental Anatomy and Occlusion (laboratory) & 2 & 4 & 4 & 3.46 & 0.57 \\
Preclinical Occlusion and TMD & 2 & 3 & 4 & 3.23 & 0.61 \\
General Pathology & 0.7 & 2.7 & 4 & 2.58 & 0.8 \\
Microbiology and Immunology & 2 & 3.3 & 4 & 3.35 & 0.57 \\
Oral Pathology & 0 & 2 & 4 & 2.4 & 0.82 \\
Cumulative GPA & & & & & \\
First-year & 2.52 & 3.51 & 4 & 3.48 & 0.34 \\
Second-year & 2.5 & 3.4 & 4 & 3.37 & 0.34 \\
\hline
\end{tabular}


Among the grades from ten courses relevant to the contents of NBDE Part I, Oral Pathology $(M=2.4, S D=0.82)$ and the General Pathology courses showed the lowest mean average grades $(M=2.58, S D=0.8)$, while Dental Anatomy and Occlusion (lecture) was the highest $(M=3.77, S D=0.46)$. Oral Pathology and General Pathology also had the highest standard deviation, meaning the students' grades were most variable in these two courses. The mean average cumulative GPA from second-year $(M=3.37$, $S D=0.34)$ was lower than the mean average cumulative GPA from first-year $(M=3.48$, $S D=0.34)$

\section{NBDE Part I Performance}

Within the study sample, 301 (92.9\%) out of 324 dental students passed the NBDE Part I examination on their first attempt. Table 8 provides detailed demographic characteristics of the sample. Male students had a pass rate of $91.6 \%$, and the female students had a pass rate of $94.5 \%$. The first time pass rate was $93.7 \%$ for the White students and $94.4 \%$ for the URM students. Asian students had the lowest first time pass rate $(86.1 \%)$ of all race groups. Table 8 provides a descriptive comparison of NBDE Part I performance (fail and pass) among all dental students and between gender and race groups.

Table 8

\begin{tabular}{|c|c|c|c|c|c|c|}
\hline \multirow[t]{2}{*}{ Variable } & \multicolumn{2}{|c|}{ NBDE fail } & \multicolumn{2}{|c|}{ NBDE pass } & \multicolumn{2}{|c|}{ Full sample } \\
\hline & $n$ & $\%$ & $n$ & $\%$ & $n$ & $\%$ \\
\hline All Student & 23 & $7.1 \%$ & 301 & $92.9 \%$ & 324 & $100 \%$ \\
\hline \multicolumn{7}{|l|}{ Gender } \\
\hline Male & 15 & $65.2 \%$ & 164 & $54.5 \%$ & 179 & $55.2 \%$ \\
\hline Female & 8 & $34.8 \%$ & 137 & $45.5 \%$ & 145 & $44.8 \%$ \\
\hline \multicolumn{7}{|l|}{ Race } \\
\hline White & 16 & $69.6 \%$ & 236 & $78.4 \%$ & 252 & $77.8 \%$ \\
\hline Asian & 5 & $21.7 \%$ & 31 & $10.3 \%$ & 36 & $11.1 \%$ \\
\hline URM & 2 & $8.7 \%$ & 34 & $11.3 \%$ & 36 & $11.1 \%$ \\
\hline
\end{tabular}

Note. Underrepresented Minorities (URM) 


\section{Pearson Product-Moment Correlation}

Pearson product-moment correlation coefficient was computed to assess the relationship among the continuous variables in the pre-program academic performance, DAT performance, and dental program academic performance. The Pearson correlation coefficient is a measure of the strength of a linear association between two interval or ratio variables and is denoted by $r$. The Pearson correlation coefficient can range from +1 to -1 , and a value of 0 indicates that there is no association between two variables. When there is a stronger correlation, the correlation coefficient comes closer to +1 or -1 . Different approaches have been suggested to interpret the correlation coefficient. The cutoff points could be inconsistent among literatures, and should be interpreted cautiously. The absolute magnitude of correlation coefficient of 0.00 to 0.10 can be considered as negligible correlation, while the absolute value of 0.90 to 1.00 can be considered as very strong correlation. The absolute value of 0.10 to $0.39,0.40$ to 0.69 , and 0.70 to 0.89 can be considered as weak correlation, moderate correlation, and strong correlation, respectively (Schober et al., 2018).

\section{Pre-program Academic Performance}

Pearson product-moment correlation was used to examine the relationship between four undergraduate GPAs. Table 9 provides the Pearson product-moment correlation coefficients in the student's pre-program academic performance. As reported in Table 9, undergraduate GPAs were significantly correlated at $\alpha=.01$, and the range of correlation coefficients were between .442 to .962 . These findings suggested the students have higher GPA in one course subject would have higher GPA in other course subjects. The results indicated significant and very strong positive association at $\alpha=.01$ between the 
Science GPA and Biology, Chemistry, Physics GPA, $r=.962, r^{2}=.925, p=.000$, and Total GPA, $r=.921, r^{2}=.848, p=.000$. The Science GPA shared approximately $92.5 \%$ of the total variance with Biology, Chemistry, Physics GPA, and $84.8 \%$ of the total variance with Total GPA. Non-science GPA showed significant and moderate correlation at $\alpha=.01$ with Science GPA, $r=.512, r^{2}=.262, p=.000$ and Biology, Chemistry, Physics GPA, $r=.442, r^{2}=.195, p=.000$. The Non-Science GPA shared approximately $51.2 \%$ of the total variance with Science GPA, and $19.5 \%$ of the total variance with Biology, Chemistry, Physics GPA.

Table 9

\begin{tabular}{|c|c|c|c|c|}
\hline Variable & 1 & 2 & 3 & 4 \\
\hline \multicolumn{5}{|l|}{ Undergraduate GPA } \\
\hline 1. Science & ----- & & & \\
\hline 2. Non-science & .512 & ----- & & \\
\hline 3. Biology, Chemistry, Physics & .962 & .442 & ---- & \\
\hline 4. Total & .921 & .773 & .862 & ---- \\
\hline
\end{tabular}

\section{DAT Performance}

Pearson product-moment correlation was used to examine the relationship between eight standard scores reported on the DAT, and most of the standard scores were significantly correlated at the $\alpha=.01$, and the range of correlation coefficients were between .033 to .855 . As reported in Table 10, these results indicated Reading Comprehension score on the DAT had no significant association with General Chemistry, $r=.139, r^{2}=.019, p=.012$ and Organic Chemistry, $r=.033, r^{2}=.001, p=.549$. The Total Science score on the DAT had a significant and strong correlation with the Academic Average score at $\alpha=.01, r=.855, r^{2}=.731, p=.000$. The Total Science score shared approximately $73.1 \%$ of the total variance with Academic Average score. These findings suggested the students had higher standard score in one subject domain would 
have higher standard scores in other domains in the DAT. However, when the students had higher scores in Reading Comprehension, they did not have higher scores in the General Chemistry and Organic Chemistry. Table 10 provides the Pearson productmoment correlation coefficients in the student's DAT performance.

Table 10

DAT performance - Pearson product-moment correlations
\begin{tabular}{ccccccccc} 
Variable & 1 & 2 & 3 & 4 & 5 & 6 & 7 & 8 \\
\hline
\end{tabular}
Scores on the DAT

1. Perceptual Ability -

2. Quantitative Reasoning $\quad .403$

3. Reading Comprehension $\quad .180$

4. Biology 209

5. General Chemistry $\quad .209$

6. Organic Chemistry $\quad .305$

7. Total Science $\quad .305$

$.343 \quad .203$

8. Academic Average

417

.245

.252

.320

.241

.595

$\begin{array}{ccc}- & & \\ .282 & - & \\ .139 & .345 & - \\ .033 & .332 & .551 \\ .203 & .699 & .775 \\ .524 & .629 & .728\end{array}$
$-$

.775

\begin{tabular}{l}
$.728-.786$ \\
\hline
\end{tabular}

$.687 \quad .855$

Note. All correlations were significant at $p \leq .001$, except when Reading Comprehension was compared with General Chemistry and Organic Chemistry.

\section{Dental Program Academic Performance}

The individual course grades and cumulative GPAs are significantly correlated at the $\alpha=.01$ with few exceptions. As reported in Table 11, Dental Anatomy and Occlusion (laboratory) had no significant association with Biochemistry, $r=.112, r^{2}=.012, p$ $=.044$ and General Pathology, $r=.094, r^{2}=.008, p=.091$. Although the Dental Anatomy and Occlusion (laboratory) course grade were significantly associated with other grades and cumulative GPAs at $\alpha=.01$, the correlation coefficients were ranging from 0.183 (associated with Oral Pathology, $p=.001$ ) to 0.435 (associated with Firstyear Cumulative GPA, $p=.000$ ), and lower than other observed values. The Dental Anatomy and Occlusion (laboratory) course grade shared approximately $3.3 \%$ of the total variance with Oral Pathology and $18.9 \%$ of the total variance with First-year Cumulative GPA. The strongest correlation coefficient was observed between the First-year Cumulative GPA and Second-year Cumulative GPA, $r=.936, r^{2}=.876, p=.000$. This 
indicated the First-year Cumulative GPA shared approximately $87.6 \%$ of the total variance with Second-year Cumulative GPA. This result was to be expected with cumulative GPAs, since the Second-year Cumulative GPA was partly composed of the First-year Cumulative GPA. Table 11 provides the Pearson product-moment correlation coefficients in the student's dental program performance.

Table 11

\begin{tabular}{|c|c|c|c|c|c|c|c|c|c|c|c|c|}
\hline Variable & 1 & 2 & 3 & 4 & 5 & 6 & 7 & 8 & 9 & 10 & 11 & 12 \\
\hline \multicolumn{13}{|l|}{ Individual course grades } \\
\hline 1. Histology & - & & & & & & & & & & & \\
\hline 2. Physiology & .649 & - & & & & & & & & & & \\
\hline 3. Biochemistry & .532 & .540 & - & & & & & & & & & \\
\hline $\begin{array}{l}\text { 4. Survey of Dental Gross } \\
\text { and Neuroanatomy }\end{array}$ & .659 & .564 & .590 & - & & & & & & & & \\
\hline $\begin{array}{l}\text { 5. Dental Anatomy and } \\
\text { Occlusion (lecture) }\end{array}$ & .452 & .493 & .421 & .441 & - & & & & & & & \\
\hline $\begin{array}{l}\text { 6. Dental Anatomy and } \\
\text { Occlusion (laboratory) }\end{array}$ & .229 & .221 & .112 & .312 & .303 & - & & & & & & \\
\hline $\begin{array}{l}\text { 7. Preclinical Occlusion } \\
\text { and TMD }\end{array}$ & .468 & .441 & .407 & .469 & .432 & .288 & - & & & & & \\
\hline 8. General Pathology & .578 & .547 & .533 & .588 & .293 & .094 & .491 & - & & & & \\
\hline $\begin{array}{l}\text { 9. Microbiology and } \\
\text { Immunology }\end{array}$ & .517 & .450 & .514 & .557 & .312 & .234 & .485 & .501 & - & & & \\
\hline $\begin{array}{l}\text { 10. Oral Pathology } \\
\text { Cumulative GPA }\end{array}$ & .527 & .450 & .470 & .531 & .290 & .183 & .478 & .670 & .505 & - & & \\
\hline 11. First-year & .799 & .771 & .744 & .843 & .642 & .435 & .602 & .636 & .650 & .577 & - & \\
\hline 12. Second-year & .735 & .699 & .720 & .779 & .602 & .407 & .706 & .722 & .666 & .666 & .936 & - \\
\hline
\end{tabular}

Note. All correlations were significant at $p \leq .001$, except when Dental Anatomy and Occlusion (laboratory) was compared with Biochemistry and General Pathology.

\section{Independent $t$-tests and One-Way ANOVAs}

To answer the first research question, independent $t$-tests and One-Way ANOVAs were used. Prior to a series of independent $t$-tests and One-Way ANOVAs, basic assumptions related to independent tests were checked. Firstly, independence assumption was checked. All individual students in the research sample only appeared as one observation and the value of one observation does not influence or affect the value of other observations in a series of independent $t$-tests and One-Way ANOVAs. The independence of observations assumptions were met. Secondly, the obtained Q-Q plots suggested normal distributions for the continuous variables. Even though large samples $(n>100)$ can often approximate a normal distribution and analyzed with parametric tests, 
this assumption may hold even when the sample is not as large $(n>30)$ (Hazra \& Gogtay, 2016). The continuous variables were assessed graphically with Q-Q plots for normality, and they were assumed approximately normally distributed (Appendix B). The continuous variables included, pre-program GPAs (Science, Non-science, BiologyChemistry-Physics, and Total GPAs), standard scores on the DAT (Perceptual Ability, Quantitative Reasoning, Reading Comprehension, Biology, General Chemistry, Organic Chemistry, Total Science, and Academic Average), and dental program individual course scores (Histology, Physiology, Biochemistry, Survey of Dental Gross and Neuroanatomy, Dental Anatomy and Occlusion - lecture, Dental Anatomy and Occlusion - laboratory, Preclinical Occlusion and TMD, General Pathology, Microbiology and Immunology, and Oral Pathology) and cumulative GPAs (First-year and Second-year). Lastly, the homogeneity of variance assumption was checked with Levene's test. Levene's tests for equality of variances were found to be violated for some analyses. In the independent $t$ tests, Biochemistry and Second-year GPA were found with significant Levene's tests. Owing to this violated assumption, degrees of freedom were adjusted and $t$ statistics not assuming homogeneity of variance was computed and reported for the Biochemistry and Second-year GPA. In the One-Way ANOVAs, the Science GPA, Biology, Chemistry, Physics GPA, Total GPA, Academic Average, Physiology, Dental Anatomy and Occlusion (lecture), Preclinical Occlusion and TMD were found with significant Levene's tests. Owing to this violated assumption, degrees of freedom were adjusted, and Welch $F$ statistics and post hoc Games-Howell tests were performed and reported as the multiple comparison analyses for these analyses. 
The independent $t$-tests were conducted to compare the gender difference in preprogram academic performance, DAT performance, and dental program academic performance. Cohen's $d$ was reported as the effect size for the independent $t$-tests, the quantitative measure of the magnitude of a phenomenon, and the $d=0.2,0.5$ and 0.8 corresponded to small, medium and large effects (Cohen, 1988). The statistical significance for independent $t$-tests were at $\alpha=.05$. Depending on the numbers of multiple comparisons, Bonferroni correction was used to compensate for the likelihood of incorrectly rejecting a null hypothesis (inflation of Type I error). The $\alpha$ level was adjusted by testing each individual hypothesis at a significance level of $\alpha / m$, where $\alpha$ was the desired overall significance level (.05) and $m$ was the number of hypotheses (Abdi, 2007). The adjusted $\alpha$ levels to compare the gender difference in pre-program academic performance, DAT performance, and dental program academic performance were $.013, .006$, and .004 , respectively.

The One-Way ANOVAs were conducted to compare the associations of race with the dental students' pre-program academic performance, DAT performance, and dental program academic performance. To understand the subgroup differences, post hoc Tukey honest significance tests (HSD) were performed as the multiple comparison analyses. Tukey HSD tests all pairwise differences and all the contrasts as a family to reduce the probability of making a Type I error. It is also robust with unequal group sample sizes (Tukey-Kramer HSD). Since it uses a conservative estimate of alpha, Tukey HSD is less powerful to detect difference between pairs (McHugh, 2011). The adequate sample size for the omnibus test does not necessarily provide sufficient statistical power for the post hoc multiple comparisons typically performed after statistically significant (exploratory) 
omnibus test (Brooks \& Johanson, 2011). Due to the unequal group sample sizes, the statistical significance for $F$-tests were at $\alpha=.01$ (Keppel, 1991). After Bonferroni correction, the adjusted $\alpha$ levels to compare the race difference in pre-program academic performance, DAT performance, and dental program academic performance were $.0025, .0012$, and .0008 , respectively. The $\eta^{2}$ (Eta squared) was reported as the effect size for the $F$-tests, and the $\eta^{2}=0.01,0.059$ and 0.138 corresponded to small, medium and large effects (Cohen, 1988).

\section{Research Question 1}

The following sections are dedicated to address research question 1: Are there significant relationships between dental students' genders or races, and their dental admission test performances, grade point averages at the undergraduate level in the college or university, and individual course grades and cumulative grade point averages in the dental program?

Gender difference in pre-program academic performance. For gender group differences, a series of independent $t$-tests were conducted with Cohen's $d$ as an effect size indicator when appropriate. The Science GPA, Non-science GPA, Biology, Chemistry, Physics GPA, and Total GPA were used as the dependent variables while the gender was used as the independent variable. The results from independent $t$-tests indicated that, there was a significant difference at $\alpha=.013$ in the scores on the nonscience GPA at the undergraduate level between male $(M=3.66, S D=0.30)$ and female students $(M=3.75, S D=0.25), t(322)=-3.207, p=.001, d=.35$. Table 12 presents the results for the associations of gender with pre-program academic performance. It includes 
the means by gender, standard deviations by gender, $t$ values, $d f$ values, $p$ values, and Cohen's $d$.

Table 12

Associations of gender with pre-program academic performance

\begin{tabular}{|c|c|c|c|c|c|c|}
\hline & \multicolumn{2}{|c|}{ Gender } & \multirow[b]{2}{*}{$t$} & \multirow[b]{2}{*}{$d f$} & \multirow[b]{2}{*}{$p$} & \multirow[b]{2}{*}{ Cohen's $d$} \\
\hline & Males & Females & & & & \\
\hline \multicolumn{7}{|l|}{ Undergraduate GPA } \\
\hline Science & $\begin{array}{l}3.42 \\
(.34)\end{array}$ & $\begin{array}{l}3.45 \\
(.34)\end{array}$ & -.750 & 322 & .454 & .08 \\
\hline Non-science & $\begin{array}{l}3.66 \\
(.30)\end{array}$ & $\begin{array}{l}3.75 \\
(.25)\end{array}$ & $-3.207 *$ & 322 & $.001 *$ & .35 \\
\hline Biology, Chemistry, Physics & $\begin{array}{l}3.42 \\
(.35)\end{array}$ & $\begin{array}{l}3.43 \\
(.35)\end{array}$ & -.148 & 322 & .883 & .02 \\
\hline Total & $\begin{array}{l}3.51 \\
(.28)\end{array}$ & $\begin{array}{l}3.58 \\
(.25) \\
\end{array}$ & -2.209 & 322 & .028 & .25 \\
\hline
\end{tabular}

The effect size of 0.35 was found to correspond to Cohen's (1988) convention for the small to medium effects, indicating that approximately $35 \%$ of the variance in Nonscience GPA was accounted for by gender. This result suggests that, at the undergraduate level, female dental students had significantly higher Non-science GPAs at $\alpha=.013$, however, the male and female dental student had similar Science, Biology, Chemistry, Physics, and Total GPAs.

Gender difference in DAT performance. For gender group differences, a series of independent $t$-tests were conducted with Cohen's $d$ as an effect size indicator when appropriate. Eight standard scores on the DAT were used as the dependent variables while the gender was used as the independent variable. The results from independent $t$ tests indicated that, there was a significant difference at $\alpha=.006$ in the scores on the Perceptual Ability between male $(M=20.18, S D=2.21)$ and female students $(M=19.0$, $S D=1.99), t(322)=5.018, p=.000, d=.54$. The effect sizes of 0.54 found to correspond to Cohen's (1988) convention for the medium effect, indicating that approximately 54\% of the variance in Perceptual Ability were accounted for by gender. Table 13 presents the 
associations of gender with DAT performance. It includes the means by gender, standard deviations by gender, $t$ values, $d f$ values, $p$ values, and Cohen's $d$.

Table 13

Associations of gender with DAT performance

\begin{tabular}{|c|c|c|c|c|c|c|}
\hline & \multicolumn{2}{|c|}{ Gender } & \multirow[b]{2}{*}{$t$} & \multirow[b]{2}{*}{$d f$} & \multirow[b]{2}{*}{$p$} & \multirow[b]{2}{*}{ Cohen's $d$} \\
\hline & Males & Females & & & & \\
\hline \multicolumn{7}{|l|}{ Scores on the DAT } \\
\hline Perceptual Ability & $\begin{array}{l}20.18 \\
(2.21)\end{array}$ & $\begin{array}{c}19.0 \\
(1.99)\end{array}$ & $5.018^{*}$ & 322 & $.000^{*}$ & .54 \\
\hline Quantitative Reasoning & $\begin{array}{l}18.11 \\
(2.17)\end{array}$ & $\begin{array}{l}17.62 \\
(2.13)\end{array}$ & 2.016 & 322 & .045 & .22 \\
\hline Reading Comprehension & $\begin{array}{l}20.6 \\
(2.5)\end{array}$ & $\begin{array}{l}20.63 \\
(2.18)\end{array}$ & -.092 & 322 & .927 & .01 \\
\hline Biology & $\begin{array}{c}19.31 \\
(1.93)\end{array}$ & $\begin{array}{l}19.05 \\
(1.89)\end{array}$ & 1.207 & 322 & .228 & .13 \\
\hline General Chemistry & $\begin{array}{l}19.55 \\
(2.39)\end{array}$ & $\begin{array}{l}19.02 \\
(2.18)\end{array}$ & 2.050 & 322 & .041 & .23 \\
\hline Organic Chemistry & $\begin{array}{c}19.8 \\
(2.82)\end{array}$ & $\begin{array}{l}19.05 \\
(2.46)\end{array}$ & 2.499 & 322 & .013 & .28 \\
\hline Total Science & $\begin{array}{c}19.3 \\
(1.69)\end{array}$ & $\begin{array}{l}18.86 \\
(1.65)\end{array}$ & 2.386 & 322 & .018 & .26 \\
\hline Academic Average & $\begin{array}{c}19.5 \\
(1.52)\end{array}$ & $\begin{array}{l}19.06 \\
(1.44)\end{array}$ & 2.617 & 322 & .009 & .29 \\
\hline
\end{tabular}

Note. ${ }^{*}=p<.006$. Standard Deviations appear in parentheses below means.

Gender difference in dental program academic performance. For gender group differences, a series of independent $t$-tests were conducted with Cohen's $d$ as an effect size indicator when appropriate. The individual course grades and cumulative GPAs were used as the dependent variables while the gender was used as the independent variable. The results from independent $t$-tests indicated that, there were no significant gender differences in dental students' performances on all individual course grades at $\alpha$ $=.004$, including Histology, Physiology, Biochemistry, Survey of Dental Gross and Neuroanatomy, Dental Anatomy and Occlusion (lecture), Dental Anatomy and Occlusion (laboratory), Preclinical Occlusion and TMD, General Pathology, Microbiology and Immunology, Oral Pathology, and the first-year and second-year cumulative GPAs. Table 14 presents the associations of gender with dental program performance. It includes the 
means by gender, standard deviations by gender, $t$ values, $d f$ values, $p$ values, and Cohen's $d$.

Table 14

Associations of gender with dental program academic performance

\begin{tabular}{|c|c|c|c|c|c|c|}
\hline & \multicolumn{2}{|c|}{ Gender } & \multirow[b]{2}{*}{$t$} & \multirow[b]{2}{*}{$d f$} & \multirow[b]{2}{*}{$p$} & \multirow[b]{2}{*}{ Cohen's $d$} \\
\hline & Males & Females & & & & \\
\hline \multicolumn{7}{|l|}{ Individual course grades } \\
\hline Histology & $\begin{array}{l}3.14 \\
(.61)\end{array}$ & $\begin{array}{l}3.15 \\
(.59)\end{array}$ & -.078 & 322 & .937 & .01 \\
\hline Physiology & $\begin{array}{l}3.42 \\
(.65)\end{array}$ & $\begin{array}{l}3.41 \\
(.58)\end{array}$ & .075 & 322 & .940 & .01 \\
\hline Biochemistry & $\begin{array}{l}3.48 \\
(.71)\end{array}$ & $\begin{array}{l}3.60 \\
(.56)\end{array}$ & -1.631 & 322 & .095 & .18 \\
\hline Survey of Dental Gross and Neuroanatomy & $\begin{array}{l}3.12 \\
(.66)\end{array}$ & $\begin{array}{l}3.21 \\
(.58)\end{array}$ & -1.226 & 322 & .221 & .14 \\
\hline Dental Anatomy and Occlusion (lecture) & $\begin{array}{l}3.77 \\
(.44)\end{array}$ & $\begin{array}{l}3.77 \\
(.49)\end{array}$ & .106 & 322 & .916 & .01 \\
\hline Dental Anatomy and Occlusion (laboratory) & $\begin{array}{l}3.45 \\
(.58)\end{array}$ & $\begin{array}{l}3.48 \\
(.57)\end{array}$ & -.558 & 322 & .577 & .06 \\
\hline Preclinical Occlusion and TMD & $\begin{array}{l}3.18 \\
(.66)\end{array}$ & $\begin{array}{l}3.28 \\
(.55)\end{array}$ & -1.441 & 322 & .151 & .16 \\
\hline General Pathology & $\begin{array}{c}2.5 \\
(.82)\end{array}$ & $\begin{array}{l}2.68 \\
(.77)\end{array}$ & -2.038 & 322 & .042 & .23 \\
\hline Microbiology and Immunology & $\begin{array}{l}3.32 \\
(.57)\end{array}$ & $\begin{array}{l}3.38 \\
(.56)\end{array}$ & -.863 & 322 & .389 & .10 \\
\hline Oral Pathology & $\begin{array}{l}2.37 \\
(.85)\end{array}$ & $\begin{array}{l}2.44 \\
(.78)\end{array}$ & -.795 & 322 & .427 & .09 \\
\hline \multicolumn{7}{|l|}{ Cumulative GPA } \\
\hline First-year & $\begin{array}{l}3.47 \\
(.35)\end{array}$ & $\begin{array}{l}3.50 \\
(.33)\end{array}$ & -.753 & 322 & .452 & .08 \\
\hline Second-year & $\begin{array}{l}3.35 \\
(.36)\end{array}$ & $\begin{array}{l}3.40 \\
(.32)\end{array}$ & -1.447 & 319 & .144 & .16 \\
\hline
\end{tabular}

Note. Standard Deviations appear in parentheses below means.

\section{Racial group difference in pre-program academic performance. For racial}

group differences a series of One-Way ANOVAs were conducted with $\eta^{2}$ (eta squared) as an effect size indicator when appropriate. The Science GPA, Non-science GPA, Biology, Chemistry, Physics GPA, and Total GPA were used as the dependent variables while the race was used as the independent variable.

Except Non-science GPA, there were significant race differences in all other GPAs at the undergraduate level, at $\alpha=.0025$. There was a significant race different in the Science GPA at $\alpha=.0025, F(2,58)=10.046, p=.000, \eta^{2}=.081$. The result showed that $8 \%$ of the variance in the Science GPA was accounted for by the race, and the eta- 
squared $\left(\eta^{2}=.081\right)$ was of medium to large effect size. Prior to the post hoc tests to probe the significance of this finding, Levene's test was conducted. The result showed a significance at $F(2,321)=9.299, p=.000$, thus the homogeneity of variance assumption was not met. Post hoc comparisons using Games-Howell test did not indicate any group differences at $\alpha=.0025$. This finding may be due to small group sizes from the Asian and URM dental students.

Race was significantly associated with Biology, Chemistry, Physics GPA at $\alpha$ $=.0025, F(2,59)=10.046, p=.000, \eta^{2}=.074$. The result showed that $7 \%$ of the variance in the Biology, Chemistry, Physics GPA was accounted for by the race, and the eta-squared $\left(\eta^{2}=.074\right)$ was of medium to large effect size. Prior to the post hoc tests to probe the significance of this finding, Levene's test was conducted. The result showed a significance at $F(2,321)=9.009, p=.000$, thus the homogeneity of variance assumption was not met. Post hoc comparisons using Games-Howell test did not indicate any significant group differences at $\alpha=.0025$.

Race was significantly associated with Total GPA at $\alpha=.0025, F(2,57)=8.823$, $p=.000, \eta^{2}=.065$. The result showed that $6.5 \%$ of the variance in the Total GPA was accounted for by the race, and the eta-squared $\left(\eta^{2}=.065\right)$ was of medium effect size. Prior to the post hoc tests to probe the significance of this finding, Levene's test was conducted. The result showed a significance at $F(2,321)=9.295, p=.000$, thus the homogeneity of variance assumption was not met. Post hoc comparisons using GamesHowell test did not indicate any significant group differences at $\alpha=.0025$. Table 15 presents the results for the associations of race with pre-program academic performance. 
It includes the means by race, standard deviations by race, $F$ values, $\eta^{2}$ values, and $p$

values.

Table 15

Associations of race with pre-program academic performance

\begin{tabular}{|c|c|c|c|c|c|c|}
\hline & \multicolumn{3}{|c|}{ Race } & \multirow[b]{2}{*}{$F$} & \multirow[b]{2}{*}{$\eta^{2}$} & \multirow[b]{2}{*}{$p$} \\
\hline & White & Asian & URM & & & \\
\hline \multicolumn{7}{|l|}{ Undergraduate GPA } \\
\hline Science & $\begin{array}{l}3.48 \\
(.31)\end{array}$ & $\begin{array}{l}3.33 \\
(.26)\end{array}$ & $\begin{array}{l}3.19 \\
(.48)\end{array}$ & $10.046^{*}$ & .081 & $.000 *$ \\
\hline Non-science & $\begin{array}{l}3.72 \\
(.26)\end{array}$ & $\begin{array}{l}3.64 \\
(.32)\end{array}$ & $\begin{array}{c}3.62 \\
(0.32)\end{array}$ & 3.107 & .019 & .046 \\
\hline Biology, Chemistry, Physics & $\begin{array}{l}3.47 \\
(.32)\end{array}$ & $\begin{array}{l}3.30 \\
(.26)\end{array}$ & $\begin{array}{c}3.20 \\
(0.49)\end{array}$ & $10.046^{*}$ & .074 & $.000^{*}$ \\
\hline Total & $\begin{array}{l}3.58 \\
(.25)\end{array}$ & $\begin{array}{l}3.45 \\
(.22)\end{array}$ & $\begin{array}{c}3.38 \\
(0.36)\end{array}$ & $8.823 *$ & .065 & $.000^{*}$ \\
\hline
\end{tabular}

Note. ${ }^{*}=p<.0025$. Standard deviations appear in parentheses bellow means. Post-hoc multiple pairwisecomparisons did not reveal any group differences at $\alpha<.0025$. Underrepresented Minorities (URM).

Racial group difference in DAT performance. For racial group differences a series of One-Way ANOVAs were conducted with $\eta^{2}$ (eta squared) as an effect size indicator when appropriate. Eight standard scores on the DAT were used as the dependent variables while the gender was used as the independent variable. The results from One-Way ANOVAs indicated that, there were significant racial group differences with all eight standard scores on the DAT, at $\alpha=.0012$, except Perceptual Ability scores. Table 16 presents the results for the associations of race with DAT performance. It includes the means by race, standard deviations by race, $F$ values, $\eta^{2}$ values, and $p$ values.

For the scores on the Quantitative Reasoning, Total Science, and Academic Average, White and Asian dental students obtained significantly higher scores than URM dental students at $\alpha=.0012$. There was a significant race difference in the Quantitative Reasoning scores at $\alpha=.0012, F(2,321)=15.395, p=.000, \eta^{2}=.088$. The result showed that $8.8 \%$ of the variance in the Quantitative Reasoning scores was accounted for by the race, and the eta-squared $\left(\eta^{2}=.088\right)$ was of medium to large effect size. Prior to the post 
hoc tests to probe the significance of this finding, Levene's test was conducted. The result showed a non-significance at $F(2,321)=1.718, p=.181$, thus meeting the homogeneity of variance assumption. The post hoc comparisons using the Tukey HSD test indicated that the Quantitative Reasoning scores from the White $(M=18.10, S D=2.11)$ and Asian dental students $(M=18.22, S D=1.99)$ were significantly higher at $\alpha=.0012$ than the scores from URM dental students $(M=16.08, S D=1.90), p=.000$ and $p=.000$, respectively.

Table 16

Associations of race with DAT performance

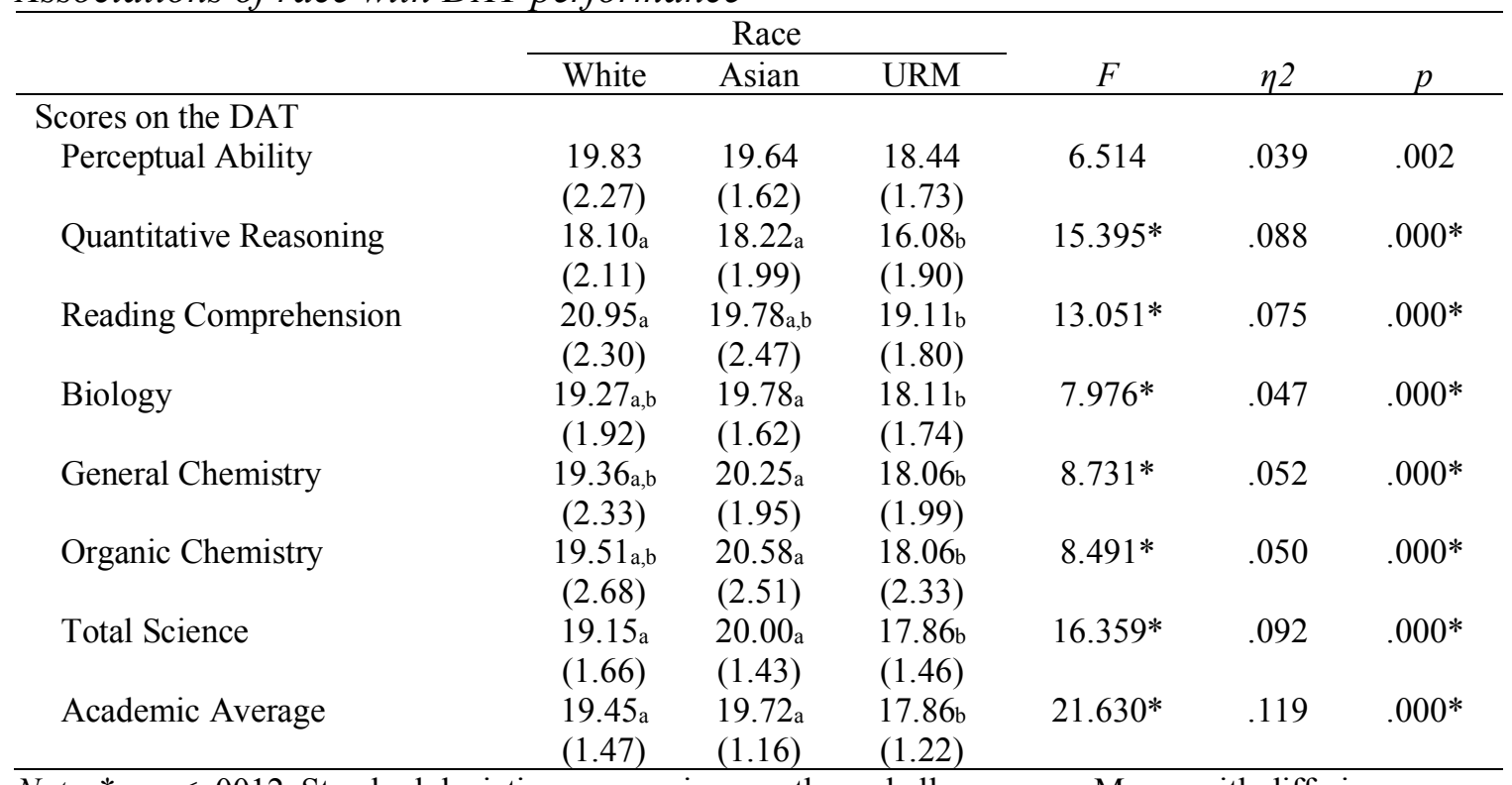

Note. ${ }^{*}=p<.0012$. Standard deviations appear in parentheses bellow means. Means with differing subscripts within rows are significantly different at the $\alpha=.0012$ based on post hoc multiple pairwisecomparisons. Underrepresented Minorities (URM).

There was a significant racial group difference in the Total Science scores at $\alpha$ $=.0012, F(2,321)=16.359, p=.000, \eta^{2}=.092$. The result showed that $9.2 \%$ of the variance in the Total Science scores was accounted for by the race, and the eta-squared $\left(\eta^{2}=.092\right)$ was of medium to large effect size. Prior to the post hoc tests to probe the significance of this finding, Levene's test was conducted. The result showed a non- 
significance at $F(2,321)=.304, p=.738$, thus meeting the homogeneity of variance assumption. More specifically, post hoc comparisons using the Tukey HSD test indicated that the Total Science scores from Asian $(M=20.00, S D=1.43)$ and White dental students $(M=19.15, S D=1.66)$ were significantly higher at $\alpha=.0012$ than the scores from URM dental students $(M=17.86, S D=1.46), p=.000$ and $p=.000$, respectively.

There was a significant racial group difference in the Academic Average scores at $\alpha=.0012, F(2,64)=28.197, p=.000, \eta^{2}=.119$. The result showed that $11.9 \%$ of the variance in the Academic Average scores was accounted for by the race, and the etasquared $\left(\eta^{2}=.119\right)$ was of medium to large effect size. Prior to the post hoc tests to probe the significance of this finding, Levene's test was conducted. The result showed a significance at $F(2,321)=3.173, p=.043$, thus the homogeneity of variance assumption was not met. Post hoc comparisons using the Games-Howell test showed that Academic Average scores from the White $(M=19.45, S D=1.47)$ and Asian dental students $(M=$ $19.72, S D=1.16$ ) were significantly higher at $\alpha=.0012$ than the scores from URM dental students $(M=17.86, S D=1.22), p=.000$ and $p=.000$, respectively.

For the scores on the Reading Comprehension, White dental students obtained significantly higher scores than URM dental students at $\alpha=.0012$. There was a significant race difference in the Reading Comprehension scores at $\alpha=.0012, F(2,321)$ $=13.051, p=.000, \eta^{2}=.075$. The result showed that $7.5 \%$ of the variance in the Reading Comprehension scores was accounted for by the race, and the eta-squared $\left(\eta^{2}=.075\right)$ was of medium to large effect size. Prior to the post hoc tests to probe the significance of this finding, Levene's test was conducted. The result showed a non-significance at $F(2,321)=$ $2.739, p=.066$, thus meeting the homogeneity of variance assumption. More specifically, 
post hoc comparisons using the Tukey HSD test indicated that the Reading Comprehension scores from the White dental students $(M=20.95, S D=2.30)$ were significantly higher at $\alpha=.0012$ than the scores from URM dental students $(M=19.11$, $S D=1.80), p=.000$.

For the scores on the Biology, General Chemistry, and Organic Chemistry, Asian dental students obtained significantly higher scores than URM dental students at $\alpha$ $=.0012$. There was a significant racial group difference in the Biology scores at $\alpha$ $=.0012, F(2,321)=7.976, p=.000, \eta^{2}=.047$. The result showed that $4.7 \%$ of the variance in the Biology scores was accounted for by the race, and the eta-squared $\left(\eta^{2}\right.$ $=.047$ ) was of medium effect size. Prior to the post hoc tests to probe the significance of this finding, Levene's test was conducted. The result showed a non-significance at $F(2,321)=.425, p=.645$, thus meeting the homogeneity of variance assumption. The post hoc comparisons using the Tukey HSD test showed that Biology scores from the Asian dental students $(M=19.78, S D=1.62)$ were significantly at $\alpha=.0012$ higher than the scores from URM dental students $(M=18.11, S D=1.74), p=.001$.

There was a significant racial group difference in the General Chemistry scores at $\alpha=.0012, F(2,321)=8.731, p=.000, \eta^{2}=.052$. The result showed that $5.2 \%$ of the variance in the General Chemistry scores was accounted for by the race, and the etasquared $\left(\eta^{2}=.052\right)$ was of medium effect size. Levene's test indicated equal variances, $F(2,321)=.425, p=.645$. Prior to the post hoc tests to probe the significance of this finding, Levene's test was conducted. The result showed a non-significance at $F(2,321)=$ $1.084, p=.339$, thus meeting the homogeneity of variance assumption. The post hoc comparisons using the Tukey HSD test showed that General Chemistry scores from 
Asian dental students $(M=20.25, S D=1.95)$ were significantly higher at $\alpha=.0012$ than the scores from URM dental students $(M=18.06, S D=1.99), p=.000$.

There was a significant racial group difference in the Organic Chemistry scores at $\alpha=.0012, F(2,321)=8.491, p=.000, \eta^{2}=.050$. The result showed that $5.0 \%$ of the variance in the Organic Chemistry scores was accounted for by the race, and the etasquared $\left(\eta^{2}=.050\right)$ was of medium effect size. Prior to the post hoc tests to probe the significance of this finding, Levene's test was conducted. The result showed a nonsignificance at $F(2,321)=.342, p=.710$, thus meeting the homogeneity of variance assumption. The post hoc comparisons using the Tukey HSD test showed that the Organic Chemistry scores from Asian dental students $(M=20.58, S D=2.51)$ were significantly higher at $\alpha=.0012$ than the scores from URM dental students $(M=18.06$, $S D=2.33), p=.000$.

Racial group difference in dental program academic performance. For racial group differences a series of One-Way ANOVAs were conducted with $\eta^{2}$ (eta squared) as an effect size indicator when appropriate. The individual course grades and cumulative GPAs were used as the dependent variables while the gender was used as the independent variable. The results from One-Way ANOVAs indicated that, there was a significant racial group difference with dental students' performances in the Preclinical Occlusion and TMD, at $\alpha=.0008$.

There was a significant racial group difference with the course grade of Preclinical Occlusion and TMD, $F(2,59)=10.760, p=.000, \eta^{2}=.062$. The result showed that $6.2 \%$ of the variance in the Preclinical Occlusion and TMD score was accounted for by the race, and the eta-squared $\left(\eta^{2}=.062\right)$ was of medium effect size. 
Prior to the post hoc tests to probe the significance of this finding, Levene's test was conducted. The result showed a significance at $F(2,321)=7.369, p=.001$, thus the homogeneity of variance assumption was not met. Post hoc comparisons using GamesHowell test did not indicate any group differences at $\alpha=.0008$. This finding may be due to small group sizes from the Asian and URM dental students. Table 17 presents the results for the associations of race with dental program academic performance. It includes the means by race, standard deviations by race, $F$ values, $\eta^{2}$ values, and $p$ values.

Table 17

Associations of race with dental program academic performance

\begin{tabular}{|c|c|c|c|c|c|c|}
\hline & \multicolumn{3}{|c|}{ Race } & \multirow[b]{2}{*}{$F$} & \multirow[b]{2}{*}{$\eta 2$} & \multirow[b]{2}{*}{$p$} \\
\hline & White & Asian & URM & & & \\
\hline \multicolumn{7}{|l|}{ Individual course grades } \\
\hline Histology & $\begin{array}{c}3.15 \\
(0.61)\end{array}$ & $\begin{array}{c}3.21 \\
(0.58)\end{array}$ & $\begin{array}{c}3.05 \\
(0.55)\end{array}$ & 690 & .004 & .502 \\
\hline Physiology & $\begin{array}{c}3.50 \\
(0.58)\end{array}$ & $\begin{array}{c}3.25 \\
(0.55)\end{array}$ & $\begin{array}{c}3.03 \\
(0.77)\end{array}$ & 8.276 & .064 & .001 \\
\hline Biochemistry & $\begin{array}{c}3.54 \\
(0.66)\end{array}$ & $\begin{array}{c}3.54 \\
(0.60)\end{array}$ & $\begin{array}{c}3.48 \\
(0.61)\end{array}$ & .123 & .001 & .885 \\
\hline Survey of Dental Gross and Neuroanatomy & $\begin{array}{c}3.19 \\
(0.62)\end{array}$ & $\begin{array}{c}3.00 \\
(0.66)\end{array}$ & $\begin{array}{c}3.11 \\
(0.59)\end{array}$ & 1.629 & .010 & .198 \\
\hline Dental Anatomy and Occlusion (lecture) & $\begin{array}{c}3.80 \\
(0.42)\end{array}$ & $\begin{array}{c}3.67 \\
(0.59)\end{array}$ & $\begin{array}{c}3.64 \\
(0.54)\end{array}$ & 2.198 & .019 & .121 \\
\hline Dental Anatomy and Occlusion (laboratory) & $\begin{array}{c}3.49 \\
(0.55)\end{array}$ & $\begin{array}{c}3.33 \\
(0.63)\end{array}$ & $\begin{array}{c}3.42 \\
(0.65)\end{array}$ & 1.277 & .008 & .280 \\
\hline Preclinical Occlusion and TMD & $\begin{array}{c}3.31 \mathrm{a} \\
(0.60)\end{array}$ & $\begin{array}{c}2.92_{\mathrm{b}} \\
(0.60)\end{array}$ & $\begin{array}{c}2.97 \mathrm{~b} \\
(0.56)\end{array}$ & $10.760 *$ & .062 & $.000^{*}$ \\
\hline General Pathology & $\begin{array}{c}2.62 \\
(0.80)\end{array}$ & $\begin{array}{c}2.51 \\
(0.85)\end{array}$ & $\begin{array}{c}2.36 \\
(0.73)\end{array}$ & 1.778 & .011 & .171 \\
\hline Microbiology and Immunology & $\begin{array}{c}3.38 \\
(0.56)\end{array}$ & $\begin{array}{c}3.26 \\
(0.62)\end{array}$ & $\begin{array}{c}3.17 \\
(0.58)\end{array}$ & 2.616 & .016 & .075 \\
\hline Oral Pathology & $\begin{array}{c}2.47 \\
(0.80)\end{array}$ & $\begin{array}{c}2.17 \\
(0.91)\end{array}$ & $\begin{array}{c}2.17 \\
(0.74)\end{array}$ & 3.879 & .024 & .022 \\
\hline \multicolumn{7}{|l|}{ Cumulative GPA } \\
\hline First-year & $\begin{array}{c}3.51 \\
(0.34)\end{array}$ & $\begin{array}{c}3.39 \\
(0.31)\end{array}$ & $\begin{array}{c}3.39 \\
(0.35)\end{array}$ & 3.525 & .021 & .031 \\
\hline Second-year & $\begin{array}{c}3.41 \\
(0.34)\end{array}$ & $\begin{array}{c}3.25 \\
(0.33)\end{array}$ & $\begin{array}{c}3.28 \\
(0.30)\end{array}$ & 5.334 & .032 & .005 \\
\hline
\end{tabular}

Note. ${ }^{*}=p<.0008$. Standard deviations appear in parentheses bellow means. Means with differing subscripts within rows are significantly different at $\alpha=.0008$ based on Tukey multiple pairwise-comparisons. Underrepresented Minorities (URM).

\section{Bivariate Logistic Regression to Test Association with NBDE Performance}

A series of binary logistic regression analyses were performed to observe if demographic factors (race and gender), pre-program academic performance, DAT 
performance, and dental program academic performance were significant predictors of NBDE performance. The model probability was $P(\mathrm{NBDE}=1)$. In the models, $\mathrm{z}$-scores were used for the continuous variables. Due to the limited number of NBDE failures, and the lack of variability of predictors, no multivariable analyses were performed. The significance level was set as $\alpha=.05$. The $\alpha$ level was adjusted with Bonferroni correction, and the adjusted $\alpha$ levels to compare the NBDE outcome differences with demographic factors, pre-program academic performance, DAT performance, and dental program academic performance were $.013, .013, .006$, and .004 , respectively.

To evaluate the usefulness of logistic model, Nagelkerke $R^{2}$ was presented in this study. The Nagelkerke $R^{2}$ is an adjusted version of the Cox \& Snell $R^{2}$ and covers the full range from 0 to 1 . While it does not measure the goodness of fit of the regression model, it indicates how useful the explanatory variables are in predicting the outcome. It could be referred to as the measure of effect sizes (Bewick, Cheek, \& Ball, 2005).

\section{Research Question 2}

The research question 2 was: Are there race and gender differences on the NBDE Part I outcome? Table 18 presents the results using bivariate logistic regression models to test association of race and gender with NBDE failure. In the table 18, \# denotes the reference groups (groups the internal coding as 0). For race, since there were 3 levels, odds ratios (OR) were calculated for all 3 comparisons (White vs Asian, White vs URM, Asian vs URM). Gender $\left(\chi_{(1)}^{2}=1.015, p=.314\right)$ and race $\left(\chi_{(2)}^{2}=2.368, p=.306\right)$ were not significant predictors of the NBDE performance $\alpha=.013$. Table 18 included coefficient for the constant $(B)$, standard error around the coefficient for the constant $(B$ 
$S E)$, Wald chi-square $\left(\chi^{2}\right)$, odds ratio, upper and lower bounds of $95 \%$ confidence interval of odds ratio, and $p$ values.

Table 18

Bivariate logistic regression models using race and gender as predictors for NBDE failures

\begin{tabular}{|c|c|c|c|c|c|c|c|}
\hline & \multirow[b]{2}{*}{$B$} & \multirow[b]{2}{*}{$B S E$} & \multirow[b]{2}{*}{ Wald $\chi^{2}$} & \multirow[b]{2}{*}{$O R$} & \multicolumn{2}{|c|}{$95 \%$ CI OR } & \multirow[b]{2}{*}{$p$} \\
\hline & & & & & Lower & Upper & \\
\hline \multicolumn{8}{|l|}{ Gender } \\
\hline Female versus Male & .45 & .45 & .98 & 1.57 & .65 & 3.81 & .322 \\
\hline \multicolumn{8}{|l|}{ Race } \\
\hline Asian versus White & .87 & .55 & 1.59 & 2.38 & .74 & 6.57 & .113 \\
\hline URM versus White ${ }^{\#}$ & -.14 & .77 & .77 & .87 & .13 & 3.23 & .854 \\
\hline URM versus Asian ${ }^{\#}$ & -1.01 & .87 & -1.16 & .36 & .05 & 1.83 & .248 \\
\hline
\end{tabular}

\section{Research Question 3}

The research question 3 was: Do the grade point averages at the undergraduate level in the college or university predict the NBDE Part I outcome? Table 19 included coefficient for the constant $(B)$, standard error around the coefficient for the constant $(B$ $S E)$, Wald chi-square $\left(\chi^{2}\right)$, odds ratio, upper and lower bounds of $95 \%$ confidence interval of odds ratio, and $p$ values.

\section{Table 19}

Bivariate logistic regression models using pre-program academic performance as predictors for $N B D E$ failures

\begin{tabular}{|c|c|c|c|c|c|c|c|}
\hline & \multirow[b]{2}{*}{$B$} & \multirow[b]{2}{*}{$B S E$} & \multirow[b]{2}{*}{ Wald $\chi^{2}$} & \multirow[b]{2}{*}{$O R$} & \multicolumn{2}{|c|}{$95 \%$ CI OR } & \multirow[b]{2}{*}{$p$} \\
\hline & & & & & Lower & Upper & \\
\hline \multicolumn{8}{|l|}{ Undergraduate GPA } \\
\hline Science & -.459 & .197 & 5.433 & .632 & .429 & .930 & .020 \\
\hline Non-Science & -.114 & .206 & .308 & .892 & .596 & 1.335 & .579 \\
\hline Biology, Chemistry, Physics & -.457 & .198 & 5.296 & .633 & .429 & .935 & .021 \\
\hline Total & -.427 & .200 & 4.554 & .652 & .440 & .966 & .033 \\
\hline
\end{tabular}

Note. $B$ - Unstandardized regression coefficient; $B S E$ - Standard error of unstandardized regression coefficient; Wald $\chi^{2}$ - Wald statistic; $O R$ - Odds ratio; $C I$ - Confidence Interval.

None of the pre-program academic performance were the significant predictors of the NBDE performance $\alpha=.013$. Non-Science GPA $\left(\chi^{2}{ }_{(1)}=.298, p=.585\right)$, Science 
GPA $\left(\chi_{(1)}^{2}=5.238, p=.022\right)$, Biology, Chemistry, Physics GPA $\left(\chi_{(1)}^{2}=5.105, p=.024\right)$, and Total GPA $\left(\chi_{(1)}^{2}=4.397, p=.036\right)$ were not significant predictors of the NBDE.

\section{Research Question 4}

The research question 4 was: Does the dental admission test performance predict the NBDE Part I outcome? None of the scores on the DAT were the significant predictors of the NBDE performance at $\alpha=.006$. Perceptual Ability $\left(\chi^{2}(1)=.609, p=.435\right)$, Quantitative Reasoning $\left(\chi_{(1)}^{2}=1.373, p=.241\right)$, Reading Comprehension $\left(\chi_{(1)}^{2}=.083, p\right.$ $=.773)$, Biology $\left(\chi_{(1)}^{2}=2.904, p=.088\right)$, General Chemistry $\left(\chi_{(1)}^{2}=1.873, p=.171\right)$, Organic Chemistry $\left(\chi_{(1)}^{2}=3.350, p=.067\right)$, Total Science $\left(\chi_{(1)}^{2}, p=.041\right)$, and Academic Average $\left(\chi^{2}(1)=2.157, p=.142\right)$ scores on the DAT were not significant predictors of the NBDE performance. Table 20 presents the results using bivariate logistic regression models to test association of DAT performance with NBDE failure, and includes coefficient for the constant $(B)$, standard error around the coefficient for the constant $(B$ $S E)$, Wald chi-square $\left(\chi^{2}\right)$, odds ratio, upper and lower bounds of $95 \%$ confidence interval of odds ratio, and $p$ values.

Table 20

Bivariate logistic regression models using DAT as predictors for NBDE failures

\begin{tabular}{|c|c|c|c|c|c|c|c|}
\hline & \multirow[b]{2}{*}{$B$} & \multirow[b]{2}{*}{$B S E$} & \multirow[b]{2}{*}{ Wald $\chi^{2}$} & \multirow[b]{2}{*}{$O R$} & \multicolumn{2}{|c|}{$95 \%$ CI OR } & \multirow[b]{2}{*}{$p$} \\
\hline & & & & & Lower & Upper & \\
\hline \multicolumn{8}{|l|}{ Scores on the DAT } \\
\hline Perceptual Ability & .166 & .212 & .618 & 1.181 & .780 & 1.788 & .432 \\
\hline Quantitative Reasoning & -.266 & .233 & 1.306 & .766 & .486 & 1.210 & .253 \\
\hline Reading Comprehension & -.063 & .218 & .083 & .939 & .613 & 1.440 & .774 \\
\hline Biology & -.396 & .240 & 2.707 & .673 & .420 & 1.079 & .100 \\
\hline General Chemistry & -.315 & .237 & 1.769 & .730 & .459 & 1.161 & .184 \\
\hline Organic Chemistry & -.434 & .248 & 3.060 & .648 & .399 & 1.054 & .080 \\
\hline Total Science & -.479 & .244 & 3.848 & .619 & .384 & 1.000 & .050 \\
\hline Academic Average & -.333 & .233 & 2.048 & .716 & .454 & 1.131 & .152 \\
\hline
\end{tabular}

Note. $B$ - Unstandardized regression coefficient; $B S E$ - Standard error of unstandardized regression coefficient; Wald $\chi^{2}$ - Wald statistic; $O R$ - Odds ratio; $C I$ - Confidence Interval. 


\section{Research Question 5}

Research question 5 was: Do the first-year and second-year dental program individual course grades and cumulative grade point averages predict the NBDE Part I outcome? Results from bivariate logistic regressions indicated that all but Dental Anatomy and Occlusion (laboratory) were significant predictors of the NBDE performance at $\alpha=.004$. Table 21 included coefficient for the constant $(B)$, standard error around the coefficient for the constant (BSE), Wald chi-square $\left(\chi^{2}\right)$, odds ratio, upper and lower bounds of $95 \%$ confidence interval of odds ratio, and $p$ values.

Table 21

Bivariate logistic regression models using dental program performance as predictors for NBDE failures

\begin{tabular}{|c|c|c|c|c|c|c|c|}
\hline & \multirow[b]{2}{*}{$B$} & \multirow[b]{2}{*}{$B S E$} & \multirow[b]{2}{*}{ Wald $\chi^{2}$} & \multirow[b]{2}{*}{$O R$} & \multicolumn{2}{|c|}{$95 \%$ CI OR } & \multirow[b]{2}{*}{$p$} \\
\hline & & & & & Lower & Upper & \\
\hline \multicolumn{8}{|l|}{ Individual course grades } \\
\hline Histology & -.867 & .246 & 12.401 & .420 & 259 & .681 & $.000^{*}$ \\
\hline Physiology & -1.147 & .245 & 21.964 & .318 & 197 & .513 & $.000^{*}$ \\
\hline Biochemistry & -.654 & .168 & 15.094 & .520 & .374 & .723 & $.000^{*}$ \\
\hline Survey of Dental Gross and Neuroanatomy & -1.046 & 248 & 17.790 & .351 & .216 & .571 & $.000 *$ \\
\hline Dental Anatomy and Occlusion (lecture) & -.882 & .177 & 24.746 & .414 & 292 & .586 & $.000 *$ \\
\hline Dental Anatomy and Occlusion (laboratory) & -.360 & .208 & 3.000 & .698 & .464 & 1.049 & .083 \\
\hline Preclinical Occlusion and TMD & -1.269 & .253 & 25.229 & .281 & 171 & .461 & $.000^{*}$ \\
\hline General Pathology & -1.350 & .300 & 20.230 & .259 & 144 & 467 & $.000 *$ \\
\hline Microbiology and Immunology & -.791 & .228 & 11.986 & .453 & 290 & .710 & $.001 *$ \\
\hline Oral Pathology & -.932 & .241 & 15.006 & .394 & 246 & .631 & $.000^{*}$ \\
\hline \multicolumn{8}{|l|}{ Cumulative GPA } \\
\hline First-year & -1.316 & .263 & 25.045 & .268 & .160 & .449 & $.000^{*}$ \\
\hline Second-year & -1.660 & .311 & 28.394 & .190 & 103 & .350 & $.000^{*}$ \\
\hline
\end{tabular}

Note. ${ }^{*}=p<.004 . B$ - Unstandardized regression coefficient; $B S E$ - Standard error of unstandardized regression coefficient; Wald $\chi^{2}$ - Wald statistic; $O R$ - Odds ratio; $C I$ - Confidence Interval.

Histology was a significant predictor of the NBDE performance $\left(\chi_{(1)}^{2}=14.201, p\right.$

$=.000$, and Nagelkerke's $R^{2}=.107$ ) at $\alpha=.004$ (Wald $\chi^{2}=12.401, p=.000$ ). The odds 
ratio for Histology was .420 (95\% CI: .259 - .681). The inversion of odds ratio of .420 was 2.381. This finding suggested that with one unit decrease in the Histology grade, dental students were 2.381 times more likely to fail the NBDE Part I. This model correctly predicted $100 \%$ of cases where the dental student passed the NBDE Part I and $0 \%$ of cases where the students failed the NBDE part I, giving an overall percentage correct prediction rate of $92.9 \%$.

Physiology was also a significant predictor of the NBDE performance $\left(\chi^{2}(1)=\right.$ 29.088, $p=.000$, and Nagelkerke's $R^{2}=.214$ ) at $\alpha=.004$ (Wald $\left.\chi^{2}=21.964, p=.000\right)$. The odds ratio for Physiology was .318 (95\% CI: .197 - .513). The inversion of odds ratio of .420 was 3.145. This finding suggested that with one unit decrease in the Physiology grade, dental students were 3.145 times more likely to fail the NBDE Part I. This model correctly predicted $100 \%$ of cases where the dental student passed the NBDE Part I and $4.3 \%$ of cases where the students failed the NBDE part I, giving an overall percentage correct prediction rate of $93.2 \%$. Likewise, Biochemistry was also a significant predictor of the NBDE performance $\left(\chi^{2}(1)=13.900, p=.000\right.$, and Nagelkerke's $\left.R^{2}=.105\right)$ at $\alpha$ $=.004\left(\right.$ Wald $\left.\chi^{2}=15.094, p=.000\right)$. The odds ratio for Biochemistry was $.520(95 \%$ CI: .374 - .723). The inversion of odds ratio of .520 was 1.923. This finding suggested that with one unit decrease in the Biochemistry grade, dental students were 1.923 times more likely to fail the NBDE Part I. This model correctly predicted $100 \%$ of cases where the dental student passed the NBDE Part I and $0 \%$ of cases where the students failed the NBDE part I, giving an overall percentage correct prediction rate of $92.9 \%$.

Survey of Dental Gross and Neuroanatomy was a significant predictor of the NBDE performance $\left(\chi_{(1)}^{2}=20.947, p=.000\right.$, and Nagelkerke's $\left.R^{2}=.156\right)$ at $\alpha=.004$ 
(Wald $\chi^{2}=17.790, p=.000$ ). The odds ratio for Survey of Dental Gross and Neuroanatomy was $.351(95 \% C I: .216-.571)$. The inversion of odds ratio of .351 was 2.849. This finding suggested that with one unit decrease in the Survey of Dental Gross and Neuroanatomy grade, dental students were 2.849 times more likely to fail the NBDE Part I. This model correctly predicted $100 \%$ of cases where the dental student passed the NBDE Part I and $0 \%$ of cases where the students failed the NBDE part I, giving an overall percentage correct prediction rate of $92.9 \%$. As a significant predictor $\chi^{2}(1)=$ 26.024, $p=.000$, and Nagelkerke's $\left.R^{2}=.192\right)$ at $\alpha=.004$ (Wald $\chi^{2}=24.746, p=.000$ ), the odds ratio for Dental Anatomy and Occlusion (lecture) was .414 (95\% CI: .292 - .586). The inversion of odds ratio of .414 was 2.415 . This finding suggested that with one unit decrease in the Dental Anatomy and Occlusion (lecture) grade, dental students were 2.415 times more likely to fail the NBDE Part I. This model correctly predicted 99.3\% of cases where the dental student passed the NBDE Part I and 13\% of cases where the students failed the NBDE part I, giving an overall percentage correct prediction rate of $93.2 \%$.

Preclinical Occlusion and TMD was also a significant predictor of the NBDE performance $\left(\chi^{2}(1)=29.925, p=.000\right.$, and Nagelkerke's $\left.R^{2}=.220\right)$ at $\alpha=.004$ (Wald $\chi^{2}=$ $25.229, p=.000)$. The odds ratio for Preclinical Occlusion and TMD was .281 (95\% $C I: .171-.461)$. The inversion of odds ratio of .281 was 3.559. This finding suggested that with one unit decrease in the Preclinical Occlusion and TMD grade, dental students were 3.559 times more likely to fail the NBDE Part I. This model correctly predicted $100 \%$ of cases where the dental student passed the NBDE Part I and $0 \%$ of cases where the students failed the NBDE Part I, giving an overall percentage correct prediction rate 
of $92.9 \%$. In addition, General Pathology was a significant predictor of the NBDE performance $\left(\chi^{2}(1)=26.921, p=.000\right.$, and Nagelkerke's $\left.R^{2}=.199\right)$ at $\alpha=.004$ (Wald $\chi^{2}=$ 20.230, $p=.000)$. The odds ratio for General Pathology was .259 (95\% CI: .144 - .467). The inversion of odds ratio of .259 was 3.861 . This finding suggested that with one unit decrease in the General Pathology grade, dental students were 3.861 times more likely to fail the NBDE Part I. This model correctly predicted $100 \%$ of cases where the dental student passed the NBDE Part I and $0 \%$ of cases where the students failed the NBDE part I, giving an overall percentage correct prediction rate of $92.9 \%$.

Likewise, Microbiology and Immunology was also a significant predictor of the NBDE performance $\left(\chi_{(1)}^{2}=13.065, p=.000\right.$, and Nagelkerke's $\left.R^{2}=.099\right)$ at $\alpha=.004$ (Wald $\chi^{2}=11.986, p=.001$ ). The odds ratio for Microbiology and Immunology was .453 (95\% CI: .290 - .710). The inversion of odds ratio of .453 was 2.208. This finding suggested that with one unit decrease in the Microbiology and Immunology grade, dental students were 2.208 times more likely to fail the NBDE Part I. This model correctly predicted $100 \%$ of cases where the dental student passed the NBDE Part I and $0 \%$ of cases where the students failed the NBDE part I, giving an overall percentage correct prediction rate of $92.9 \%$.

Oral Pathology was also a significant predictor of the NBDE performance $\left(\chi^{2}{ }_{(1)}=\right.$ $16.777, p=.000$, and Nagelkerke's $\left.R^{2}=.126\right)$ at $\alpha=.004\left(\right.$ Wald $\left.\chi^{2}=15.006, p=.000\right)$. The odds ratio for Oral Pathology was .394 (95\% CI: .246 - .631). The inversion of odds ratio of .394 was 2.538. This finding suggested that with one unit decrease in the Oral Pathology grade, dental students were 2.538 times more likely to fail the NBDE Part I. This model correctly predicted $100 \%$ of cases where the dental student passed the NBDE 
Part I and $0 \%$ of cases where the students failed the NBDE part I, giving an overall percentage correct prediction rate of $92.9 \%$.

As a significant predictor, First-year Cumulative GPA $\left(\chi^{2}{ }_{(1)}=32.601, p=.000\right.$, and Nagelkerke's $R^{2}=.239$ ) at $\alpha=.004$ (Wald $\chi^{2}=25.045, p=.000$ ). The odds ratio for First-year Cumulative GPA was .268 (95\% CI: .160 - .449). The inversion of odds ratio of .268 was 3.731. This finding suggested that with one unit decrease in the First-year Cumulative GPA, dental students were 3.731 times more likely to fail the NBDE Part I. This model correctly predicted $100 \%$ of cases where the dental student passed the NBDE Part I and 13\% of cases where the students failed the NBDE part I, giving an overall percentage correct prediction rate of 93.8\%. Lastly, Second-year Cumulative GPA was also a significant predictor of the NBDE performance $\left(\chi^{2}{ }_{(1)}=42.662, p=.000\right.$, and Nagelkerke's $R^{2}=.308$ ) at $\alpha=.004\left(\right.$ Wald $\left.\chi^{2}=28.394, p=.000\right)$. The odds ratio for Second-year Cumulative GPA was .190 (95\% CI: .103 - .350). The inversion of odds ratio of .190 was 5.263. This finding suggested that with one unit decrease in the Secondyear Cumulative GPA, dental students were 5.263 times more likely to fail the NBDE Part I. This model correctly predicted $100 \%$ of cases where the dental student passed the NBDE Part I and 13\% of cases where the students failed the NBDE Part I, giving an overall percentage correct prediction rate of $93.8 \%$.

\section{Summary of Results}

Chapter 4 presented the findings for the four research sub-questions and the overall focal research question for the study. Findings from this study showed that gender and race were significantly associated with the dental students' academic performance. At the undergraduate level, female students had significantly higher non-science and total 
GPAs, while male students had significantly higher scores on six out of eight standard scores the DAT. When in the dental program, male and female students performed approximately at the same level except in the General Pathology course. Female dental students performed significantly better than the male students in the General Pathology course. Gender, however, was not a significant predictor to the dental student's performance in the NBDE Part I. At the undergraduate level, White dental students performed significantly better than the Asian and URM students in the Science, Biology, Chemistry, Physics, and Total GPAs, while Asian and URM students performed similarly. White and Asian students had significantly higher scores on the DAT, when compared with the URM students. When in the dental program, White dental students significantly outperformed the Asian and URM students in the Physiology, Preclinical Occlusion and TMD, and Second-year Cumulative GPAs. However, race was not a significant predictor of the dental student's performance in the NBDE Part I.

Student's pre-program academic performance, DAT performance, and dental program performance were significantly associated with the NBDE Part I outcomes. At the undergraduate level, Science, Biology, Chemistry, Physics, and Total GPAs at the undergraduate level were significant predictors of the NBDE performance. Out of eight standard scores on the DAT, only Total Science score was significant predictor of the NBDE performance. While in the dental program, many course grades and cumulative GPAs were significant predictors of the NBDE performance, including Histology, Physiology, Biochemistry, Survey of Dental Gross and Neuroanatomy, Dental Anatomy and Occlusion (lecture), Preclinical Occlusion and TMD, General Pathology, Microbiology and Immunology, Oral Pathology, first-year cumulative GPA, and second- 
year cumulative GPA. Using the above results, Chapter 5 presents a discussion of the

findings, implications, and recommendations for further study. Table 22 summarizes the

key findings for each question.

Table 22

Summary of key findings

\begin{tabular}{|c|c|c|}
\hline Research Question & Variables & Summary \\
\hline \multirow[t]{6}{*}{1} & $\begin{array}{l}\text { Gender and Pre-program } \\
\text { Academic Performance }\end{array}$ & $\begin{array}{l}\text { Female dental students had significantly higher non- } \\
\text { science GPA. }\end{array}$ \\
\hline & Gender and DAT Performance & $\begin{array}{l}\text { Male dental students had significantly higher standard } \\
\text { scores of Perceptual Ability on the DAT. }\end{array}$ \\
\hline & $\begin{array}{l}\text { Gender and Dental Program } \\
\text { Academic Performance }\end{array}$ & $\begin{array}{l}\text { There were no significant gender differences in dental } \\
\text { students' performances on all individual course grades } \\
\text { and cumulative GPAs. }\end{array}$ \\
\hline & $\begin{array}{l}\text { Race and Pre-program } \\
\text { Academic Performance }\end{array}$ & $\begin{array}{l}\text { There were significant racial group differences with all } \\
\text { pre-program GPAs, except Non-science GPA. White } \\
\text { dental student performed better than the Asian and URM } \\
\text { students in Science, Biology, Chemistry, Physics, and } \\
\text { Total GPAs. }\end{array}$ \\
\hline & Race and DAT Performance & $\begin{array}{l}\text { There were significant racial group differences with all } \\
\text { eight standard scores on the DAT, except Perceptual } \\
\text { Ability. URM students had significantly lower scores } \\
\text { than the White or Asian dental students. }\end{array}$ \\
\hline & $\begin{array}{l}\text { Race and Dental Program } \\
\text { Academic Performance }\end{array}$ & $\begin{array}{l}\text { There was significant racial group difference with dental } \\
\text { students' performances on the Preclinical Occlusion and } \\
\text { TMD, and White dental students have significantly higher } \\
\text { scores than the Asian or URM dental students. }\end{array}$ \\
\hline 2 & $\begin{array}{l}\text { Gender, Race, and NBDE } \\
\text { performance }\end{array}$ & $\begin{array}{l}\text { Gender and race were not significant predictors of the } \\
\text { NBDE performance. }\end{array}$ \\
\hline 3 & $\begin{array}{l}\text { Pre-Program Academic } \\
\text { Performance and NBDE } \\
\text { performance }\end{array}$ & $\begin{array}{l}\text { GPAs at the undergraduate level were not significant } \\
\text { predictors of the NBDE performance. }\end{array}$ \\
\hline 4 & $\begin{array}{l}\text { DAT Performance and NBDE } \\
\text { performance }\end{array}$ & $\begin{array}{l}\text { Standard scores on the DAT were not significant } \\
\text { predictor of the NBDE performance. }\end{array}$ \\
\hline 5 & $\begin{array}{l}\text { Dental Program Performance } \\
\text { and NBDE performance }\end{array}$ & $\begin{array}{l}\text { Histology, Physiology, Biochemistry, Survey of Dental } \\
\text { Gross and Neuroanatomy, Dental Anatomy and } \\
\text { Occlusion (lecture), Preclinical Occlusion and TMD, } \\
\text { General Pathology, Microbiology and Immunology, Oral } \\
\text { Pathology, first-year cumulative GPA, and second-year } \\
\text { cumulative GPA were significant predictors of the NBDE } \\
\text { performance. }\end{array}$ \\
\hline
\end{tabular}




\section{CHAPTER V \\ DISCUSSION}

Using the independent $t$-tests and One-Way ANOVAs, this study tested the associations of student demographic characteristics (gender and race) with the preprogram academic performance, DAT performance, and dental program academic performance. In addition, using bivariate logistic regression, this study examined if various factors (demographic factors, pre-program academic performance, DAT performance, and dental program academic performance) were related to dental students' NBDE Part I performance at the first attempt. This chapter discussed the relevant and important conclusions found in the statistical analyses presented in Chapter IV. The chapter examined the key findings presented in Table 22, and compared the key findings with existing literature. The presentation of results is then followed by a discussion of the implications for practice and recommendations for future research and conclusions.

\section{Key Findings}

\section{Demographic Characteristics and Academic Performance}

Diversity in healthcare has become an important topic in academia and clinical practice to address health disparities. Different cultural identities, such as race, ethnicity, socioeconomic status, sexual orientation and identity, religion, and gender, may all influence patients' healthcare-seeking behaviors from diverse backgrounds. In dental 
education, the American Dental Association has included the recommendation for the dental curricula to incorporate the cultural competence. The Commission on Dental Accreditation (CODA) Standard 2-16 states, "graduates must be competent in managing a diverse patient population and have the interpersonal and communications skills to function successfully in a multicultural work environment" (American Dental Association, 2019a). The dental programs seek solutions to continuously and intentionally nurture diversity in the context of the dental education environment.

Gender gap in academic performance. The first key finding of this study is that there were significant gender differences with the student's academic achievement at the undergraduate level and the DAT. However, gender differences were not significant in the dental students' academic performances in the dental program. It was also not predictive of their NBDE Part I performance at the first attempt. Overall, based on the findings of this study, gender gap was more evident in the academic performance at the undergraduate level and the DAT; however, the gender gap diminished in the dental program academic performance and the NBDE Part I outcome.

In this study, female dental students had significantly higher non-science GPA at the undergraduate level than the male students. However, the male dental students had significantly higher Perceptual Ability scores on the DAT. One meta-analysis evaluated gender differences in their academic performance in elementary, middle, or high school or at the university level. It showed a consistent female advantage for all course content areas in the educational programs (Voyer \& Voyer, 2014). In contrast, male students significantly outperformed female students in all areas of DAT, except reading comprehension, biology, and organic chemistry (Behar-Horenstein et al., 2011; Fields et 
al., 2003). After entering the dental program, the results from this study showed the female students performed at similar levels with the male dental students during the first and second years in the dental program, and in the NBDE Part I. One previous study also showed that there was no significant gender difference in the NBDE Part I pass rate (Fields et al., 2003). However, a previous study demonstrated female dental students had significantly higher total entering GPAs and graduating GPAs than male dental students (Stewart et al., 2006).

The psychologists proposed different hypotheses for gender gaps on high-stakes examinations, such as DAT and NBDE. For example, self-efficacy expectations refer to a person's beliefs regarding his or her ability to perform a given task (Bandura, 1977). Applying the self-efficacy theory, female students often show lower self-esteem (Stewart et al., 2006). Female students tend to be more socially oriented in the learning strategies and the male students tend to be more independent. Female student may outperform the male students in the course grades because of their social collaborative skills and learning behaviors, whereas the male students may have advantages in independent standardized testing conditions (Choi \& Chang, 2011). When compared with objective faculty assessments, both male and female students underestimated their ability and female students demonstrated a higher degree of underestimation (Minter, Gruppen, Napolitano, \& Gauger, 2005). Especially in a male-dominated profession, the knowledge of cultural stereotypes could affect female student's performance in the high-stakes examinations (Steel, 1997). Maccoby concluded that men had better abilities in quantitative and visualspatial areas, while women exceeded verbal ability (Maccoby \& Jacklin, 1974). 
Even though the gender gap was not well-documented in the dental programs, many studies have shown the significant female advantage in other academic programs such as in elementary, middle, or high school or at the undergraduate level. The influence of stereotype threat could be a possible explanation of gender differences in school achievement. Starting from an early age, both boys and girls believe that adults expect girls to be better students than boys. The stereotype threat may affect expectancy for success, affecting higher effort and persistence from female students in the classroom (Hartley \& Sutton, 2013). Gender-differentiated parental encouragement has been shown to attribute to the generalized female advantage in the academic programs (Varner \& Mandara, 2014). This may also help explain the reduced gender gap in the academic achievement in the dental program, since the students in the professional schools, such as dental programs, are more independent and much less influenced by parental encouragement.

The association of race with academic performance. The second key finding of this study is that there were significant racial group differences with the student's academic achievement at the undergraduate level and the DAT, but the race was not predictive of their NBDE Part I performance at the first attempt. Regarding the students' performances in the dental program, only the course grade of Preclinical Occlusion and TMD showed significant differences between racial groups. Overall, based on the findings of this study, there was a significant race gap in the academic performance at the undergraduate level and the DAT; however, the race gap greatly decreased in the dental program academic and the NBDE Part I performance. More specifically, White students significantly outperformed Asian or URM students in the pre-program academic 
performance (Science, Biology, Chemistry, Physics, and Total GPAs) and dental program academic performance (Preclinical Occlusion and TMD). White and Asian students significantly outperformed URM students in all standard scores on the DAT, except Perceptual Ability scores.

Although the associations of the race with dental students' academic and licensure examination performances are scarce, the findings on the present study are consistent with what has been reported in the literature. The URM status is negatively associated with the students' performance in the dental program and but not the NBDE performance. A retrospective study reviewed eight classes from 2011 to 2018, comparing the top and bottom performing students in the dental program (Perez et al., 2018). A total of 174 students were included in the study to test the association of 21 predictor variables (such as scores on the DAT, GPAs at the undergraduate level, geographic backgrounds, and the participation of pipeline program) and binary outcomes of student performances on the academic rankings (top ten or bottom ten students in a class) and the need for the dental students to withdraw, be dismissed, enter a decompressed five-year curriculum. The results from this study suggested that URM status was related to low performance, and 35 of 38 URM students were in the low performing population. The URM status was a significant predictor for the students to be at the bottom ten in class rank, withdraw or be dismissed from a dental program, or voluntarily or involuntarily enter the five-year (reduced load) curriculum. Another study showed that race was not a significant predictor of the NBDE Part I outcome (Sabato, Perez, Jiang, \& Feldman, 2019).

No other studies reported the race gap in the dental students' DAT performance; however, one research has shown that the URM and socioeconomically disadvantaged 
applicants in the dental programs often reported a higher total number of employment hours and presented with lower undergraduate GPAs (Chaviano-Moran et al., 2019). The study focused on the demographic bias in selecting dental program candidates based on their undergraduate GPAs and DAT performance and found that undergraduate overall grade point average was the most decisive factor in selecting interview candidates. While there was no significant selection bias due to self-reported gender, the race was a significant factor in a disparity of dental program applicants' undergraduate GPAs. Regardless of students' socioeconomically disadvantaged status, the Asians and Caucasians interviewed and accepted to the dental program had similar ranges of undergraduate GPAs. In contrast, the URMs students' undergraduate GPAs skewed toward the lower range. The study concluded that in screening dental program's applicant pool, metrics-based candidate selection would favor those candidates in the 80th percentile of undergraduate GPA and Academic Average scores on the DAT, and the reliance on these two metrics will favor the majority, traditional, and non-URM applicants in the admission process.

\section{Significant Predictors of NBDE Part I Performance}

Predicting student performance in the licensure examination is an essential mission of dental programs. Although it remains a focus area in dental research, there is a shortage of studies focusing on this issue. Identifying poor-performing students in an academic program and licensure examination can allow educators to provide these at-risk students assistance and help prepare them for success. The present study examined the pre-program factors, scores on the DAT, and dental program factors as the possible predictors for student's NBDE Part I performance. 
Pre-program academic performance as predictors for NBDE Part I. The third key finding of this study was that GPAs at the undergraduate level were not significant predictors of the NBDE outcomes.

The predictive nature of pre-program academic performance on NBDE Part I is unclear from the literature. Sandow, Jones, Peek, Courts, and Watson (2002) examined the relationship between admission criteria and dental school performance at the University of Florida College of Dentistry (UFCD), and their findings were different than the present study. Dental students' science GPA at the undergraduate level showed a significant positive correlation with NBDE Part I performance $(r=.31, p<.05)$. The undergraduate science GPA was consistently the most important predictor for both NBDE Part I and Part II scores and dental school GPAs. The undergraduate non-science GPA showed no correlations with the NBDE performance and dental school GPAs (Sandow et al., 2002).

A few other studies showed similiar results when compared with this present study. Kingsley, Sewell, Ditmyer, O’Malley, and Galbraith (2007) investigated the relationship between admissions criteria (undergraduate science and cumulative GPAs) and academic success in the dental program (NBDE Part I results). This study showed that the undergraduate science and cumulative GPAs had non-significant, and weak to no associations with dental students' NBDE performance $(r=0.227$ and $r=0.222)$ (Kingsley et al., 2007). Hermesch, McEntire, Thomas, and Berrong (2005) also reported that undergraduate GPAs did not have strong correlations with the student's NBDE performance. This study set out to compare the dental school of the students accepted by the Dental Early Acceptance Program to those accepted by the standard admissions 
process. This study found that the undergraduate cumulative GPA only had weak correlations the NBDE Part I score ( $r=.39$ for early acceptance students, significant at $\alpha$ $=.05 ; r=.28$ for standard admissions students, significant at $\alpha=.05$ ) (Hermesch et al., 2005). In another study, Holmes, Doering, and Spector (2008) investigated the associations between admission criteria and dental school achievement measures. The NBDE Part I performance only moderately correlated with undergraduate science GPA ( $r$ $=0.527$, significant at $\alpha=.05)$, and overall predental GPA $(r=0.497$, significant at $\alpha$ $=.05)$ (Holmes et al., 2008).

Overall, the findings from this study suggested that GPAs at the undergraduate level were not significant predictors of the NBDE performance, and the predictive nature of pre-program academic performance on NBDE Part I remains inconsistent from literature.

DAT Performance as predictors for NBDE Part I. The fourth key finding of this study was that none of the scores on the DAT were the significant predictors of the NBDE performance. The scores on the DAT is one of the most studied predictors in dental education. Many studies tested the predictive validity of the scores on the DAT concerning dental students' NBDE performance and academic performance in the dental program. The finding from the present study is not consistent with what has been reported in the literature.

The findings from the American Dental Association found that the scores on the DAT have a significant positive relationship with the scores on the NBDE Part I performance (American Dental Association, 2009). Holmes, Doering, and Spector (2008) investigated five preadmission credentials (Academic Average, Perceptual Ability, and 
Total Science scores on the DAT, and undergraduate science and total GPAs) and five measures of dental school achievement (including the NBDE performance). The results showed that the NBDE Part I performance was moderately correlated with DAT Academic Average score $(r=0.610$, significant at $\alpha=.05)$, DAT Total Science score $(r=$ 0.582 , significant at $\alpha=.05$ ), and weakly correlated with the DAT Perceptual Ability score $(r=0.363$, significant at $\alpha=.05)$ (Holmes et al., 2008). Another study used multiple regression to examine the relationships between NBDE Part I performance in each of the basic science areas and the scores on the DAT. The Perceptual Ability and General Chemistry scores were not significant predictors of NBDE Part I performance, and the Reading Comprehension score was the most consistent predictor (De Ball et al., 2002). Bergman, Susarla, Howell, and Karimbux (2006) also found that the Reading Comprehension score was the most consistent predictor for the NBDE Part I performance. However, the results from this study suggested that the scores on the DAT only accounted for a small percentage of variance in different subsets of scores from the NBDE Part I, including $6 \%$ for anatomical sciences $\left(R^{2}=.06\right), 8 \%$ for biochemistry and physiology $\left(R^{2}=.08\right), 11 \%$ for microbiology and pathology $\left(R^{2}=.11\right)$, and $10 \%$ for dental anatomy and occlusion $\left(R^{2}=.10\right)$ (Bergman et al., 2006).

Overall, the finding from this study suggested that none of the scores on the DAT were the significant predictors of the NBDE performance. Although the predictive nature of the scores on the DAT has been confirmed in the literature, different findings from the present study suggest that replicating the study in different schools (such as public versus private programs or nonmetropolitan versus metropolitan) may be necessary to provide 
additional information as to whether the results from individual studies can be generalized across all dental schools (Bergman et al., 2006).

Dental program academic performance as predictors for NBDE Part I. The fifth key finding of this study was that among all tested dental program academic performance (individual course grades and cumulative GPAs), only Dental Anatomy and Occlusion (laboratory) was not a significant predictor of the NBDE performance. Even though far fewer studies in dentistry have examined dental program academic factors' ability to predict student success on the NBDE Part I, the results from the present study seem to be consistent with the literature.

Holmes, Doering, and Spector (2008) examined the correlation among various measures of dental school achievement, including (NBDE Part I and Part II performance, overall dental school GPA, final clinical grade, and pass/fail of the Central Regional Dental Testing Service licensure examination on the first attempt). The results showed that the overall dental school GPA was strongly correlated with NBDE Part I ( $r=0.757$, significant at $\alpha=.05$ ) (Holmes et al., 2008). In another study, the academic performance of dental students admitted through the early acceptance program (DEAP program) was compared to the students accepted through the standard, competitive admission process. For all dental students, the dental school GPA was found to be strongly correlated with scores on NBDE Part I performance ( $r=0.74$ for Early Acceptance students, significant at $\alpha=.05 ; r=0.60$ for standard admissions students, significant at $\alpha=.05$ ) (Hermesch et al., 2005).

\section{Implications for Practice}


Admission to a dental program is a competitive process, and the admission process is often designed to predict an applicant's potential for academic performance in the dental programs. Dental program admission committees may consider demographic factors, pre-program academic performance, DAT performance in the decision process to accept the most suitable candidates. With the increasingly diverse patient population, a diverse dental program can provide a better educational experience for all students and lead to better access to healthcare for patients. While the financial status and the lack of dental insurance are the primary barriers for accessing oral healthcare, a variety of other social determinants, such as race, ethnicity, socioeconomic status, sexual orientation and identity, religion, and gender, can exacerbate disparities in oral health. Multiple barriers have been proposed as the limiting factors to provide quality care to individuals from culturally diverse backgrounds. Following the Accreditation Standards for Predoctoral Dental Education Programs, dental programs have different policies to engage in ongoing systematic and focused efforts to attract and retain students, faculty, and staff from diverse backgrounds.

The first important implication for practice is that there were significant gender and race differences with dental students' pre-program academic performance and DAT performance. Guided by the findings of this study, the educators and administrators in the dental program should continuously evaluate the admission criteria, and provide applicants with different demographic background equitable access to dental program acceptance. In particular, the gender and race gaps in the academic achievements were more extensive at the undergraduate level and scores on the DAT. The gender and race gaps diminished in the dental program and the NBDE performance. The findings suggest 
that dental students with different gender and racial backgrounds all have the potential to be successful in a dental program once admitted. The admission criteria limited to the undergraduate GPA and scores on the DAT may unintentionally eliminate viable candidates with different demographic backgrounds. Diversity should be continuously and intentionally nurtured in the context of the dental education environment. While each dental school has unique historical and geographic aspects, dental schools should consider the strategies to recruit students from diverse backgrounds and foster their professional development throughout the dental program. A number of approaches could assist in this recruitment. For example, dental schools might consider the pipeline programs and partner with undergraduate colleges that have large numbers of URM. These would include Historically Black Colleges and Universities (HBCUs) and Hispanic-Serving Institutions. Such partnerships could include links to college departments in the physical and biological sciences-so that URM students majoring in those fields are aware of opportunities for enrolling in dental school and the satisfactions of a career in dentistry.

Dental students are required to challenge the licensure examinations to practice dentistry successfully. The failed attempt by candidates on the licensure examinations will consume additional resources and create additional financial burdens for the students, faculty, and dental school administrators. Educators and administrators must recognize the risk factors associated with NBDE performance to facilitate early identification and intervention for at-risk dental students. The findings from this study can assist faculty and administrators in identifying the predictors of NBDE Part I performance throughout the first and second year of the dental curriculum, and aid in 
identifying existing students at-risk for NBDE Part I failure at the first attempt. Guided by the findings of this study, the dental program can be structured to have performance benchmarks starting at program admission and continuing through the end of the second year.

For instance, the strongest predictors from the dental program performance (Preclinical Occlusion and TMD, Dental Anatomy and Occlusion - lecture, Physiology, and First-year and Second-year cumulative GPAs) can be used at performance benchmarks. Using the means and standard deviations obtained from this study, the students who receive the scores at one standard deviation below the means may be considered at-risk students who may fail the NBDE at the first attempt. The benchmarks for the students who at-risk failing NBDE can be set at Preclinical Occlusion and TMD course grade of C, Dental Anatomy and Occlusion - lecture course grade of C, Physiology course grade of C, First-year cumulative GPA of 3.14, and Second-year cumulative GPA of 3.03. The performance benchmarks would help identify at-risk students early and provide them with additional academic support. After identifying atrisk students, they can participate in the supplemental programs to improve their academic performance and remediate the deficiencies. Through early detection of at-risk students, educators and administrators can increase the pass rate of licensure examination and decrease student attrition due to poor academic performance. The findings from this study can provide evidence for the dental programs' effectiveness on the curriculum and if specific courses in the dental program align with the content of licensure examination.

Similar to the NBDE Part I, NBDE Part II is part of the licensure examinations developed by the Joint Commission on National Dental Examination (JCNDE) to 
determine the qualifications of individuals who seek licensure to practice dentistry. NBDE Part I and Part II assess the ability to understand important information from the biomedical and dental sciences and apply it in a problem-solving context (Joint Commission on National Dental Examination, 2020a). The current format allows the dental students to be qualified and challenged the NBDE Part I by the end of the secondyear dental curriculum and the NBDE Part II during their fourth-year dental program. The NBDE Part I focuses on examining students' basic science knowledge, and the NBDE Part II contains the test items concentrating on the clinical disciplines and patient management. A new examination format (INBDE) with the integration of NBDE Parts I and II will be implemented shortly. It will be designed to integrate the biomedical, clinical, and behavioral sciences in its evaluation of candidates' dental cognitive skills. The INBDE contains 56 Clinical Content (CC) areas and 10 Foundation Knowledge (FK) areas (Joint Commission on National Dental Examination, 2020b). Same content domains from NBDE Part I are integrated into the INBDE. While this study examined the predictors for the NBDE Part I, the findings could provide valid information to prepare the students for the INBDE until new studies can investigate the predictors for INBDE performance. Following the current research design, demographic data from the new student cohorts, their academic achievements, and licensure examination performance on the INBDE can be analyzed to prepare dental students better to be successful.

\section{Implications for Research}

This study provides an examination and addition of existing literature and knowledge on predicting NBDE Part I performance. However, additional research is warranted to test the literature gap in predicting student's success in the dental program: 
1. The study population was a convenience sample from a single dental program at a large, public university located in an urban setting within the southeast region of the US. A study with a larger sample size from dental programs in various US regions can further improve the generalizability of the study results.

2. Additional predictors, including non-cognitive factors, student affective factors, professional integration factors, personality traits, and psychological outcomes, can be investigated to assist the educators in developing admission selection criteria to admit candidates who are most likely to be successful.

3. Due to the small number of URM and Asian students in the sample, future studies exploring how prediction models may vary based on race would be prudent. With a growing diverse student body, a larger sample of URM and Asian students is recommended for future study to explore group differences in the academic outcomes. This could provide meaningful evidence to improve the admission process and education program further.

4. Supplemental education programs can be designed to support equity for the diverse student body. Using this research as a foundation to evaluate admission criteria and dental curriculum, additional enrichment programs for URM students can be established and prospectively examined to maximize the future success of the enrolled diverse student body. 
5. After the early identification of at-risk students, these students should participate in the structured supplemental or interventional programs to improve their academic performance. Additional research can be conducted to evaluate the program outcomes and examine the supplemental or interventional programs' effectiveness.

6. The study was limited to examine the predictors of NBDE Part I. A longitudinal study of multiple student cohorts can be studied to explore the predictors for other student success landmarks, such as performance in the regional clinical licensure examination, acceptance into the graduate specialty programs, post-graduation work placement, and satisfaction, or long-term professional achievement.

7. The evolving nature of the education environment, student population, and licensure examination format and content require continuous efforts to establish current and timely information for accurate student success prediction. Similar research can be conducted yearly to examine the effectiveness of admission criteria and dental program curriculum. Furthermore, after implementing a new examination format (INBDE), future research should be conducted to assess the predictors for the latest licensure examination.

\section{Conclusion}

Dental students are required to challenge the different licensure examinations to practice dentistry successfully, and the NBDE is an essential step toward that goal. Numerous failed attempts by candidates on the NBDE may threaten the viability of a 
dental program and consume additional resources for students, faculty, and dental school administrators, preparing them to re-challenge the examination. Despite the fact that the new examination format (INBDE) with the integration of NBDE Parts I and II will be implemented in the near future, however, research and analysis for INBDE will not be available immediately. The same content domains will still be incorporated into the examination. The findings from this study could still provide valid information to prepare the students for the INBDE until new studies can be conducted to investigate the predictors for INBDE performance. The focus of this study aimed to study the relationships among the demographic factors, DAT factors, pre-program academic factors, dental program academic factors, and the students' NBDE Part I performance. In addition, this study aimed to examine the relationships between students' demographic characteristics and their academic and the NBDE Part I performances. The researcher utilized a retrospective, correlational design to explore significant predictors.

This study's results showed that there were gender and race gaps in the students' academic performances. Overall, the gender and race gaps were more significant at the undergraduate level, and the DAT performance and the gaps diminished in the dental program academic and the NBDE Part I performance. The educators and administrators in the dental program could develop holistic admission criteria to provide applicants with diverse demographic background equitable access to dental program acceptance. The findings suggest that dental students with different gender and race backgrounds all have the potential to be successful in a dental program once admitted.

The study results also revealed the predictors of NBDE Part I outcomes. Students' demographic backgrounds, pre-program academic performance, and the scores on the 
DAT were not significant predictors of the NBDE outcomes. In the dental program, many course grades and cumulative GPAs were all significant predictors of the NBDE performance, such as Histology, Physiology, Biochemistry, Survey of Dental Gross and Neuroanatomy, Dental Anatomy and Occlusion (lecture), Preclinical Occlusion and TMD, General Pathology, Microbiology and Immunology, Oral Pathology, first-year cumulative GPA, and second-year cumulative GPA.

Guided by this research, educators can establish different benchmarks in the dental program to identify students at risk of NBDE failures and enroll them in the supplemental intervention academic programs. Even though the study was limited to a large, public dental program in a metropolitan setting, the findings can provide the initial framework for understanding NBDE performance across program types and geographic locations. Future studies can be conducted in multiple dental programs with a larger sample size, after the implementation of new INBDE examination, or with the inclusion of additional predictors to further improve the generalizability of the study results. 


\section{REFERENCES}

Abdi, H. (2007). Bonferroni and Šidák corrections for multiple comparisons. Encyclopedia of measurement and statistics, 3, 103-107.

American Dental Association. (2009). Dental Admission Testing Program User's Manual. American Dental Association, Joint Commission on National Dental Examinations. http://www.ada.org/ /media/ADA/Education\%20and\%20Careers/ Files/dat_users_manual.pdf?la=en

American Dental Association. (2017a). Dental Admission Test (DAT) 2017 Program Guide. American Dental Association, Joint Commission on National Dental Examinations. https://www.ada.org/en/education-careers/dental-admissiontest/dat-guide

American Dental Association. (2017b). State Licensure for US Dentists. American Dental Association. https://www.ada.org/en/education-careers/licensure/state-dentallicensure-for-us-dentists

American Dental Association. (2018). 2017-18 Survey of Dental Education - Report 2. American Dental Association, Commission on Dental Accreditation. https:// www.ada.org/ /media/ADA/Science\%20and\%20Research/HPI/Files/SDE2_2017 $-18 . x 1 s x$

American Dental Association. (2019a). Accreditation Standards for Dental Education Programs. American Dental Association, Commission on Dental Accreditation. http://www.ada.org/ /media/CODA/Files/predoc.ashx 
American Dental Association. (2019b). Dental School Admissions. American Dental Association. https://www.ada.org/en/education-careers/careers-in-dentistry/be-adentist/applying-for-dental-school

American Dental Association. (2019c). Education. American Denta Association. https://www.ada.org/en/science-research/health-policy-institute/dentalstatistics/education

American Dental Association. (2020). Dental Admission Test (DAT) Validity Study: 2016-2018 Data. American Dental Association, Joint Commission on National Dental Examinations. http://www.ada.org/ /media/ADA/Education\%20and\% 20Careers/Files/dat_validity_study.pdf?la=en

American Dental Education Association. (2002). Competencies for the new dentist. The Journal of Dental Education, 66(7), 849-851.

American Dental Education Association. (2019a). Chapter 2: Why Diversity Matters. American Dental Education Association. https://www.adea.org/dental_education _pathways/AFASA/transforming/Pages/Ch2studentDiversity.aspx

American Dental Education Association. (2019b). Education debt. American Dental Education Association. https://www.adea.org/GoDental/Money_Matters/ Educational_Debt.aspx

American Dental Education Association. (2020). Time to Apply. American Dental Education Association. https://www.adea.org/GoDental/Application_Prep/ The_Admissions_Process/Timeline_to_apply.aspx American Educational Research Association, American Psychological Association, \& National Council on Measurement in Education. (2014). The standards for 
educational and psychological testing: Washington, DC : American Educational Research Association.

American Student Dental Association. (2017). Taking the NBDE Parts I and II. American Student Dental Association. https://www.asdanet.org/index/dentalstudent-resources/taking-the-nbde-parts-i-and-ii

Andriole, D. A., \& Jeffe, D. B. (2010). Prematriculation variables associated with suboptimal outcomes for the 1994-1999 cohort of US medical school matriculants. JAMA, 304(11), 1212-1219.

Astin, A. W. (1968). Undergraduate achievement and institutional "excellence.". Science, 161(3842), 661-668.

Astin, A. W. (1993). Assessment for excellence: The philosophy and practice of assessment and evaluation in higher education. Phoenix, AZ: Oryx Press.

Astin, A. W., \& Antonio, A. L. (2012). Assessment for excellence: The philosophy and practice of assessment and evaluation in higher education. Lanham, MD: Rowman \& Littlefield Publishers.

Astin, A. W., \& Sax, L. J. (1998). How undergraduates are affected by service participation. Service Participation, 39(3), 251.

Austin, P. C., \& Steyerberg, E. W. (2015). The number of subjects per variable required in linear regression analyses. Journal of clinical epidemiology, 68(6), 627-636.

Bandura, A. (1977). Self-efficacy: toward a unifying theory of behavioral change. Psychological review, 84(2), 191.

Barr, D. A. (2017). Gender differences in medicine-from medical school to medicare. Paper presented at the Mayo Clinic Proceedings. 
Behar-Horenstein, L., Garvan, C. W., Bowman, B., Bulosan, M., Hancock, S., Johnson, M., \& Mutlu, B. (2011). Cognitive and learning styles as predictors of success on the National Board Dental Examination. The Journal of Dental Education, 75(4), $534-543$.

Bergman, A. V., Susarla, S. M., Howell, T. H., \& Karimbux, N. Y. (2006). Dental Admission Test scores and performance on NBDE Part I, revisited. The Journal of Dental Education, 70(3), 258-262.

Bewick, V., Cheek, L., \& Ball, J. (2005). Statistics review 14: Logistic regression. Critical Care, 9(1), 112.

Birnbaum, O. (1962). Equal Employment Opportunity and Executive Order 10925. University of Kansas Law Review, 11, 17.

Bolarinwa, O. A. (2015). Principles and methods of validity and reliability testing of questionnaires used in social and health science researches. Nigerian Postgraduate Medical Journal, 22(4), 195.

Braxton, J. M., Shaw Sullivan, A. V., \& Johnson, R. M. (1997). Appraising Tinto's theory of college student departure. Appraising Tinto's theory of college student departure Volume XII, 107-164.

Brooks, G. P., \& Johanson, G. A. (2011). Sample size considerations for multiple comparison procedures in ANOVA. Journal of Modern Applied Statistical Methods, 10(1), 10.

Carnevale, A. P., Smith, N., Gulish, A., \& Beach, B. H. (2012). Healthcare. Georgetown University Center on Education and the Workforce. 
Chaviano-Moran, R., Chuck, E., \& Perez, H. (2019). Unintended demographic bias in GPA/DAT-based pre-admission screening: an argument for holistic admissions in dental schools. The Journal of Dental Education, 83(11), 1280-1288.

Choi, N., \& Chang, M. (2011). Interplay among School Climate, Gender, Attitude toward Mathematics, and Mathematics Performance of Middle School Students. Middle Grades Research Journal, 6(1), 15-28.

Cohen, J. (1988). Statistical power analysis for the behavioral sciences: Academic press.

Cooper, L. A., Beach, M. C., Johnson, R. L., \& Inui, T. S. (2006). Delving below the surface. Journal of General Internal Medicine, 21(1), 21-27.

Cooper, L. A., \& Roter, D. L. (2003). Patient-provider communication: the effect of race and ethnicity on process and outcomes of healthcare. Unequal treatment: Confronting racial and ethnic disparities in health care, 552-593.

Courvoisier, D. S., Combescure, C., Agoritsas, T., Gayet-Ageron, A., \& Perneger, T. V. (2011). Performance of logistic regression modeling: beyond the number of events per variable, the role of data structure. Journal of clinical epidemiology, 64(9), 993-1000.

Creswell, J. W. (2012). Educational research: Planning, conducting, and evaluating quantitative and qualitative research (4th ed.). Upper Saddle River, NJ: Merrill. Cronbach, L. J. (1951). Coefficient alpha and the internal structure of tests. Psychometrika, 16(3), 297-334.

Davis, D., Dorsey, J. K., Franks, R. D., Sackett, P. R., Searcy, C. A., \& Zhao, X. (2013). Do racial and ethnic group differences in performance on the MCAT exam reflect test bias? Academic Medicine, 88(5), 593-602. 
De Ball, S., Sullivan, K., Horine, J., Duncan, W. K., \& Replogle, W. (2002). The relationship of performance on the dental admission test and performance on Part I of the National Board Dental Examinations. The Journal of Dental Education, $66(4), 478-484$.

DeWald, J. P., Gutmann, M. E., \& Solomon, E. S. (2004). Effect of grade point average and enrollment in a dental hygiene National Board review course on student performance on the National Board Examination. The Journal of Dental Education, 68(1), 77-80.

Donoff, R. B. (2006). It is time for a new Gies report. The Journal of Dental Education, 70(8), 809-819.

Dworkin, S. (1970). Dental aptitude test as performance predictor over four years of dental school: analyses and interpretations. The Journal of Dental Education, $34(1), 28-38$.

Evans, J. D. (1996). Straightforward statistics for the behavioral sciences. Pacific Grove, CA: Brooks/Cole Publishing.

Ferguson, E., James, D., \& Madeley, L. (2002). Factors associated with success in medical school: systematic review of the literature. BMJ, 324(7343), 952-957.

Field, M. J. (1995). Dental education at the crossroads: challenges and change: National Academies Press.

Fields, H. W., Fields, A. M., \& Beck, F. M. (2003). The impact of gender on high-stakes dental evaluations. The Journal of Dental Education, 67(6), 654-660. 
Flexner, A. (1910). Medical education in the United States and Canada: a report to the Carnegie Foundation for the Advancement of Teaching: Carnegie Foundation for the Advancement of Teaching.

Geis, W. J. (1926). Dental education in the United States and Canada; a report to the Carnegie Foundation for the Advancement of Teaching. New York: The Carnegie Foundation for the Advancement of Teaching.

Ginley, T. J. (1966). Present status and future plans of the dental aptitude testing program. The Journal of Dental Education, 30(2), 163-174.

Glazer, G., Bankston, K., Clark, A., \& Ying, J. (2014). Holistic Admissions in Health Professions: Findings from a National Survey. Urban Universities for Health Report.

Gohara, S., Shapiro, J. I., Jacob, A. N., Khuder, S. A., Gandy, R. A., Metting, P. J., . . Kleshinski, J. (2011). Joining the Conversation: Predictors of Success on the United States Medical Licensing Examinations (USMLE). Learning Assistance Review, 16(1), 11-20.

Gray, S. A., Deem, L. P., \& Straja, S. R. (2002). Are traditional cognitive tests useful in predicting clinical success? The Journal of Dental Education, 66(11), 1241-1245.

Hartley, B. L., \& Sutton, R. M. (2013). A stereotype threat account of boys' academic underachievement. Child Development, 84(5), 1716-1733.

Hazra, A., \& Gogtay, N. (2016). Biostatistics series module 3: comparing groups: numerical variables. Indian Journal of Dermatology, 61(3), 251. 
Hermesch, C. B., McEntire, J. F., Thomas, D. D., \& Berrong, J. (2005). Outcome assessment of the dental early acceptance program. The Journal of Dental Education, 69(11), 1238-1241.

Hernandez, J., \& Kumar, A. (2018). A Preliminary Review of Diversity in the Healthcare Workplace. Asian Journal of Medicine and Health, 1-6.

Hoekstra, R., Kiers, H., \& Johnson, A. (2012). Are assumptions of well-known statistical techniques checked, and why (not)? Frontiers in Psychology, 3, 137.

Holmes, D. C., Doering, J. V., \& Spector, M. (2008). Associations among predental credentials and measures of dental school achievement. The Journal of Dental Education, 72(2), 142-152.

House, J. D. (1999). The effect of entering characteristics and instructional experiences on student satisfaction and degree completion and degree completion: An application. International Journal of Instructional Media, 26(4), 423.

Jeffreys, M. R. (2015). Jeffreys's Nursing Universal Retention and Success model: overview and action ideas for optimizing outcomes A-Z. Nurse Education Today, $35(3), 425-431$.

Joint Commission on National Dental Examination. (2016). Technical Report National Board Dental Examinations. American Dental Association, Joint Commision on National Dental Examininations. http://www.ada.org/en/jcnde/newsresources/technical-reports

Joint Commission on National Dental Examinations. (2017a). National Board Dental Examination, Part I 2017 Guide. American Dental Association, Joint Commision 
on National Dental Examininations. http://www.ada.org/ /media/JCNDE/pdfs/ nbde01_examinee_guide.pdf?la=en

Joint Commission on National Dental Examinations. (2017b). National Board Dental Examination, Part II 2017 Guide. American Dental Association, Joint Commision on National Dental Examininations. http://www.ada.org/ /media/JCNDE/pdfs/ nbde02_examinee_guide.pdf?la=en

Joint Commission on National Dental Examinations. (2018). Technical Report National Board Dental Examinations. American Dental Association, Joint Commision on National Dental Examininations. https://www.ada.org/ /media/JCNDE/pdfs/ NBDE_Technical_Rpt.pdf?la=en

Joint Commission on National Dental Examinations. (2020a). National Board Dental Examination, Part II 2020 Candidate Guide. American Dental Association, Joint Commision on National Dental Examininations. https://www.ada.org/ /media/ JCNDE/pdfs/nbde02_examinee_guide.pdf?la=en

Joint Commission on National Dental Examinations. (2020b). Integrated National Board Dental Examination (INBDE) 2020 Candidate Guide. American Dental Association, Joint Commision on National Dental Examininations. https:// www.ada.org/ /media/JCNDE/pdfs/INBDE_Guide.pdf?la=en

Kassebaum, D. K., \& Tedesco, L. A. (2017). The 21st-Century Dental Curriculum: A Framework for Understanding Current Models. The Journal of Dental Education, 81(8), eS13-eS21.

Keppel, G. (1991). Design and analysis: A researcher's handbook: Prentice-Hall, Inc. 
Kim, M., \& Lee, J. I. (2007). Variables predicting students' first semester achievement in a graduate-entry dental school in Korea. The Journal of Dental Education, 71(4), $550-556$.

Kingsley, K., Sewell, J., Ditmyer, M., O’Malley, S., \& Galbraith, G. M. (2007). Creating an evidence-based admissions formula for a new dental school: University of Nevada, Las Vegas, School of Dental Medicine. The Journal of Dental Education, 71(4), 492-500.

Kramer, G. A. (1986). Predictive validity of the dental admission test. The Journal of Dental Education, 50(9), 526-531.

Kramer, G. A., \& DeMarais, D. R. (1986). Trends in academic qualifications and performance of dental students. J Dent Educ, 50(4), 213-220.

Kramer, G. A., \& DeMarais, D. R. (1992). Reliability and validity of the pilot National Board Dental Examination. The Journal of Dental Education, 56(4), 236-241.

Kramer, G. A., \& Neumann, L. M. (2003). Confirming the validity of Part II of the National Board Dental Examinations: a practice analysis. The Journal of Dental Education, 67(12), 1286-1298.

Kuder, G. F., \& Richardson, M. W. (1937). The theory of the estimation of test reliability. Psychometrika, 2(3), 151-160.

Kuh, G. D., Kinzie, J. L., Buckley, J. A., Bridges, B. K., \& Hayek, J. C. (2006). What matters to student success: A review of the literature (Vol. 8): National Postsecondary Education Cooperative Washington, DC. 
Lacy, E. S., McCann, A. L., Miller, B. H., Solomon, E., \& Reuben, J. S. (2012). Achieving student diversity in dental schools: a model that works. The Journal of Dental Education, 76(5), 523-533.

Maccoby, E., \& Jacklin, C. (1974). Jacklin CN: The Psychology of Sex Differences: Stanford, CA: Stanford University Press.

McCluggage, R. W. (1959). A history of the American Dental Association: a century of health service: American Dental Association.

McHugh, M. L. (2011). Multiple comparison analysis testing in ANOVA. Biochemia medica: Biochemia medica, 21(3), 203-209.

Messick, S. (1995). Validity of psychological assessment: Validation of inferences from persons' responses and performances as scientific inquiry into score meaning. American Psychologist, 50(9), 741.

Minter, R. M., Gruppen, L. D., Napolitano, K. S., \& Gauger, P. G. (2005). Gender differences in the self-assessment of surgical residents. The American Journal of Surgery, 189(6), 647-650.

Munson, B., \& Vujicic, M. (2018). Supply of Full-Time Equivalent Dentists in the U.S. Expected to Increase Steadily. Retrieved from https://www.ada.org/ /media/ADA/Science\%20and\%20Research/HPI/Files/HPIB rief_0718_1.pdf?la=en

Nick, T. G. (2007). Descriptive statistics Topics in biostatistics (pp. 33-52): Springer.

Osborne, J. W. (2015). Best practices in logistic regression. Thousand Oaks, CA: Sage Publications. 
Peduzzi, P., Concato, J., Kemper, E., Holford, T. R., \& Feinstein, A. R. (1996). A simulation study of the number of events per variable in logistic regression analysis. Journal of Clinical Epidemiology, 49(12), 1373-1379.

Perez, H. L., Sabato, E. H., Jiang, S., \& Feldman, C. A. (2018). The effect of undergraduate coursework on students' performance in the first year at a US dental school. The Journal of Dental Education, 82(9), 936-942.

Pew Charitable Trusts. (2015). Federal and state funding of higher education: A changing landscape: Author Washington, DC.

Prideaux, D., Roberts, C., Eva, K., Centeno, A., Mccrorie, P., Mcmanus, C., Wilkinson, D. (2011). Assessment for selection for the health care professions and specialty training: consensus statement and recommendations from the Ottawa 2010 Conference. Medical Teacher, 33(3), 215-223.

Ranney, R. R., Wilson, M. B., \& Bennett, R. B. (2005). Evaluation of applicants to predoctoral dental education programs: review of the literature. The Journal of Dental Education, 69(10), 1095-1106.

Raphel, A. (2015, December 9). Affirmative action in university admissions: Research roundup. Journalist's Resource. https://journalistsresource.org/studies/society/ race-society/affirmative-action-in- university-admissions-research-roundup/

Sabato, E. H., Perez, H. L., Jiang, S., \& Feldman, C. A. (2019). Elements of undergraduate education related to students' academic performance in the first year of dental school. The Journal of Dental Education, 83(5), 510-520. 
Sandow, P. L., Jones, A. C., Peek, C. W., Courts, F. J., \& Watson, R. E. (2002). Correlation of admission criteria with dental school performance and attrition. The Journal of Dental Education, 66(3), 385-392.

Sawair, F. A., Baqain, Z. H., Al-Omari, I. K., Wahab, F. K., \& Rajab, L. D. (2009). Effect of gender on performance of undergraduate dental students at the University of Jordan, Amman. The Journal of Dental Education, 73(11), 13131319.

Schober, P., Boer, C., \& Schwarte, L. A. (2018). Correlation coefficients: appropriate use and interpretation. Anesthesia \& Analgesia, 126(5), 1763-1768.

Sesate, D. B., Milem, J. F., McIntosh, K. L., \& Bryan, W. P. (2017). Coupling admissions and curricular data to predict medical student outcomes. Research in Higher Education, 58(3), 295-312.

Sinkford, J. C., \& Valachovic, R. W. (2003). Affirmative action: essential to achieving justice and good health care for all in America. The Journal of Dental Education, $67(4), 468-472$.

Smithers, S., Catano, V., \& Cunningham, D. (2004). What predicts performance in Canadian dental schools? The Journal of Dental Education, 68(6), 598-613.

Sperandei, S. (2014). Understanding logistic regression analysis. Biochemia medica: Biochemia medica, 24(1), 12-18.

Steel, C. (1997). A Threat in the Air: How Stereotypes Affect Identity Identity and Achievement. American Psychologist, 52(6), 613-629. 
Stewart, C. M., Bates, R. E., Smith, G. E., \& Young, L. (2006). Impact of gender on dental state licensure examination performance. The Journal of Dental Education, $70(5), 525-530$.

Supreme Court of the United States. (2016). Fisher v. University of Texas at Austin, June $23,2016$.

Szumilas, M. (2010). Explaining odds ratios. Journal of the Canadian Academy of Child and Adolescent Psychiatry, 19(3), 227.

Thomas, B. R., \& Dockter, N. (2019). Affirmative action and holistic review in medical school admissions: Where we have been and where we are going. Academic Medicine, 94(4), 473-476.

Thurmond, V. A., \& Popkess-Vawter, S. (2003). Examination of a middle range theory: Applying Astin's input-environment-outcome (IEO) model to web-based education. Online Journal of Nursing Informatics, 7(2), 1-11.

Tinto, V. (1975). Dropout from higher education: A theoretical synthesis of recent research. Review of Educational Research, 45(1), 89-125.

Truman, M. (2012). Identifying predictors of National Council Licensure Examination for Registered Nurses (NCLEX-RN) success in an associate degree nursing program. International Journal of Applied Science and Technology, 2(7).

Tsai, T.-H., Neumann, L. M., \& Littlefield, J. H. (2012). Validating the standard for the national board dental examination part II. The Journal of Dental Education, 76(5), $540-544$.

U.S. News \& World Report L.P. (2019). Dentist Ranks Among Best Jobs of 2019. Retrieved from https://money.usnews.com/careers/best-jobs/dentist 
United States Medical Licensing Examination. (2017). United States Medical Licensing Examination.

Urbina, S. (2014). Essentials of psychological testing: John Wiley \& Sons.

Varner, F., \& Mandara, J. (2014). Differential parenting of African American adolescents as an explanation for gender disparities in achievement. Journal of Research on Adolescence, 24(4), 667-680.

Vittinghoff, E., \& McCulloch, C. E. (2007). Relaxing the rule of ten events per variable in logistic and Cox regression. American Journal of Epidemiology, 165(6), 710718.

Voyer, D., \& Voyer, S. D. (2014). Gender differences in scholastic achievement: A metaanalysis. Psychological Bulletin, 140(4), 1174.

Wainer, H., \& Kiely, G. L. (1987). Item clusters and computerized adaptive testing: A case for testlets. Journal of Educational Measurement, 24(3), 185-201.

Witzburg, R. A., \& Sondheimer, H. M. (2013). Holistic review-shaping the medical profession one applicant at a time. New England Journal of Medicine, 368(17), $1565-1567$.

Wright, B. D., \& Stone, M. H. (1979). Best Test Design. Rasch Measurement.

Wombacher, K. (2017). Reliability, Kuder-Richardson Formula. In M. Allen (Ed), The SAGE encyclopedia of communication research methods (pp. 1418-1420). SAGE Publications. https://dx.doi.org/10.4135/9781483381411 


\section{APPENDICES}

A: Institutional Review Board exemption notification

B: Q-Q plots 


\title{
Appendix A
}

\author{
Institutional Review Board Exemption Notification
}

\section{U N I VERSITY O F LOUISVILLE}

DATE:

TO:

FROM:

IRB NUMBER:

STUDY TITLE:

REFERENCE \#:

DATE OF REVIEW:

IRB STAFF CONTACT:

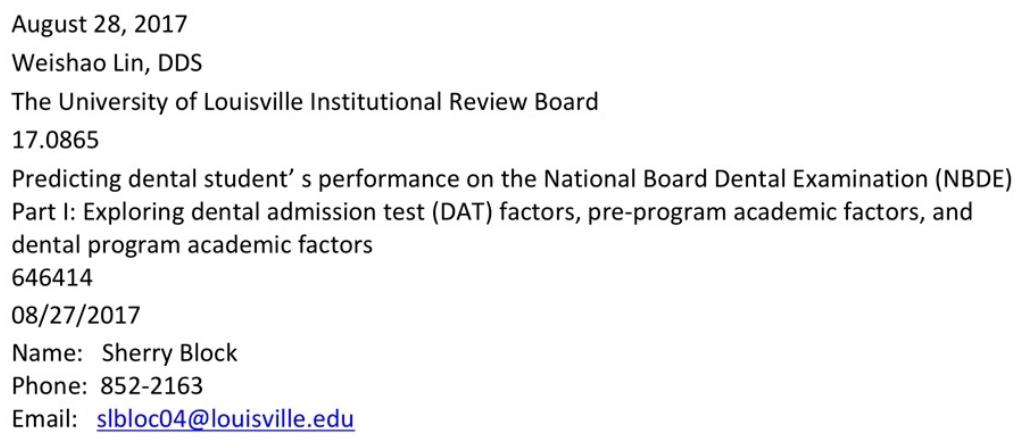

The IRB Chair/Vice-Chair has reviewed your submission and the project described does not meet the "Common Rule" definition of human subjects' research. Therefore, this project does not require IRB review.

If you are using protected health information, the HIPAA Privacy rules still apply. Institutional guidelines on patient privacy must be followed.

If you have any questions, please contact the IRB analyst listed above or the Human Subjects Protection Program office at hsppofc@louisville.edu.

We value your feedback. Please let us know how you think we are doing: https://www.surveymonkey.com/r/CCLHXRP

Sincerely,

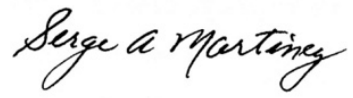

Serge A. Martinez, M.D., J.D., Vice Chair, Biomedical Institutional Review Board 
Appendix B

Normal Q-Q Plots of Continuous Variables

Normal Q-Q Plots of Undergraduate Science (SciUGrad), Non-science(NonSciUGrad), Biology, Chemistry, Physics (UGradBCP), and Total GPAs (TotalUGrad).
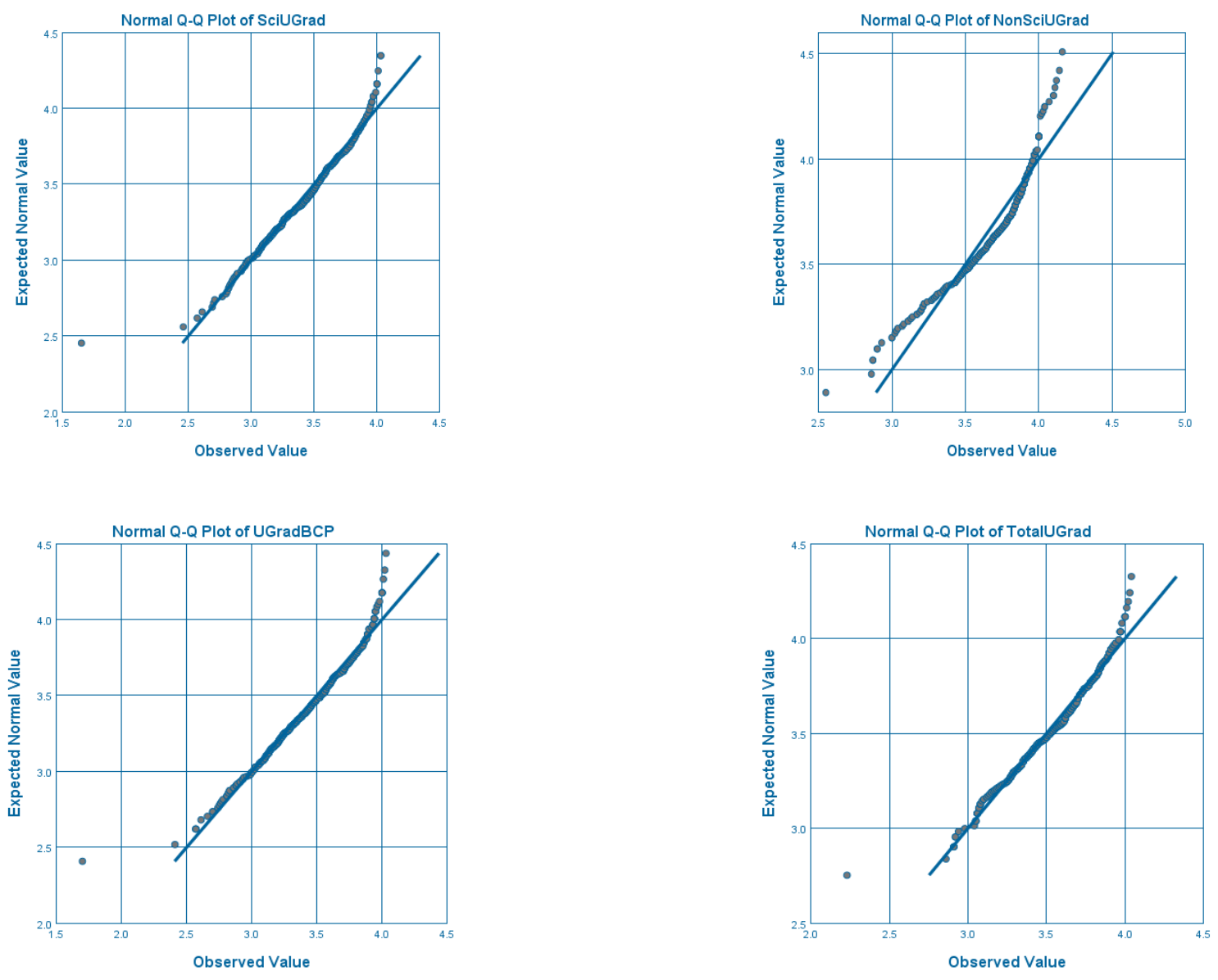
Normal Q-Q Plots of Scores on the DAT, Including Perceptual Ability (PAT), Quantitative Reasoning (QR), Reading Comprehension (RC), Biology, General Chemistry (GC), Organic Chemistry (OC), Total Science (TS), Academic Average $(\boldsymbol{A} A)$.
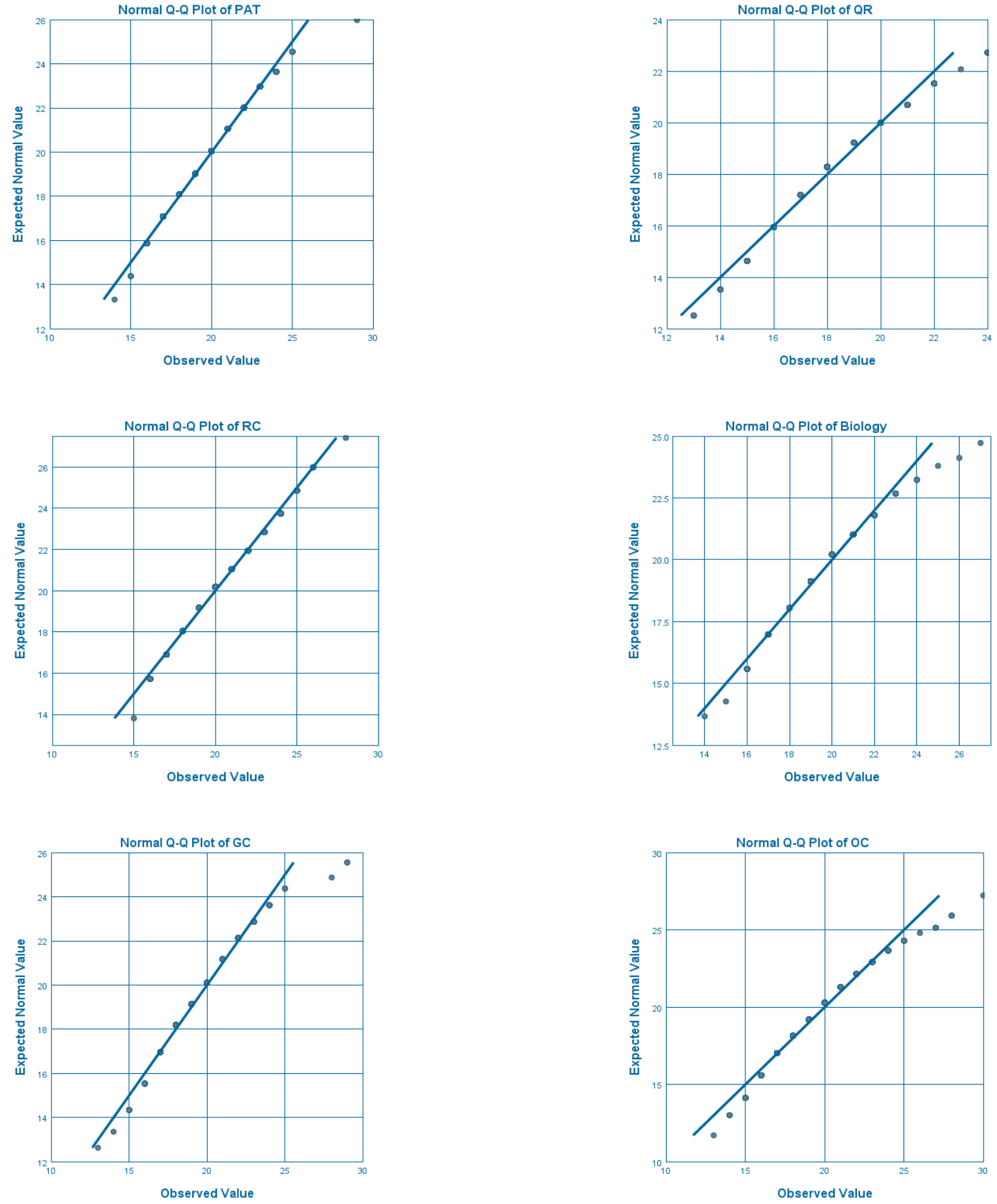

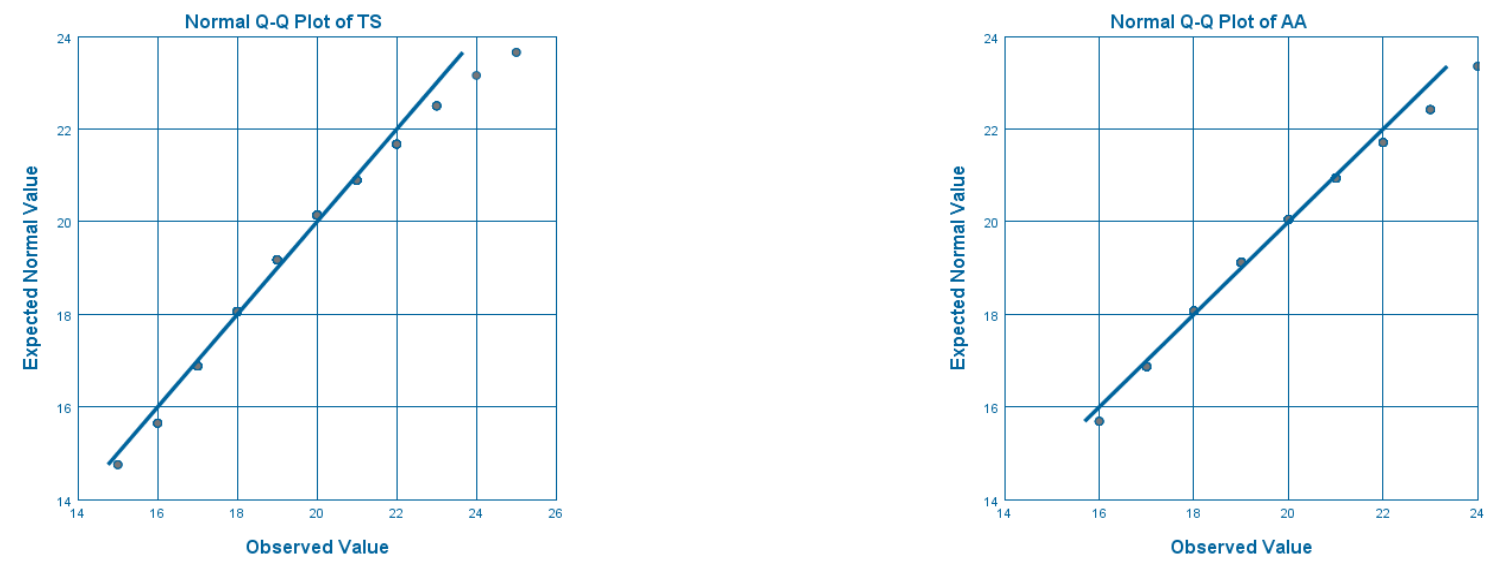
Normal Q-Q Plots of Histology, Physiology, Biochemistry, Survey of Dental Gross and Neuroanatomy, Dental Anatomy and Occlusion (lecture), Dental Anatomy and Occlusion (laboratory), Preclinical Occlusion and TMD, General Pathology, Microbiology and Immunology, Oral Pathology, and First-year and Second-year Cumulative GPA.
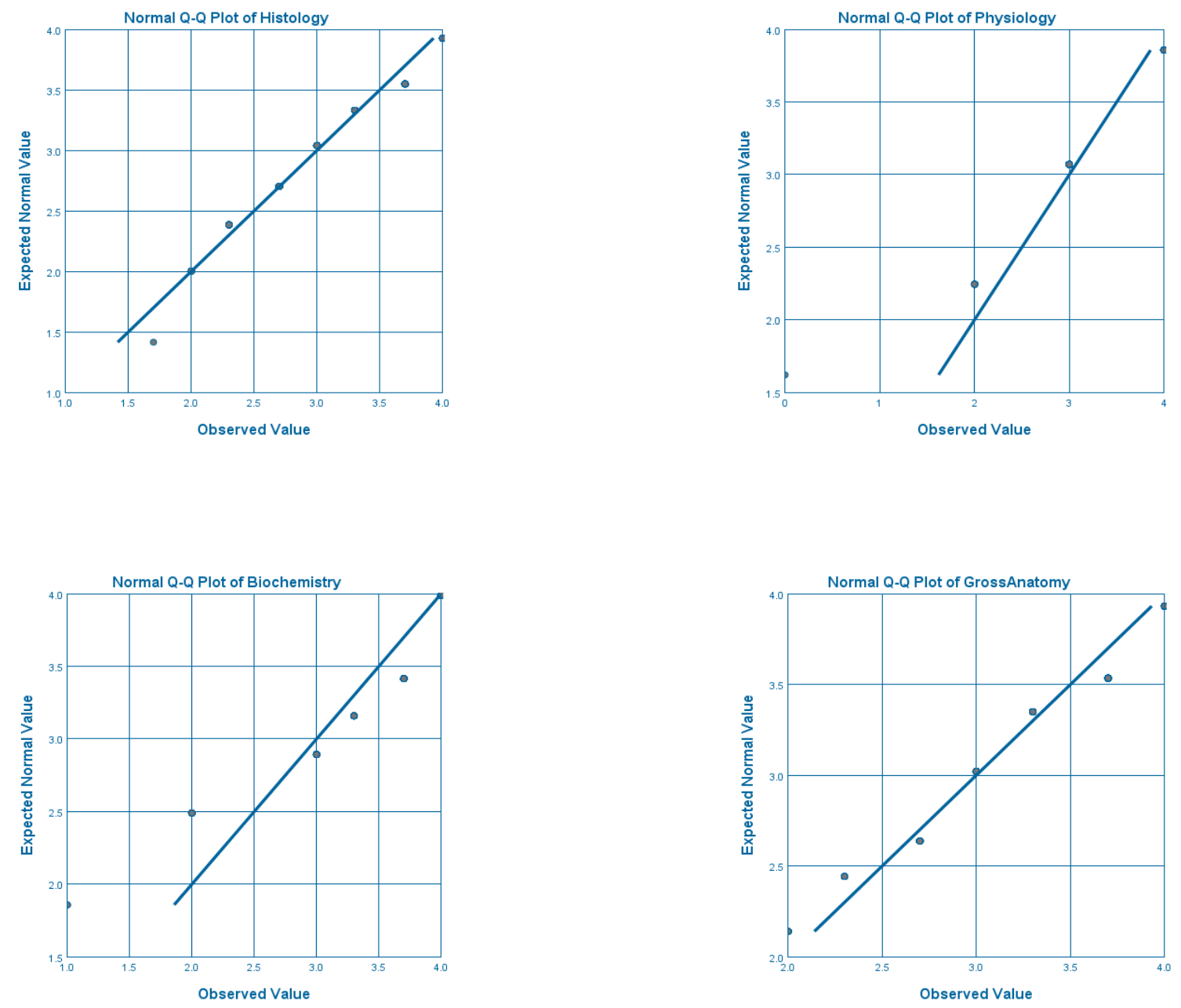

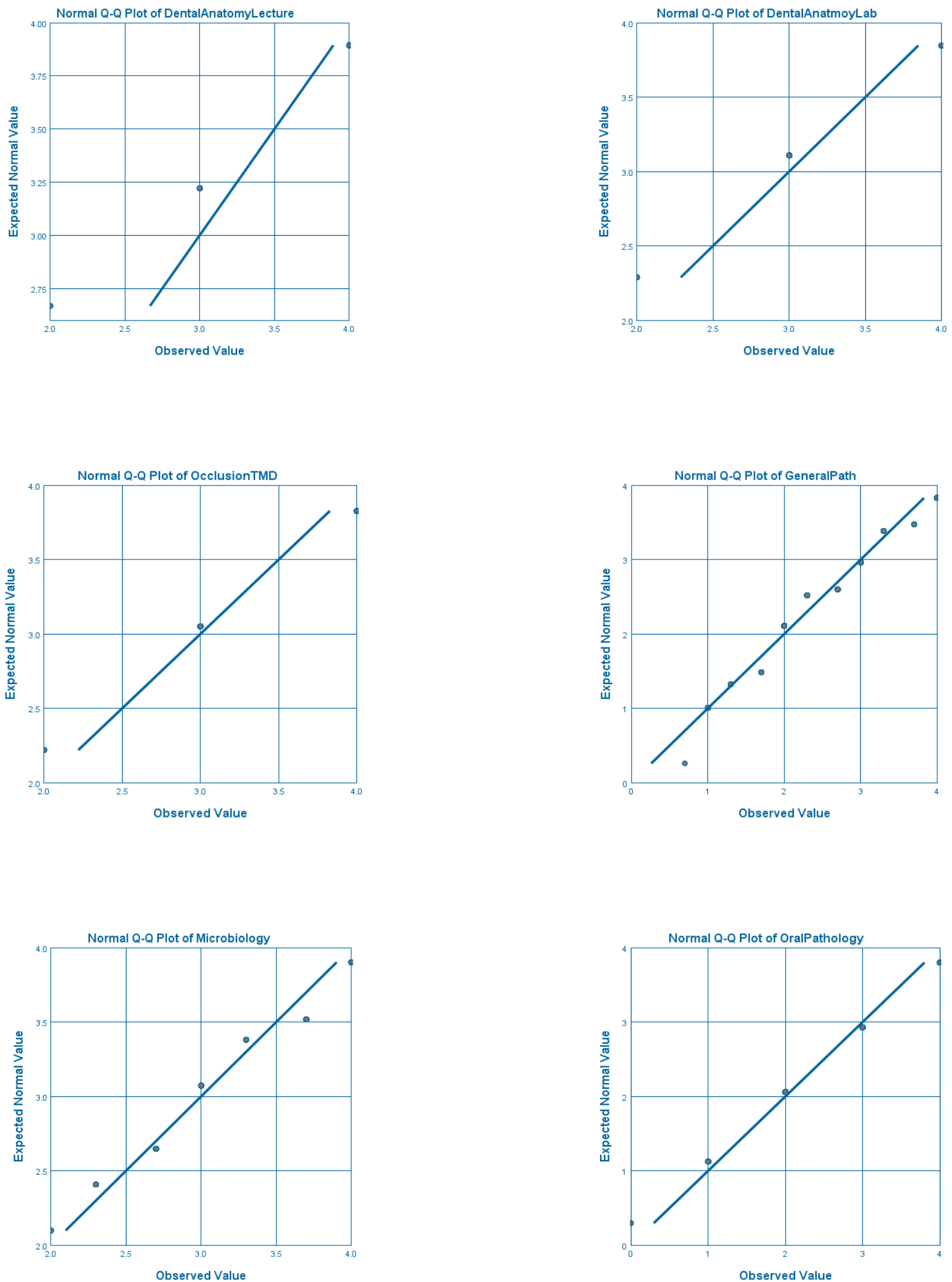

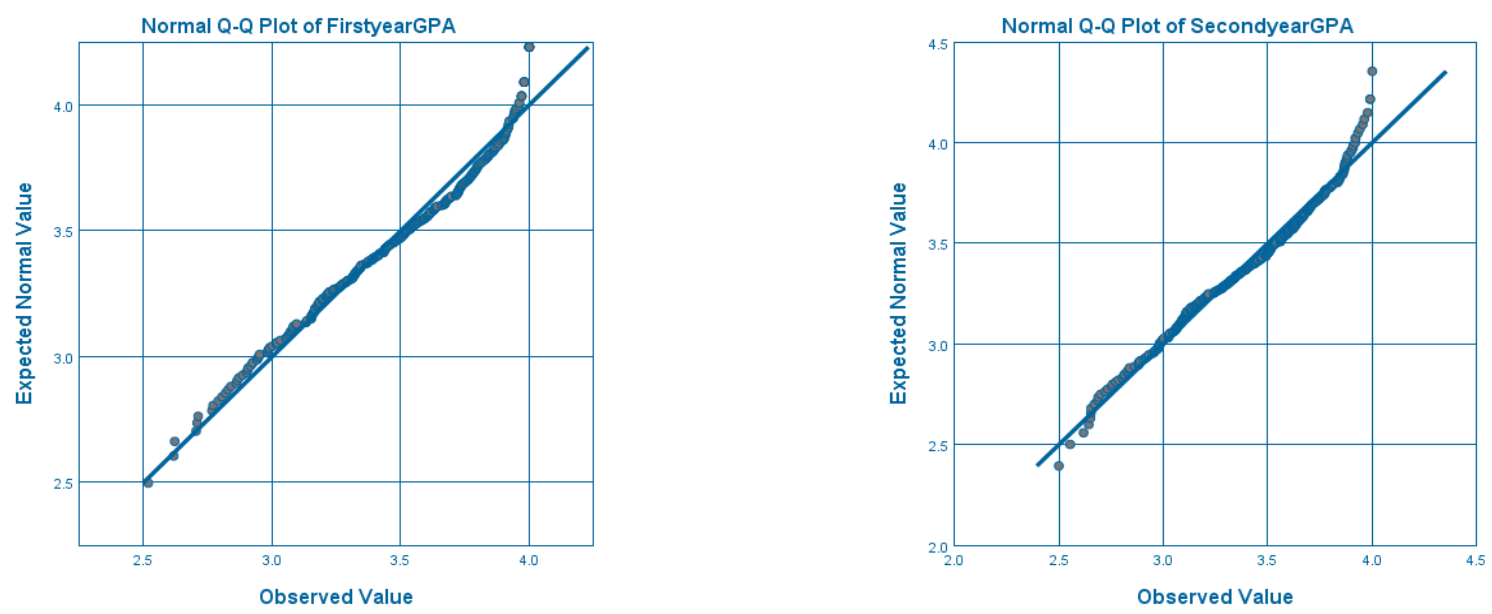


\section{CURRICULUM VITA}

Wei-Shao Lin, DDS, FACP

Program Director

Advanced Education Program in Prosthodontics

Interim Chair, Department of Prosthodontics

Indiana University School of Dentistry

1121 W. Michigan Street, Office: DS-S406

Indianapolis, IN 46202-5186

Email: weislin@,iu.edu

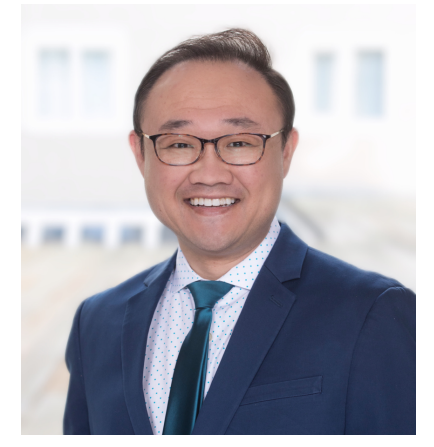

\section{BRIEF DESCRIPTION OF DUTIES}

2020 - Present Associate Professor (Tenured)

Program Director, Advanced Education Program in

Prosthodontics

Interim Chair, Department of Prosthodontics

Indiana University School of Dentistry

2019 - Present $\quad$ Associate Professor (Tenured)

Program Director, Advanced Education Program in

Prosthodontics

Department of Prosthodontics

Indiana University School of Dentistry

2018 - Present Associate Professor (Tenured)

Department of Prosthodontics

Indiana University School of Dentistry

2017 - $2018 \quad$ Associate Professor (Tenured)

Director, ITI Scholarship Program

Department of Oral Health and Rehabilitation

University of Louisville School of Dentistry 
$2015-2017 \quad$ Affiliated Faculty

Rapid Prototyping Center

J.B. Speed School of Engineering

University of Louisville

2015 - 2017 Associate Professor (Tenured granted in 2016)

Director of Division of Prosthodontics

Director, ITI Scholarship Program

Department of Oral Health and Rehabilitation

University of Louisville School of Dentistry

2010 - 2015 Discipline Coordinator and Course Director

Clinical Fixed Prosthodontics

Department of Oral Health and Rehabilitation

University of Louisville School of Dentistry

2010 - $2015 \quad$ Assistant Professor (Tenure Accruing)

Department of Oral Health and Rehabilitation

University of Louisville School of Dentistry

\section{AREAS OF SPECIALIZATION}

2018 - Present Diplomate, American Board of Prosthodontics

3. EDUCATIONAL BACKGROUND

2014 - Present: $\quad$ PhD in progress

Educational Leadership and Organization Development

College of Education and Human Development

University of Louisville

$2009-2010$ Postgraduate Specialty Certificate in Implantology Eastman

Institute for Oral Health

University of Rochester

2006 - 2010 Postgraduate Specialty Certificate in Prosthodontics Eastman

Institute for Oral Health

University of Rochester

$1997-2003 \quad$ Doctor of Dental Surgery (DDS)

Dental School

Chung-Shan Medical University, Taiwan

\section{EMPLOYMENT BACKGROUND}




\begin{tabular}{|c|c|}
\hline 2018 - Present & $\begin{array}{l}\text { Associate Professor } \\
\text { Indiana University School of Dentistry }\end{array}$ \\
\hline $2015-2018$ & $\begin{array}{l}\text { Associate Professor } \\
\text { University of Louisville School of Dentistry }\end{array}$ \\
\hline $2010-2015$ & $\begin{array}{l}\text { Assistant Professor } \\
\text { University of Louisville School of Dentistry }\end{array}$ \\
\hline $2003-2006$ & $\begin{array}{l}\text { Associate Dentist (Private Dental Practice) } \\
\text { Union Dental Center } \\
\text { Taiwan }\end{array}$ \\
\hline
\end{tabular}

5. TEACHING, ADVISING AND/OR INSTRUCTIONAL

\begin{tabular}{|c|c|}
\hline 2019 - Present & $\begin{array}{l}\text { Course Co-Director } \\
\text { Research: Prosthodontics } \\
\text { [FA20-IN-DENT-G923-22802] } \\
\text { [FA19-IN-DENT-G923-22266] } \\
\text { Prosthodontic Graduate Program } \\
\text { Indiana University School of Dentistry }\end{array}$ \\
\hline 2019 - Present & $\begin{array}{l}\text { Course Co-Director } \\
\text { Advanced Clinical Prosthodontics } \\
\text { [FA20-IN-DENT-R965-25043] } \\
\text { [SP20-IN-DENT-R965-22037] } \\
\text { [FA19-IN-DENT-R965-24687] } \\
\text { [SP19-IN-DENT-R965-23293] } \\
\text { Prosthodontic Graduate Program } \\
\text { Indiana University School of Dentistry }\end{array}$ \\
\hline 2019 - Present & $\begin{array}{l}\text { Course Co-Director } \\
\text { Maxillofacial Prosthetics Clinic } \\
\text { [SP20-IN-DENT-R921-19753] } \\
\text { [FA19-IN-DENT-R921-22295] } \\
\text { [SP19-IN-DENT-R921-20770] } \\
\text { Prosthodontic Graduate Program } \\
\text { Indiana University School of Dentistry }\end{array}$ \\
\hline 2018 - Present & $\begin{array}{l}\text { Course Co-Director } \\
\text { Prosthodontics Literature Review } \\
\text { [FA20-IN-DENT-R930-26711] } \\
\text { [FA19-IN-DENT-R930-26517] } \\
\text { [SP19-IN-DENT-R930-20774] } \\
\text { [FA18-IN-DENT-R930-25250] }\end{array}$ \\
\hline
\end{tabular}


Prosthodontic Graduate Program

Indiana University School of Dentistry

$2015-2018 \quad$ Course Director

Classic Literature Review [PROS-700.12] [PROS-700.22] [PROS700.32]

Advanced Education Program in Prosthodontics

University of Louisville School of Dentistry

2015 - $2018 \quad$ Course Director

Current Literature Review [PROS-710.12] [PROS-710.22] [PROS710.32]

Advanced Education Program in Prosthodontics

University of Louisville School of Dentistry

2015 - $2018 \quad$ Course Director

Clinical Prosthodontics [PROS-740.12] [PROS-740.22] [PROS-

740.32]

Advanced Education Program in Prosthodontics

University of Louisville School of Dentistry

$2015-2018 \quad$ Director

ITI Scholarship Program

Department of Oral Health and Rehabilitation

University of Louisville, School of Dentistry

$2010-2017 \quad$ Course Director

DMD Program

D3 Clinical Fixed Prosthodontics [OHR-888-56]

University of Louisville, School of Dentistry

$2010-2017 \quad$ Course Director

DMD Program

D4 Clinical Fixed Prosthodontics [OHR-895-78]

University of Louisville, School of Dentistry

$2015-2018 \quad$ Course Faculty

DMD Program

Implant Dentistry [OHR 881-05]

University of Louisville, School of Dentistry

$2012-2015 \quad$ Course Faculty

DMD Program

Evidence Based Dentistry [DSPR 880-01]

University of Louisville, School of Dentistry 
$2011-2018 \quad$ Course Faculty

DMD Program

Principles of Aesthetic Dentistry [DSPR 876]

University of Louisville, School of Dentistry

$2011-2017 \quad$ Course Faculty

DMD Program

Advanced Concepts in Dentistry I [OHR 853-07]

University of Louisville, School of Dentistry

$2010-2016 \quad$ Course Faculty

DMD Program

Removable Partial Dentures II [OHR 836-04]

University of Louisville, School of Dentistry

$2010-2016 \quad$ Course Faculty

DMD Program

Introduction to Indirect Restorations [OHR 815-03]

University of Louisville, School of Dentistry

$2010-2016 \quad$ Course Faculty

DMD Program

Preclinical Fixed Prosthodontics [OHR 819-04]

University of Louisville, School of Dentistry

$2010-2015 \quad$ Course Director

DMD Program

Advanced Concepts in Dentistry II [DSPR 854-07]

University of Louisville, School of Dentistry

$2010-2013 \quad$ Course Faculty

DMD Program

Indirect Restorations Laboratory [OHR 816-03]

University of Louisville, School of Dentistry

$2010-2013 \quad$ Course Faculty

DMD Program

Preclinical Fixed Laboratory [OHR 820-04]

University of Louisville, School of Dentistry

$2010-2012 \quad$ Course Faculty

DMD Program

Removable Partial Dentures I [OHR 817-03]

University of Louisville, School of Dentistry 
$2010-2012 \quad$ Course Faculty

DMD Program

Removable Partial Dentures Lab [OHR 818-03]

University of Louisville, School of Dentistry

$2010-2012 \quad$ Course Faculty

DMD Program

Preclinical Complete Dentures [OHR 821-04]

University of Louisville, School of Dentistry

$2010-2012 \quad$ Course Faculty

DMD Program

Preclinical Complete Dentures Lab [OHR 822-04]

University of Louisville, School of Dentistry

\section{GRADUATE FACULTY STATUS}

$2012-2018$ Member, Graduate Faculty, University of Louisville

2018 - Present Member, Graduate Faculty, Indiana University School of Dentistry

\section{PATENTS AND CREATIVE WORKS}

Patents

1. Zandinejad AA, Lin WS, Morton D. July 21, 2020. United States Patent $10,716,64$. Methods for fabricating dental restorations

2. Lin WS, Zandinejad AA, Morton D. August 14, 2018. United States Patent $10,045,839$. Methods for fabricating dental restorations

3. Zandinejad AA, Lin WS, Morton D. 2016, November US National Application 15/308,551, Methods for fabricating dental restorations. ULRF Ref.: 12059

4. Zandinejad AA, Lin WS, Morton D. 2015, May PCT International Application No. PCT/US15/28629, Methods for fabricating dental restorations. ULRF Ref.: 12059

5. Lin WS, Zandinejad AA, Morton D. 2015, February U. S. National Stage Patent Application No. 14/421,188, National Stage of PCT/US13/54751, Methods for fabricating dental restorations. ULRF Ref: 12059

6. Zandinejad AA, Lin WS, Morton D. 2014, May U. S. Provisional Patent Application Serial No. 61/987,643. Methods for fabricating dental restorations; ULRF Ref: 12059 
7. Lin WS, Zandinejad AA, Morton D. 2013, August PCT International Application No. PCT/US13/54751. Methods for fabricating dental restorations; ULRF Ref: 12059

8. Lin WS, Zandinejad AA, Morton D. 2012, August U. S. Provisional Patent Application Serial No. 61/682,474. Methods for fabricating dental restorations; ULRF Ref: 12059

\section{PUBLICATIONS}

Summary of Scholarship Profile (Google Scholar, 08/25/2020)

Citation numbers: 1027 ; h-index: 18 ; i10-index:29

Peer-Reviewed Publications

1. Su FY, Tsai JC, Morton D, Lin WS. Use of intraoral scan for implant-supported dental prosthesis to design and fabricate a CAD-CAM verification device: A dental technique. Accepted by J Prosth D. 2020.

2. Yang Y, Yang Z, Lin WS, Chen L, Tan J. Digital duplication and 3D printing for implant overdenture fabrication. Accepted by J Prosthodont. 2020.

3. Sa Y, Morton D, Lin WS. Using existing interim complete dentures as an aid for an interocclusal record to align edentulous intraoral scans for implant-retained overdentures. Accepted by J Prosth D. 2020.

4. Sa Y, Lin WS, Morton D, Huang C. Coronavirus disease 2019 (COVID-19): Experiences and protocols from the Department of Prosthodontics at the Wuhan University. Accepted by J Prosth D. 2020.

5. Orgev A, Gonzaga L, Martin W, Morton D, Lin WS. Addition of an irrigation channel to a surgical template to facilitate cooling during implant osteotomy. Accepted by J Prosth D. 2020.

6. Yao Q, Morton D, Eckert GJ, Lin WS. The effect of surface treatments on the color stability of CAD-CAM interim fixed dental prostheses. Accepted by $\mathrm{J}$ Prosth D. 2020.

7. Lin WS, AlQallaf H, Morton D. Using an existing surgical template as an aid for a virtual interocclusal record. J Prosthet Dent. 2020 Jan 16. pii: S00223913(19)30746-2. doi: 10.1016/j.prosdent.2019.11.009. [Epub ahead of print]

8. Alfaifi AA, Lin WS, Aldhaian BA, Levon JA, Gregory RL. Impact of caffeine on metabolic activity and biofilm formation of Candida albicans on acrylic denture resin in the presence of nicotine. J Prosthet Dent. 2019 Nov 5. pii: 
S0022-3913(19)30599-2. doi: 10.1016/j.prosdent.2019.09.007. [Epub ahead of print]

9. Pollini A, Morton D, Arunyanak SP, Harris BT, Lin WS. Evaluation of esthetic parameters related to a single implant restoration by laypeople and dentists. $\mathrm{J}$ Prosthet Dent. 2019 Nov 18. pii: S0022-3913(19)30547-5. doi: 10.1016/j.prosdent.2019.08.017. [Epub ahead of print]

10. Chen L, Yang Z, Liu X, Lin WS, Tan J. CAD-CAM titanium preparation template for the socket-shield technique. J Prosthet Dent. 2019 Nov 5. pii: S0022-3913(19)30421-4. doi: 10.1016/j.prosdent.2019.06.009. [Epub ahead of print]

11. Ren S, Morton D, Lin WS. Accuracy of virtual interocclusal records for partially edentulous patients. J Prosthet Dent. 2019 Oct 28. pii: S00223913(19)30543-8. doi: 10.1016/j.prosdent.2019.08.013. [Epub ahead of print]

12. Thorn A, Lin WS, levon JA, Morton D, Eckert GJ, Lippert F. The effect of Theobromine on the in vitro De- and Remineralization of Enamel Carious Lesions. J of Dent X. 2020 May 1;3:100013.

13. Lin WS, Yang CC, Polido WD, Morton D. CAD-CAM cobalt-chromium surgical template for static computer-aided implant surgery: A dental technique. J Prosthet Dent. 2020 Jan;123(1):42-44.

14. Su FY, Tsai JC, Morton D, Lin WS. Use of open source CAD software and additive manufacturing technology to design and fabricate a definitive cast for retrofitting a crown to an existing removable partial denture. J Prosthet Dent. 2019 Oct;122(4):351-354.

15. Li C, Lin WS, Polido WD, Eckert GJ, Morton D. Accuracy, reproducibility, and dimensional stability of additively manufactured surgical templates. J Prosthet Dent. 2019 Sep;122(3):309-314.

16. Morton D, Phasuk K, Polido WD, Lin WS. Consideration for Contemporary Implant Surgery. Dent Clin North Am. 2019 Apr;63(2):309-329.

17. Lin WS, Eckert SE. Clinical performance of intentionally tilted implants versus axially positioned implants: a systematic review of the literature. Clin Oral Implants Res. 2018 Oct;29 Suppl 16:78-105. (This article is among the top 10\% most downloaded papers among works published in the Clinical Oral Implants Research between January 2018 and December 2019)

18. Morton D, Gallucci G, Lin WS, Pjetursson B, Polido W, Roehling S, Sailer I. Group 2 ITI Consensus Report Prosthodontics and implant dentistry. Clin Oral Implants Res. 2018 Oct;29 Suppl 16:215-223. (This article is among the top 
$10 \%$ most downloaded papers among works published in the Clinical Oral Implants Research between January 2018 and December 2019)

19. Lin WS, Harris BT, Pellerito J, Morton D. Fabrication of an interim complete removable dental prosthesis with an in-office digital light processing 3D printer: A proof of concept technique. J Prosthet Dent. 2018 Sep;120(3):331-334.

20. Peng L, Chen L, Harris BT, Bhandari B, Morton D, Lin WS. Accuracy and reproducibility of virtual edentulous casts created by the laboratory impression scan protocols. J Prosthet Dent. 2018 Sep;120(3):389-395.

21. Lin WS, Chou JC, Charette JR, Metz MJ, Harris BT, Choi N. Creating virtual 3dimensional models for teaching preclinical tooth preparation: Students' usages and perceptions. Eur J Dent Educ. 2018 Aug;22(3):e573-e581

22. Kuric KM, Harris BT, Azevedo B, Morton D, Lin WS. Integrating hinge axis approximation and the virtual facial simulation of prosthetic outcomes for treatment with CAD-CAM immediate dentures: A clinical report of a patient with microstomia. J Prosthet Dent. 2018 Jun;119(6):879-886.

23. Dawson JH, Hyde B, Mitch H, Harris BT, Lin WS. Polyetherketoneketone (PEKK), a framework material for complete fixed and removable dental prostheses: A clinical report. J Prosthet Dent. 2018 Jun;119(6):867-872

24. Dawson JH, Dix G, Harris BT, Lin WS. Importance of Prototype Use for Implant-Supported Complete Fixed Dental Prosthesis (ICFDP). Compend Contin Educ Dent. 2018 May;39(5):e5-e8.

25. Lin WS. Harris BT, Phasuk K, Llop DR, Morton D. Integrating a facial scan, virtual smile design, and 3-dimensional virtual patient for treatment with CADCAM ceramic veneers: A clinical report. J Prosthet Dent. 2018 Feb;119(2):200205.

26. Peng L, Chen L, Harris BT, Morton D, Lin WS. Managing complications resulting from limited prosthetic space with a monolithic, multichromatic CADCAM implant-retained overdenture: A dental technique. J Prosthet Dent. 2017 Dec;118(6):712-716

27. Lin WS, Harris BT, Morton D. Use of CBCT Imaging, Open-Source Modeling Software, and Desktop Stereolithography 3D Printing to Duplicate a Removable Dental Prosthesis-A Proof of Concept. Compend Contin Educ Dent. 2017 Sep;38(8):e5-e8.

28. Marti AM, Harris BT, Metz MJ, Morton D, Scarfe WC, Metz CJ, Lin WS. Comparison of digital scanning and polyvinyl siloxane impression techniques 
by dental students. Instructional efficiency and attitudes towards technology. Eur J Dent Educ. 2017 Aug;21(3):200-205.

29. Harris BT, Chen L, Lin WS. Digital Imaging and Prosthetic-Driven Implant Planning: Efficient, Accurate, and Reliable Treatment. Compend Contin Educ Dent. 2017 Jul;38(7):492-494.

30. Ballard E, Metz MJ, Harris BT, Metz CJ, Chou JC, Morton D, Lin WS. Satisfaction of Dental Students, Faculty, and Patients with Tooth ShadeMatching Using a Spectrophotometer. J Dent Educ. 2017 May;81(5):545-553.

31. Harris BT, Montero D, Grant GT, Morton D, Llop DR, Lin WS. Creation of a 3dimensional virtual dental patient for computer-guided surgery and CAD-CAM interim complete removable and fixed dental prostheses. A clinical report. J Prosthet Dent. 2017; 117(2): 197-204.

32. Metz M, Durski M, Chou J, Crim G, Harris B, Lin WS. Microleakage of Lithium Disilicate Crown Margins Finished on Direct Restorative Materials. Oper Dent. 2016; 41(5): 552-562.

33. Harris BT, WC Scarfe, Llop DR, Lin WS. Using Dental GPS to Navigate Implant Placement. Compend Contin Educ Dent. 2016 Sep;37(8):520-525.

34. Metz MJ, Metz CJ, Durski MT, Aiken SA, Mayfield TG, Lin WS. Using an Audience Response System to Calibrate Dental Faculty Assessing Student Clinical Competence. J Dent Educ. 2016; 80(9): 1109-1118.

35. Charette JR, Goldberg J, Harris BT, Morton D, Llop DR, Lin WS. Cone beam computed tomography imaging as a primary diagnostic tool for computerguided surgery and $\mathrm{CAD} / \mathrm{CAM}$ interim removable and fixed dental prostheses. $\mathrm{J}$ Prosthet Dent 2016; 116(2): 157-165

36. Arunyanak SP, Harris BT, Grant GT, Morton D, Lin WS. Digital approach to planning computer-guided surgery and immediate provisionalization in a partially edentulous patient. J Prosthet Dent 2016; 116(1): 8-14

37. Metz MJ, Stapleton B, Harris BT, Lin WS. A cost-effective treatment for generalized erosion and loss of vertical dimension of occlusion: Laboratoryfabricated composite resin restorations. A case report. Gen Dent. 2015; 63(5): e12-7.

38. Lewis RC, Harris BT, Sarno R, Morton D, Llop DR, Lin WS. Maxillary and mandibular immediately loaded implant supported interim complete fixed dental prosthesis on immediately placed dental implants with a digital approach. A clinical report. J Prosthet Dent 2015; 114(3): 315-322 
39. Khan M, Elathamna EN, Lin WS, Harris BT, Farman AG, Scheetz JP, Morton D, Scarfe W. Comparison of virtual implant planning using the full crosssectional and transaxial capabilities of cone beam computed tomography vs. reformatted panoramic imaging and 3D modeling. Int J Oral Maxillofac Implants 2015; 30(4): 814-819

40. Lin WS, Chou JC, Metz MJ, Harris BT, Morton D. Use of intraoral digital scanning for a CAD/CAM-fabricated milled bar and superstructure framework for an implant-supported removable complete dental prosthesis. J Prosthet Dent 2015; 113(6): 509-515

41. Lin WS, Zandinejad A, Metz M, Harris B, Morton D. Predictable restorative workflow for Computer-Aided Design/Computer Aided Manufacture fabricated ceramic veneers utilizing a virtual smile design principle. Oper Dent 2015; 40(4): $357-363$

42. Zandinejad A, Lin WS, Atarodi M, Abdel-Azim T, Metz M, Morton D. Digital workflow for virtually designing and milling lithium disilicate veneers: A clinical report. Oper Dent 2015; 40(4): 241-246

43. Zandinejad A, Metz M, Stevens P, Lin WS, Morton D. Virtually designed and CAD/CAM fabricated lithium disilicate prostheses for an esthetic maxillary rehabilitation: A senior dental student clinical report. J Prosthet Dent 2015; 113(4): 282-288

44. Lin WS, Harris BT, Elathamna EN, Abdel-Azim T, Morton D. Effect of implant divergence on the accuracy of definitive casts created from traditional and digital implant-level impressions: An in vitro comparative study. Int J Oral Maxillofac Implants 2015; 30(1): 102-109

45. Ntounis A, Pitman LM, Pollini A, Vidal R, Lin WS, Harris BT, Greenwell H, Morton D. The ABC protocol for replacement of congenitally missing teeth with implant restorations. Case Series. Int J Periodontics Restorative Dent. 2015; 35(4): 561-9

46. Metz MJ, Miller CJ, Lin WS, Azim TA, Crim G. Dental Student Perception and Assessment of Their Clinical Knowledge in Educating Patients about Preventive Dentistry. European Journal of Dental Education. 2015; 19(2): 81-6

47. Abdel-Azim T, Zandinejad A, Elathamna E, Lin WS, Morton D. The influence of digital fabrication options on the accuracy of dental implant-based single units and complete arch frameworks. Int J Oral Maxillofac Implants 2014; 29(6): 1281-1288

48. Lin WS, Metz MJ, Pollini A, Ntounis A, Morton D. Digital data acquisition for a CAD/CAM fabricated titanium framework and zirconium oxide restorations 
for an implant supported fixed complete dental prosthesis. J Prosthet Dent 2014. 112(6): 1324-1329

49. Lin WS, Harris BT, Metz MJ, Morton D. A technique for verifying and correcting a milled polyurethane definitive cast for non-segmental implant restoration in an edentulous jaw. J Prosthet Dent 2014; 112(3): 658 - 652

50. Stapleton BM, Lin WS, Ntounis A, Harris BT, Morton D. Application of digital impression, virtual planning and computer guided implant surgery for a CAD/CAM fabricated implant supported fixed dental prosthesis: A clinical report. J Prosthet Dent 2014; 112(3): 402 - 408

51. Lin WS, Harris BT, Zandinejad A, Morton D. CAD/CAM fabricated telescopic prostheses on periodontally compromised abutments of a patient undergoing intravenous bisphosphonate treatment for osteoporosis: A case report. Gen Dent 2014; 62(3): e1-5

52. Metz MJ, Abdel-Azim T, Miller CJ, Lin WS, Zandinejad A, Oliveira GM, Morton D. Implementation of a laboratory quality assurance program: The Louisville Experience. J Dent Educ 2014; 78(2): 195-205

53. Lin WS, Harris BT, Zandinejad A, Morton D. Use of digital data acquisition and CAD/CAM technology for the fabrication of a fixed complete dental prosthesis on dental implants. J Prosthet Dent 2014; 111(1): 1-5

54. Harris BT, Caicedo R, Lin WS, Morton D. Treatment of a maxillary central incisor with class III invasive cervical resorption and compromised ferrule. A clinical report. J Prosthet Dent. 2014; 111(5): 356-61.

55. Lin WS, Harris BT, Zandinejad A, Martin WC, Morton D. Use of prefabricated titanium abutments and customized anatomic lithium disilicate structures for cement-retained implant restorations in the esthetic zone. J Prosthet Dent. 2014; 111(3): 181-5.

56. Lin WS, Harris BT, Morton D. Use of implant-supported interim restorations to transfer periimplant soft tissue profiles to a milled polyurethane definitive cast. J Prosthet Dent 2013; 109(5): 333-337

57. Lin WS, Harris BT, Ozdemir E, Morton D. Maxillary rehabilitation with a CAD/CAM fabricated, long-term interim and anatomic contour definitive prosthesis with a digital workflow. A clinical report. J Prosthet Dent 2013; 110(1): 1-7

58. Zandinejad AA, Abdel-Azim T, Lin WS, Morton D. Fabrication of a fixed multipurpose template retained by existing dental implants. J Prosthet Dent 
$2013 ; 110(2): 144-146$

59. Lee HW, Lin WS, Morton D. A retrospective study of complications associated with 100 consecutive maxillary sinus augmentations via lateral window approach. Int J Oral Maxillofac Implants 2013; 28(3): 860-868

60. Lin WS, Starr T, Harris BT, Zandinejad AA, Morton D. Additive machining technology (direct metal laser sintering) as a novel approach to fabricate functionally graded titanium implants. Preliminary investigation of various fabrication parameters. Int J Oral Maxillofac Implants 2013; 28(6): 1490-1495

61. Lin WS, Harris BT, Morton D. The use of a scannable impression coping and digital impression technique to fabricate a customized anatomic abutment and zirconia restoration in the esthetic zone. J Prosthet Dent 2013; 109(3): 187-191

62. Özdemir E, Lin WS, Tuncer AH. Interfacial evaluation of endodontically treated teeth: an SEM analysis. J Dent Sci. 2013; 8: 365-72

63. Özdemir E, Erkut S, Gulsahi K, Lin WS, Orucoglu H. Influence of Dynamic Loading and Different Adhesive Systems on the Microleakage in Root Canals. Journal of Adhesion Science and Technology. 2012; 26: 2517-2530

64. Lin WS, Ercoli C, Lowenguth R, Yerke LM, Morton D. Oral rehabilitation of a patient with bruxism and cluster implant failures in the edentulous maxilla: A clinical report. J Prosthet Dent 2012; 108(1): 1-8

65. Lin WS, Ercoli C, Feng C, Morton D. The effect of core material, veneering porcelain and fabrication technique on the biaxial flexural strength and Weibull analysis of selected dental ceramics. J Prosthodont 2012; 21(5): 353-362

66. Lin WS, Ozdemir E, Morton D. A three-appointment alternative treatment protocol for fabricating an implant-supported milled bar overdenture. J Prosthet Dent 2012; 107(2): 75-79

67. Lin WS, Harris, BT, Morton D. Trial insertion procedures for milled lithium disilicate restorations in the precrystallized state. J Prosthet Dent 2012; 107(1): 59-62

68. Özdemir E, Lin WS, Erkut S. Management of interproximal soft tissue with a resin-bonded prosthesis after immediate implant placement: a clinical report. J Prosthet Dent. 2012; 107(1): 7-10

69. Lin WS, Ercoli C. A technique for indirect fabrication of an implant-supported, screw-retained, fixed provisional restoration in the esthetic zone. J Prosthet Dent. 2009; 102(6): 393-6 
Additional Publications

1. Lin WS. Peer-to-peer Interview: 3D print efficiently and accurately. Inside Dental Technology. 2020 April; 50.

2. Lin WS, Morton D. 3D printing - evolving technology shaping today and tomorrow's dentistry. ACP Messenger. 2020 Winter; 8-10.

3. Morton D, Polido W, Lin WS. Current State of CAD/CAM Technology in Implant Dentistry. Forum Implantologicum, Fall 2019.

4. Dawson HJ, Harris BT, Lin WS. Importance of Prototype use for ImplantSupported Complete Fixed Dental Prosthesis (ICFDP). Straumann white paper. 2017.

5. Lin WS. Meet the researchers - "Effect of Implant Angulations and Impression Techniques on Dimensional Accuracy of Resulting CAD/CAM Titanium Frameworks: An In Vitro Comparative Study”. Forum Implantologicum. 2015; 11(2).

6. Lin WS, Morton D. Single tooth replacement using contemporary impressions and fabrication methods. ACP Messenger. 2013; 12-14.

7. Lin WS and Working Group 9.71. American Dental Association, Technical Report No. 146, CAD/CAM Abutments in Dentistry.

Book Chapters

1. Lin WS, Polido W, Charette JR, Morton D. Rehabilitating an Edentulous Maxilla with a Conventional Removable Denture and an Edentulous Mandible with a Fixed Dental Prosthesis Using s-CAIS. ITI Treatment Guide Volume 11. Chapter 13-11, Page 251-61.

2. Morton D, Abdel-Azim T, Lin WS. Relationship between Abutment Geometry and Peri-Implant Tissue in Esthetic Zone Patients.

In: Fixed Implant Prosthodontics. A clinical and laboratory manual. John Wiley and Sons Ltd. Oxford, UK. Editor: Shafie H. doi: 10.1002/9781118928547. Chapter 7. 2014.

\section{THESIS RESEARCH COMMITTEE / GRADUATE INDEPENDENT STUDY}

Indiana University School of Dentistry

1. Majeed-Saidan A (MSD) Accuracy of Intraoral Scans in Different Partially Edentulous Conditions. Committee Chair.

Lin WS, Levon J, Dutra V, Chu TM, Morton D. 
2. Lai YC (MSD) The effects of additive manufacturing technologies and finish line designs on the accuracy and dimensional stability of 3D-printed dies. Committee Chair.

Lin WS, Levon J, Chu TM, Yang CC, Morton D.

3. Laks E (MSD) The effects of anodization on the esthetic outcomes of the periimplant soft tissue and the physical and biological properties of titanium abutments - A systematic review. Committee Chair. Lin WS, Yang CC, Kirkup M, Sochacki S, Levon J.

4. Anderson B (MSD) The effects of anodization protocols and immersion solutions on the color stability of anodized titanium alloy. Committee Chair. Lin WS, Yang CC, Levon J, Chu TN, Morton D.

5. Ferry K (MSD) Evaluation of the accuracy of the soft tissue thickness measurements with three different methodologies. Committee member. Hamada Y, Blanchard S, Lin WS, Dutra V.

6. Almejrad L (Graduate Independent Study) The effects of food discolorations on the $3 \mathrm{D}$ printed interim restorations. Advisor/Mentor.

7. Tanaka Y (MSD) Analysis of the buccal bone thickness in the anterior maxilla: CBCT and histology study. Committee member. Hamada Y, Levon J, Lin WS, Blanchard S, Dutra V.

8. Hanes B (MSD) Fracture Resistance Behavior of Zirconia and Titanium Abutments in a Full Ceramic Implant Fixture: an in vitro study. Committee Chair.

Lin WS, Kamolphob P, Feitosa S, Levon J, Morton D.

9. Kim C (MSD) Surface wear resistance of CAD-CAM denture base material. Committee Co-Chair. Lippert F, Lin WS, Yang CC, Levon J, Morton D.

10. Alfaraj A (MSD) Accuracy of denture base adaptation on CAD-CAM obturator prosthesis. Committee Chair.

Lin WS, Yang CC, Levon J, Morton D.

11. Thorn AK (MSD) The effect of Theobromine on the De- and Remineralization of Enamel Carious Lesions. Committee Member. Lippert F, Lin WS, Morton D, Levon J.

12. Rubayo DD (MSD) Build angle and surgical template design: Do those factors influence accuracy and reproducibility of additively manufactured surgical templates. Committee Member. 
Phasuk A, Morton D, Levon J, Lin WS.

13. Bellicchi $\mathrm{T}$ (MSD) Influence of disinfection agents on dimensional stability for two biocompatible additive manufactured resins. Committee Member.

Phasuk A, Morton D, Levon J, Lin WS.

14. Alfaifi A (MSD) Effect Of Caffeine And Nicotine On Acrylic Denture Resin With Candida albicans. Committee Member. Gregory RL, Levon J, Lin WS.

15. Ren S (Graduate Independent Study) Accuracy of virtual interocclusal records for partially edentulous patients. Advisor/Mentor.

University of Louisville School of Dentistry

1. Yousef H. (MSD) Dimensional changes in dental casts made by conventional and digital paths over 3 months. Master of Science in Dentistry Program. Committee Chair.

2. White K. (MS) Factors influencing the Final Shade of Dental Crown Restorations. Masters in Oral Biology Program Student. Committee Member.

3. Venkatehswaran S. (MS). Comparison of Subepithelial Connective Tissue Graft and Acellular Dermal matrix for root coverage - A Meta-analysis. Masters in Oral Biology Program Student. Committee Member.

4. Jestel S. (MS). Marginal Staining between Pressed Lithium Disilicate Ceramic Crowns and Direct Restorative Materials by Various Fluids: a Microleakage Study. Masters in Oral Biology Program Student. Committee Member.

5. Kuric KM. (MSD) Accuracy of Indirect Digital Scanning of Different Fixed Restoration Designs. Master of Science in Dentistry Program. Committee Chair.

6. Lindman MV. (MSD) The Effect of Fixed Dental Prosthesis Marginal Designs on the Accuracy of Indirect Digital Scanning Method. Master of Science in Dentistry Program. Committee Chair.

7. Pollini A. (MSD). Layperson and clinician evaluation of 10 esthetic parameters related to single implant restoration in the esthetic zone. Master of Science in Dentistry Program. Committee Chair.

8. Dawson JH. (MSD). In vitro comparison of mechanical strength and dynamic fatigue behavior of 4 types of abutments in the reduced diameter, titanium/zirconium dental implants. Master of Science in Dentistry Program. Committee Co-Chair. 
9. Aiken SA. (MS) Implementation of an Audience Response System for Calibrating General Dentistry Faculty to Clinical Operative Dentistry Terminology and Concepts. Masters in Oral Biology Program Student. Committee Member.

10. Lewis RC, Mohammed S. (MSD). Comparing the Accuracy of Two Methods to Cure Resilient Denture Attachment into an Acrylic Denture Base using an Ivobase Curing Unit (Indirectly) and the Traditional Direct Method. Master of Science in Dentistry Program. Committee Co-Chair.

11. Charette JR. Creating virtual 3-dimensional models for teaching preclinical tooth preparation - Students' usages and perceptions. Master of Science in Dentistry Program. Committee Co-Chair.

12. Deepika Joshi (MS) Facial Alveolar bone changes associated with Endosseous Implants in the pre-maxilla. Masters in Oral Biology Program Student. Committee Member.

13. Ballard E. (MS) Objective Evaluation of Student's Shade Matching Performance in the School of Dentistry. Masters in Oral Biology Program Student. Committee Chair.

14. Stapleton B. (MSD) Effect of finish line designs, comparing digital data acquisition protocols and abutment selection on the marginal adaptation of chairside Computer Aided Design/Computer Aided Manufacturing restorations. Master of Science in Dentistry Program. Committee Co-Chair.

15. Marti AM. (MSOB) Comparison of digital scanning and polyvinyl siloxane impression techniques by dental students: Instructional efficiency and attitudes towards technology. Masters in Oral Biology Program Student. Committee Chair.

16. Khan MA. (MSOB) Clinical Efficacy of cross-sectional imaging compared with panoramic radiography and virtual surface models for the assessment of optimal dental implant placement in the molar region of both jaws. Masters in Oral Biology Program Student. Committee Member.

University of Toronto Faculty of Dentistry

17. Lee HW. (MS) The effect of contamination of implant screws on de-torque values. Master of Science. Committee External Reviewer. (Completed June, 2014)

\section{LECTURES, SPEECHES OR POSTERS PRESENTED AT PROFESSIONAL CONFERENCES/MEETINGS}


International

2020

2020

2020

2020

2019

2018

2018

2017

2015

Invited Speaker. Ain Shams University, $4^{\text {th }}$ International Dental Conference. Virtual patient in the contemporary prosthodontics and implant treatment. Egypt. October, 2020.

Invited Speaker. Saudi Prosthodontic Society, Looking Back, Learning Forward - Contemporary Technologies in the Prosthodontics and Implant Dentistry. Saudi Arabia (via Online Lecturing platform). April, 2020.

Invited Speaker. Saudi Society of Restorative Dentistry, Restoring dental implants using contemporary technologies. Saudi Arabia (via Online Lecturing platform). April, 2020.

Invited Speaker. Online Lecture series with Chinese Clinicians. Contemporary Options in implant dentistry. China (via Online Lecturing platform). January, 2020.

Invited Speaker. Chinese Academy of Implant \& Esthetic Dentistry. Implant Assisted Dentistry - Contemporary Options: Finding Success and Avoiding Complications. Taiwan. December, 2019.

Invited Speaker. Department of Dentistry, Chang Gung Memorial Hospital, Kaohsiung Medical Center, Chang Gung University College of Medicine. Integrating Digital Technologies in Dental Implant Treatments. Taiwan. December, 2018

Invited Speaker/Author. Clinical performance of intentionally tilted implants versus axially positioned implants. ITI Consensus Conference. Amsterdam, Netherlands. April 2018.

Invited Speaker. Contemporary Prosthodontics. Less is More. International College of Prosthodontists. Santiago, Chile. September 2017

Invited Speaker. Utilization of Digital Technology in Implant Dentistry. Taipei, Taiwan. July 2015

National/Regional 
Invited Speaker. US ITI Webinar series on "Management of Implant Complications". November, 2020.

Invited Speaker. University of Buffalo School of Dentistry. Treating Complete Edentulous Patients with Implant-Supported Fixed Dental Prostheses. Buffalo (via Online Lecturing platform). April, 2020.

Invited Speaker. Straumann. Knock it out of the Park with Digital Dentistry. Montgomery, AL. March 2020

Invited Speaker. 2020 ADEA Annual Session. Your pathway in the new digital dentistry era. National Harbor, MD. March 2020 (Meeting cancelled due to COVID-19)

Invited Speaker. American College of Prosthodontists 2019 Annual Session Virtual patient in the contemporary prosthodontics treatment. Fontainebleau, Miami Beach. November 2019

Invited Speaker. Philadelphia Tri-State ITI Study Club. The Frontier of Digital Dentistry. Feasterville, PA. September, 2019

Invited Speaker. Knock it out of the Park with Digital Dentistry. Fort Wayne, Ind. August, 2019

Invited Speaker. ITI North America Congress. Technology Pod: What to know before you buy an intraoral scanner. San Francisco, CA. April, 2019

Invited Speaker. Digital Workflow Options in Dentistry: Learning to Use Contemporary Pathways. Indianapolis, IN. May, 2019

Invited Speaker. ITI Study Club. Integrating Digital Technologies in Dental Implant Treatments. Columbus, IN. January, 2019

2018 Invited Speaker. John F Johnston Society Refresher Course: InOffice 3D printing. Indianapolis, IN. June 2018. Full Arch Considerations: Fixed vs Removable vs Ceramic (Texas Shootout). Frisco, TX. May 2018. Expanding Capabilities with 3D Printing. Louisville, KY. July 2017. 
Invited Speaker. Straumann. Restoring Edentulous Patients with Hybrid Solutions. Canton, OH. April 2017

Invited Speaker. Straumann. Restoring Edentulous Patients with Hybrid Solutions. Madison, WI. April 2017

Invited Speaker. Indiana University School of Dentistry. Implant Dentistry in the Digital World. Indianapolis, IN. March 2017

Invited Speaker. University of Rochester, Eastman Institute of Oral Health. Utilization of Digital Technology in Implant Dentistry. Rochester, NY. October 2016

Invited Speaker. Pacific Coast Society for Prosthodontics - The 81st Annual Meeting and Scientific Session. Implant Dentistry in the Digital World: Working and Succeeding Together. San Francisco, CA. July 2016

Invited Speaker. ITI Congress North America. Integrating Digital Technologies in Restorative Implant Treatments for Edentulous Patients. Chicago, IL. April 2016

Invited Speaker. ITI Study Club. Utilization of Digital Technology in Implant Dentistry. St Louis, MO. November 2015

Invited Speaker. Straumann. Restoring Edentulous Patients with Hybrid Solutions. Destin, FL. October 2015

Invited Speaker. American Dental Education Association - Annual Session Program. Workshop: Quality Assurance Assessment and Calibration of Student Fabricated Laboratory Cases. Boston, MA. March 2015

Invited Speaker. Straumann. Utilization of Digital Technology in Implant Dentistry. Pittsburgh, PA. October 2014

Invited Speaker. Straumann. Utilization of Digital Technology in Implant Dentistry. Louisville, KY. October 2014

2014 Invited Speaker. Annual South East General Practice Residency Program Directors (SEPDr) meeting. Utilization of Digital Technology in Implant Dentistry. Louisville, KY. September 2014

2014 Invited Speaker. Straumann. Implant restorations for Everyday Practice. Maple Grove, MN. February 2014 
Invited Speaker. University of Louisville, School of Dentistry. Digital Dentistry Education Center Program: Implant Dentistry in the Digital World: Working and Succeeding Together. Louisville, KY. November 2013

2013

Invited Speaker. ITI Congress North America, Technology Pod Clinical perspectives of Lithium Disilicate in the Implant Dentistry. Chicago, IL. April 2013

2013

2013

2012

2012

Invited Speaker. Academy of Osseointegration 28th Annual Meeting. Contemporary Material Options for Esthetic Implant Restorations. Tampa, FL. March 2013

Invited Speaker. ITI Study Club. Digital restorative dentistry. Louisville, KY. March 2013

Invited Speaker. University of Louisville. ULSD Faculty Development Course: Digital Dentistry and the CAD/CAM Restorations. Louisville, KY. December 2012

Invited Speaker. University of Louisville. Digital Dentistry Education Center Program: Implant Dentistry in the Digital World: Working and Succeeding Together. Louisville, KY. July 2012

Invited Speaker. Study Club. Clinical Perspective and Digital application in All ceramic systems. Cincinnati, OH. March 2012

Invited Speaker. Study Club. Clinical Perspective and Digital application in All ceramic systems. Louisville, KY. May 2011

Posters

SA Alqahtani, Lin WS. Implant-supported CAD/CAM Milled Zirconia prosthesis supported by titanium bar. Indianapolis, IN. April 2020. (Meeting changed to online format due to COVID-19)

A Alfaraj, Lin WS. Accuracy of denture base adaptation on CADCAM obturator prosthesis - Pilot Experiment. Indianapolis, IN. April 2020. (Meeting changed to online format due to COVID-19)

YC Lai, Morton D, Levon, J, Lin WS. Implant surgical planning in a patient with severely atrophic mandible. Indianapolis, IN. April 2020. (Meeting changed to online format due to COVID-19)

2020 Miranda ME, Su FY, Levon, J, Lin WS. Comparison of Surgical Template Accuracy in Positioning and Removal Timing. 
Indianapolis, IN. April 2020. (Meeting changed to online format due to COVID-19)

2020: $\quad$ Orgev A, Lin WS, Martin WC, Morton D. Novel Guided Surgical Template Design with Irrigation Channel. Indiana University School of Dentistry Research Day. Indianapolis, IN. April 2020. (Meeting changed to online format due to COVID-19)

2020:

Tanaka Y, Levon J, Lin WS. Full-Arch Maxillary Rehabilitation Using Dual Scan CBCT of an Existing Prosthesis. Indiana University School of Dentistry Research Day. Indianapolis, IN. April 2020. (Meeting changed to online format due to COVID-19)

2020: $\quad$ Orgev A, Morton D, Lin WS. Novel Irrigation Channel Design for Static Computer-Aided Implant Surgery (s-CAIS). ITI World Symposium, Singapore. May, 2020. (Meeting postponed due to COVID-19)

Orgev A, Morton D, Lin WS. Individualized Emergence Profile Development for the Implant Prosthesis with Mirror Copy in Digital Workflow. ITI World Symposium, Singapore. May, 2020. (Meeting postponed due to COVID-19)

Tanaka Y, Yang CC, Hamada Y, Azar C, Lin WS, Morton D. Application of Intra-Oral Scanner at the Implant placement for the Modified "One Abutment One Time" Concept. 2020 Annual Meeting - Academy of Osseointegration. Seattle, WA. March 1821, 2020. (Poster changed to online format due to COVID-19)

2020 Kiettipirodom W, Levon JA, Morton D, Lin WS. Application of 3D facial scan in digital smile design: A clinical report. American Academy of Fixed Prosthodontics, 2020 Annual Session. Chicago, IL. February 2020.

2019 Almejrad L, Lin WS, Cayetano O, Levon J, Morton D. Threedimensional printing (3DP) of interim implant supported fixed complete denture (IFCD). American Academy of Fixed Prosthodontics, 2020 Annual Session. Chicago, IL. February 2020.

2019 Gadah T, Dutra V, Polido W, AlShahrani A, AlSedan A, Lin WS, Morton D. Dual-purpose 3D printed surgical template for the fractured dental implant removal and new implant placement. American College of Prosthodontists 2019 Annual Session. Fontainebleau, Miami Beach. November 2019. 
Almejrad L, Lin WS, Cayetano O, Levon J, Morton D. Threedimensional printing (3DP) of interim implant supported fixed complete denture (IFCD). American College of Prosthodontists 2019 Annual Session. Fontainebleau, Miami Beach. November 2019.

Su FY, Morton D, Rogers J, Lin WS. Exploration of 3D Facial Scanning Techniques Capturing Patient Smile. American College of Prosthodontists 2019 Annual Session. Fontainebleau, Miami Beach. November 2019.

AlQallaf H, Su FY, Hamada Y, Lin WS, Polido WD, Morton D. Static Computer-Aided Implant Surgery (s-CAIS) in Treating Edentulous Patient with Hybrid Prosthesis - Technique and Limitations. The 13th International Symposium on Periodontal \& Restorative Dentistry. Boston, MA. June 2019.

Li C, Lin WS, Polido WD, Eckert GJ, Morton D. Accuracy, reproducibility, and dimensional stability of additively manufactured surgical templates. Indiana University School of Dentistry Research Day. Indianapolis, IN. April 2019.

Kim Chin, Levon J, Lin WS. An Alternative Treatment using Resilient Liner for Mandibular Denture. Indiana University School of Dentistry Research Day. Indianapolis, IN. April 2019.

Hanes B, Molina I, Lin WS, Morton D. Removal and Site Construction of Malpositioned Implant in the Esthetic Zone. Indiana University School of Dentistry Research Day. Indianapolis, IN. April 2019.

Su FY, Tsai JC, Morton D, Lin WS. The application of open source CAD software and additive manufacturing technology in prosthodontics. American Prosthodontics Society. Chicago, IL. February 2019. supported complete denture: Prosthodontics rehabilitation of severely atrophic maxilla with zygomatic implants. American College of Prosthodontists. Baltimore, MD. November 2018 source CAD software and additive manufacturing technology in prosthodontics. American College of Prosthodontists. Baltimore, MD. November 2018 
Kuric KM, Pollini A, Chen L, Harris BT, Lin WS. Utilizing an inoffice 3D Printer for the Modified One Abutment/One-Time Concept. Academy of Osseointegration Annual Meeting. Los Angeles, CA. February 2018

Lindman M, Pollini A, Kuric KM, Harris BT, Lin WS. Conservative Management of the Malpositioned Implant. Annual Session - American College of Prosthodontists. San Francisco, CA. November 2017

Kuric KM, Lindman M, Harris BT, Lin WS. Digital Pathway to Treating the Worn Dentition- A Clinical Report. Annual Session American College of Prosthodontists. San Francisco, CA. November 2017 virtual edentulous casts created from different scanning protocols. ITI World Symposium. Basel, Switzerland. May 2017

Chen L, Peng L, Harris BT, Morton D, Lin WS. Managing complication resulted from limited prosthetic space with a monolithic, multi-chromatic CAD/CAM implant-retained overdenture. ITI World Symposium. Basel, Switzerland. May 2017

Power JA, Azevedo B, Metz MJ, Harris BT, Lin WS, Scarfe WC. Frequency of Intraoral Imaging at Insertion of Implant Supported Restorations at an Academic Institution. American Dental Education Association - Annual Session Program. Long Beach, CA. March 2017

Dawson JH, Hyde B, Hurst M, Harris BT, Lin WS. PolyEtherKetoneKetone (PEKK), An Alternative Framework Material for Implant-Supported Complete Fixed Dental Prosthesis - A Clinical Report. The American Prosthodontic Society - Annual Session Program. Chicago, IL. February 2017

Pollini A, Dix G, Harris BT, Lin WS, Zandinejad AA. Oral rehabilitation of a patient with Hereditary Gingival Fibromatosis. The American Prosthodontic Society - Annual Session Program. Chicago, IL. February 2017

Kuric, KM, Harris BT, Lin WS. A Digital Pathway to Treating the Edentulous Microstomic Patient. The American Prosthodontic Society - Annual Session Program. Chicago, IL. February 2017 
Charette JR, Chou JC, Harris BT, Lin WS. Creating virtual 3dimensional models for teaching preclinical tooth preparation Students' usages and perceptions. Kentucky Dental Association Annual Session Program. Louisville, KY. August 2016

Charette JR, Harris BT, Lin WS. CAD/CAM-fabricated interim removable complete dental prosthesis and implant-supported complete fixed dental prosthesis: A single diagnostic appointment approach. American College of Prosthodontics - Annual Session Program. Orlando, FL. October 2015

2015 Power A, Azevedo B, Harris BT, Lin WS, Metz MJ, Scarfe WC. Post-Operative Dental Implant Imaging at an Academic Institution: Conformity to Established Guidelines, Frequency and Cause of Non-Diagnostic Imaging. Research!Louisville. Louisville, KY. October 2015

Metz MJ, Metz CJ, Lin WS. Dental Student Perception and Assessment of Their Clinical Knowledge in Educating Patients about Preventive Dentistry. Research!Louisville. Louisville, KY. October 2015

Hill I, Lin WS, Durski M, Metz MJ. Retrospective Review of Lithium Disilicate Crowns Adhesively Bonded over Various Core Materials: Success Rates at ULSD. Research!Louisville. Louisville, KY. October 2015

Ballard E, Metz MJ, Harris BT, Metz CJ, Chou JC, Lin WS. Objective Evaluation of Student's Shade-Matching Performance in the Student Dental Clinic, University of Louisville.

Research!Louisville. Louisville, KY. October 2015

Hill I, Lin WS, Zandinejad AA, Metz MJ. Compressive Strength of Pressed Lithium Disilicate Crowns Supported by Various Core Materials: An in vitro Evaluation. IADR/AADR/CADR General Session \& Exhibition. Boston, MA. March 2015

Lewis RC, Sarno R, BT Harris, Morton D, Lin WS. Maxillary and mandibular immediately loaded implant-supported interim complete fixed dental prostheses on immediately placed dental implants with a digital approach: A clinical report. The American Prosthodontic Society - Annual Session Program. Chicago, IL. February 2015

2015 Stapleton B, Lin WS, Ntounis A, Harris BT, Morton D. Application of digital diagnostic impression, virtual planning, and 
computer-guided implant surgery for a CAD/CAM-fabricated, implant-supported fixed dental prosthesis: A clinical report. The American Prosthodontic Society - Annual Session Program.

Chicago, IL. February 2015

2014

Lewis RC, Harris BT, Morton D, Lin WS. Treatment of an implant supported full arch all ceramic fixed dental prosthesis fabricated with a contemporary digital approach. American College of Prosthodontists - Annual Session Program. New Orleans, LA. November 2014

2014 Metz MJ, Zandinejad AA, Miller CJ, Lin WS. Implementation of a Laboratory Quality Assurance Program: The Louisville Experience. Research!Louisville. Louisville, KY. September 2014

2014 Czechura T, Metz MJ, Lin WS, Mayfield TG. Factors associated with longevity of dental implants placed at the University of Louisville School of Dentistry: A retrospective review from 20082013. Research!Louisville. Louisville, KY. September 2014

2014

Marti AM, Harris BT, Metz MJ, Lin WS. Comparison of digital scanning and polyvinyl siloxane impression techniques by dental students: Instructional efficiency and attitudes towards technology. Research!Louisville. Louisville, KY. September 2014

2014

Hill I, Lin WS, Zandinejad AA, Metz MJ. Compressive Strength of Pressed Lithium Disilicate Crowns Supported by Various Core Materials: An in vitro Evaluation. Research!Louisville. Louisville, KY. September 2014

2014 Reece C, Lin WS, Metz MJ. Evaluation of Clinical Experience Integrating the International Caries Detection and Assessment System (ICDAS) into ULSD Curricula. Research!Louisville. Louisville, KY. September 2014

\section{CONTRACTS, GRANTS and AWARDS}

Grants

2019-2020 Morton D, Lin WS. In vitro comparison of mechanical strength and dynamic fatigue behavior of 4 types of abutments in the reduced diameter, titanium/zirconium dental implants. ITI Foundation Grant (No. 1058_2015). \$ 22,486.51 USD Co-Principal Investigator. (The residuals transferred from previous institution)

IU Grant Account: \#41-761-21 
Harris BT, Chen L, Lin WS. Conventional and Digital duplication of complete removable dental prosthesis: Accuracy, Reproducibility, Dimensional stability and Efficiency Evaluation. ULSD Faculty Research Grant, Co-Principal Investigator. $\$ 2,500.00$ USD

2016-2017 Grant GT, Harris BT, Lin WS. Digital Dentistry Development and Education Fellowship/Scholar. Institut Straumann. Co-Principal Investigator. \$50,000.00 USD

2015-2017 Morton D, Dawson H, Harris BT, Lin WS. In vitro comparison of mechanical strength and dynamic fatigue behavior of 4 types of abutments in the reduced diameter, titanium/zirconium dental implants. ITI Foundation Grant (No. 1058_2015). Co-Principal Investigator. \$49,060.00 USD

2015-2016 Miller C, Metz MJ, Lin WS, Immekus JC. Establishing a Science Outreach Program for Under-Represented Students in West Louisville. University of Louisville School of Medicine Basic Grant and University of Louisville School of Dentistry Supplemental Grant. Investigator. \$35,000.00 USD

2015-2016 Lewis RC, Harris BT, Lin WS, Morton D. Comparing the accuracy of two methods to cure resilient denture attachments into an acrylic denture base. Ivoclar Vivodent Materials Support Grant. CoPrincipal Investigator. \$4,000.00 USD

2015-2016 Yang L, Lin WS, Morton D. Performance evaluation of a low modulus titanium dental implant made with laser additive machining. University of Louisville Multidisciplinary Research Grant. Co-Principal Investigator. \$10,000.00 USD

2014 -2015 Zandinejad A, Lin WS, Atarodi M, Morton D. Reducing biomechanical failure in implant dentistry using graded structure design. ITI Foundation Grant (No. 929-2013). Investigator. $\$ 47,900.00$ USD

2013-2014 Metz MJ, Miller CJ, Lin WS, Morton D, Crim G. Effects of Finishing Crown Margins on Direct Restorative Materials with Pressed Lithium Disilicate Ceramics in the Esthetic Zone: A Microleakage Evaluation. Ivoclar Vivodent Materials Support Grant. Investigator. \$3,500.00 USD

2013-2014 Stapleton B, Harris BT, Zandinejad AA, Morton D, Lin WS. Effect of finish line design, digital data acquisition protocols and abutment selection on the marginal adaptation of chairside 
CAD/CAM restorations. Ivoclar Vivodent Materials Support Grant. Principal Investigator. \$3,500.00 USD

2011-2013 Abdel-Azim T, Lin WS, Morton D. The influence of digital fabrication options on the accuracy of dental implant-based single tooth and complete arch frameworks. ITI Foundation Grant (No. 201-2010). Investigator. \$47,000.00 USD

2011-2013 Lin WS, Morton D. Effect of implant angulations and impression techniques on dimensional accuracy of resulting definitive casts. Part 2. ITI Foundation Grant (no. 749-2011). Principal Investigator. $\$ 47,600.00$ USD

2011-2012 Lin WS, Morton D. The rapid prototyping technique as a novel approach to fabricating functionally graded titanium dental implants - preliminary fatigue property testing. University of Louisville Research Initiation Grant. Principal Investigator. $\$ 5,000.00$ USD

Awards and Honors

$2016 \quad$ Outstanding reviewer

Elsevier

$2016 \quad$ Omicron Kappa Upsilon

The National Dental Honor Society

2016 Judson C. Hickey Scientific Writing Award

The Journal of Prosthetic Dentistry

2014 Greenberg Award in Medical Education Research. Second Place. Research Louisville

2014 ITI Research Award. Best Oral Presentation. ITI World Symposium. Geneva, Switzerland

2010 Bibby Research Award, American Association of Dental Research, Rochester Section

2009 Tylman Award, Second Place. American Academy of Fixed Prosthodontics

Awards and Honors of Mentoring Students/Residents

$2020 \quad$ Clinical Poster Award, The American Academy of Fixed Prosthodontics, Annual Session Program. 
Gadah T, Dutra V, Polido W, Lin WS, Morton D. Dual-purpose 3D printed surgical template for the fractured dental implant removal and new implant placement.

Poster Presentation First Place in Clinical Category, The American Prosthodontic Society, Annual Session Program.

Kuric, KM, Harris BT, Lin WS. A Digital Pathway to Treating the Edentulous Microstomic Patient.

Poster Presentation Second Place in Clinical Category, The American Prosthodontic Society, Annual Session Program. Dawson JH, Hyde B, Hurst M, Harris BT, Lin WS. PolyEtherKetoneKetone (PEKK), An Alternative Framework Material for Implant-Supported Complete Fixed Dental Prosthesis.

2017 Poster Presentation Third Place in Clinical Category, The American Prosthodontic Society, Annual Session Program. Pollini A, Dix G, Harris BT, Lin WS, Zandinejad AA. Oral rehabilitation of a patient with Hereditary Gingival Fibromatosis.

2016 Poster Presentation Second Place, Kentucky Dental Association, Annual Session Program.

Charette JR, Chou JC, Harris BT, Lin WS. Creating virtual 3dimensional models for teaching preclinical tooth preparation Students' usages and perceptions.

Poster Presentation Third Place in Clinical/Public Health Research, Annual American Dental Association (ADA)/DENTSPLY Student Clinician Research Award Program

Marti AM, Harris BT, Metz MJ, Scarfe WC, Morton D, Lin WS. Comparison of digital scanning and polyvinyl siloxane impression techniques by dental students: Instructional efficiency and attitudes towards technology.

2015 Poster Presentation Second Place, Kentucky Dental Association, Annual Session Program.

Metz MJ, Stapleton B, Harris BT, Lin WS. A cost-effective treatment for generalized erosion and loss of vertical dimension of occlusion: Laboratory-fabricated composite resin restorations. A case report.

2015 Tuition Scholarship Award (ULSD) Ballard E, Morton D, Zandinejad A, Miller C, Metz MJ, Lin WS. Objective Evaluation of Student's Shade Matching Performance in the School of Dentistry. 
Poster Presentation Second Place, The American Prosthodontic Society, Annual Session Program.

Lewis RC, Harris BT, Sarno R, Morton D, Llop DR, Lin WS. Maxillary and mandibular immediately loaded implant-supported interim complete fixed dental prostheses on immediately placed dental implants with a digital approach: A clinical report.

2014 Greenberg Award in Medical Education Research, Third Place Marti AM, Harris BT, Metz MJ, Scarfe WC, Morton D, Lin WS. Comparison of digital scanning and polyvinyl siloxane impression techniques by dental students: Instructional efficiency and attitudes towards technology.

\section{UNIVERSITY GOVERNANCE AND SERVICE}

$2020 \quad$ Indiana University School of Dentistry Clinical Director Search Committee (Chair)

Center for Implant, Esthetic and Innovative Dentistry

2019-2020 Indiana University-Purdue University Indianapolis Program Review and Assessment Committee (PRAC)

2018-2019 Indiana University School of Dentistry Faculty Search Committee (Chair) Department of Prosthodontics

2018-2020 Indiana University School of Dentistry CODA 2020, Predoctoral DDS Self Study Sub-Committees (STANDARD 2 - Educational Program-Clinical SciencesCompetencies 2-24)

2018-2020 Indiana University-Purdue University Indianapolis Graduate Student Research Committee

2017-2018 University of Louisville School of Dentistry Graduate Research Program Oversight Committee

2016-2018 University of Louisville School of Dentistry Research Committee

2016-2018 University of Louisville School of Dentistry Faculty Personnel Committee

2016-2018 University of Louisville School of Dentistry Advanced Digital Dental Technologies Committee 
2016-2017 University of Louisville School of Dentistry Advanced Co-Director for ITI Study Club

2013-2017 University of Louisville School of Dentistry Search Committees (Chair)

Divisions of Prosthodontics and Periodontics

Department of Oral Health and Rehabilitation

2015-2016 University of Louisville School of Dentistry

Curriculum Committee

2012-2016 University of Louisville School of Dentistry

Clinical Operations and Patient Care Committee

2013-2014 University of Louisville School of Dentistry

Student Evaluations Assessment Team for the CODA Site visit

2013-2014 University of Louisville School of Dentistry

Educational Program Subcommittee (Standards 2-21 to 2-25,

Clinical Sciences) for the 2015 CODA Site visit

2012-2014 University of Louisville School of Dentistry

Curriculum Committee

2012-2014 University of Louisville School of Dentistry

Search Committee for Chair, Department of General Dentistry and Oral Medicine

2011-2014 University of Louisville School of Dentistry

Laboratory Quality Assurance Team

2012-2014 University of Louisville School of Dentistry

Material and Equipment Committee

12. CONSULTATIONS and POSITIONS OUTSIDE THE UNIVERSITY

2015-2017 International Team for Implantology

US section Education Committee

2011-2016 American Dental Association Committee

SCDP SC9 / U.S Sub-TAG (CAD/CAM in dentistry)

Working Group 9.70 (Interfaces for Dental CAD/CAM Systems)

Working Group 9.71 (CAD/CAM Implant Abutments)

Working Group 9.72 (Accuracy of CAD/CAM SLA Models) 


\section{EDITOR OF A SCHOLARLY JOURNAL, SERVICE ON AN EDITORIAL ADVISORY BOARD OR REVIEWER FOR A SCHOLARLY JOURNAL \\ 2016-Present Reviewer, Journal of Clinical Oral Implants Research \\ 2016-Present Reviewer, Journal of Prosthodontics \\ 2016-Present Reviewer and Editorial Review Board, Journal of prosthetic dentistry \\ 2015-Present Reviewer, MedEdPORTAL Publications \\ 2015-2018 Editorial Review Board, Journal of Dental Education \\ 2014-Present Reviewer, The International Journal of Oral \& Maxillofacial Implants}

14. CLINICAL SERVICE

2018-Present Practice limited to prosthodontics and dental implants Center for Implant, Esthetic and Innovative Dentistry Indiana University School of Dentistry

2010-2018 Practice limited to prosthodontics and dental implants. University of Louisville Faculty Practice Associates

15. MEMBERSHIP AND ACTIVITIES

National Member, American Dental Education Association Diplomate, American Board of Prosthodontics Fellow, American College of Prosthodontists

International Fellow, International Team for Implantology

16. FACULTY DEVELOPMENT ACTIVITIES (CONFERENCES ATTENDANCE)

Present $\quad \mathrm{PhD}$ in Educational Leadership and Organization Development", College of Education and Human Development, University of Louisville, Louisville, KY, United States. (January 1, 2014 Present).

2020 Conference attendance, "AARD 2020 Annual Session", American Academy of Restorative Dentistry (AARD), Chicago, IL, United States. (February 22, 2020 - February 23, 2020). 
Conference attendance, "AAFP 2020 Annual Session", American Academy of Fixed Prosthodontics (AAFP), Chicago, IL, United States. (February 20, 2020 - February 22, 2020).

Conference attendance, "ACP 2019 Annual Session", American College of Prosthodontists (ACP), Miami Beach, FL, United States. (October 30, 2019 - November 2, 2019).

Conference attendance, "ITI Congress North America: Evolution, Revolution, Solution", ITI, San Francisco, CA, United States. (April 17, 2019 - April 18, 2019).

Conference attendance, "JFJ REFRESHER COURSE", IUSD, Indianapolis, IN, United States. (June 8, 2018 - June 9, 2018).

Conference attendance, "2018 ITI American Section annual meeting", ITI, Frisco, TX, United States. (May 4, 2018 - May 5, 2018).

Conference attendance, "ITI Consensus Conference 2018", ITI, Amsterdam, Netherlands. (April 17, 2018 - April 20, 2018).

Conference attendance, "Cultural Competency Program for Oral Health Professionals", Online. (August 15, 2017).

Conference attendance, "Faculty Development: Partial Removable Denture Prosthesis - Keep it Simple", University of Louisville, Louisville, KY, United States. (August 2, 2017).

2017 Conference attendance, "Medical Emergencies in the Dental Practice", University of Louisville, Louisville, KY, United States. (July 6, 2017).

Conference attendance, "ITI World Symposium 2017 - Key factors for long-term success", ITI, Messe Basel, Switzerland. (May 4, 2017 - May 6, 2017).

Conference attendance, "ADEA Annual Session \& Exhibition Shaping Tomorrow Together", American Dental Education Association (ADEA), Denver, CO, United States. (March 12, 2016 - March 14, 2016).

Conference attendance, "ITI Congress North America: Integrating Digital Technologies", ITI, Chicago, IL, United States. (April 28, 2016 - April 30, 2016). 
Conference attendance, "Preventing and Reporting Harassment and Abuse", University of Louisville School of Dentistry, Louisville, KY, United States. (July 2, 2015).

Conference attendance, " ADEA Annual Session \& Exhibition Igniting minds unlocking potential", American Dental Education Association (ADEA), Boston, MA, United States. (March 7, 2015 March 10, 2015).

2014 Conference attendance, "Medical Emergencies in the Dental Practice", University of Louisville School of Dentistry, Louisville, KY, United States. (August 11, 2014).

2014 Conference attendance, "The Dental Professional's Role in Recognizing and Reporting Domestic Violence and Abuse", University of Louisville School of Dentistry, Louisville, KY, United States. (August 11, 2014).

2014 Conference attendance, "Speaker Development Series: Digital Dental Photography SDS- II", Devright, Dallas, TX, United States. (June 20, 2014 - June 21, 2014).

Conference attendance, "Immediate loading of the failing dentition by achieving predictability through simplicity in treatment", Columbus Dental Forum, French Lick, IN, United States. (May 30, 2014 - May 31, 2014).

2014 Conference attendance, "ITI World Symposium 2014

Knowledge is key", ITI, Geneva, Switzerland. (April 24, 2014 April 26, 2014).

Conference attendance, "Annual Patient Centered Care Symposium: 'Humanistic Communication for Improved Health Outcomes'", University of Louisville School of Dentistry, Louisville, KY, United States. (April 11, 2014).

2013 Conference attendance, "ITI Congress North America: Connectivity in Implant Dentistry: Putting the Pieces Together.", ITI, Chicago, IL, United States. (April 4, 2013 - April 6, 2013). Annual Meeting", Academy of Osseointegration, Tampa, FL, United States. (March 7, 2013 - March 9, 2013). 
Conference attendance, "Academic Summit: Scientific Updates and Training", Ivoclar Vivadent, Amherst, NY, United States. (October 26, 2012).

2012

Conference attendance, "Promoting Excellence in Prosthodontic Education", ACP Invitational Joint Educators Conference,

Rosemont, IL, United States. (April 20, 2012 - April 21, 2012). 